
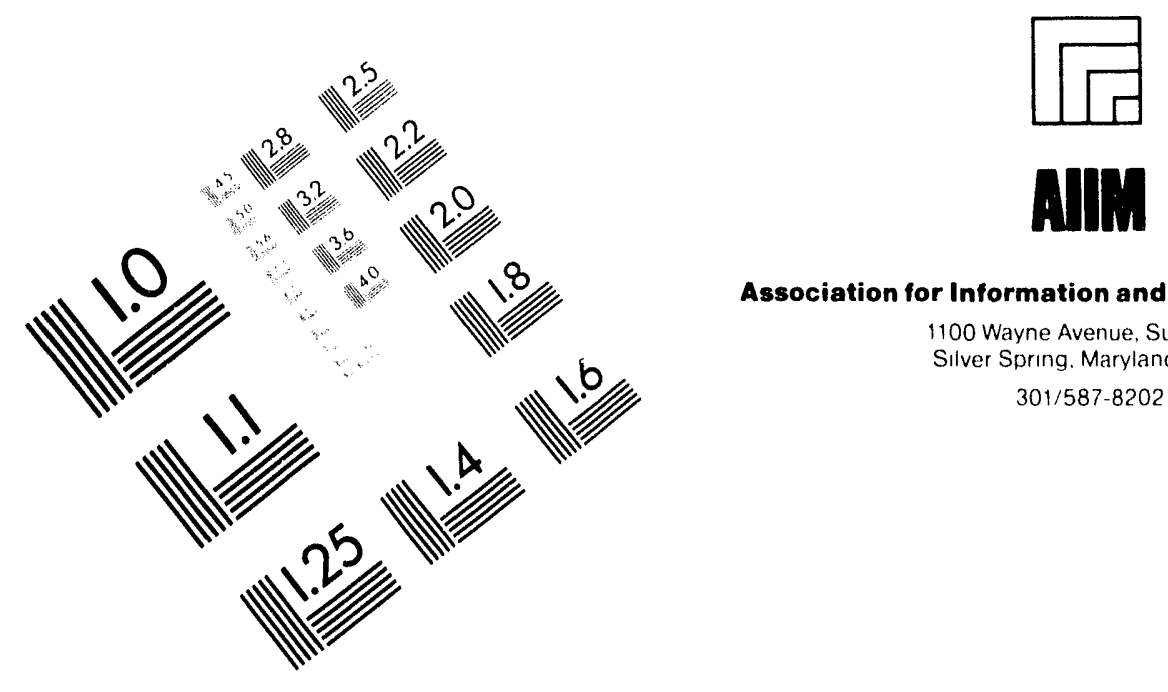

Association for Information and Image Management

1100 Wayne Avenue, Suite 1100

Silver Spring. Maryland 20910

301/587-8202

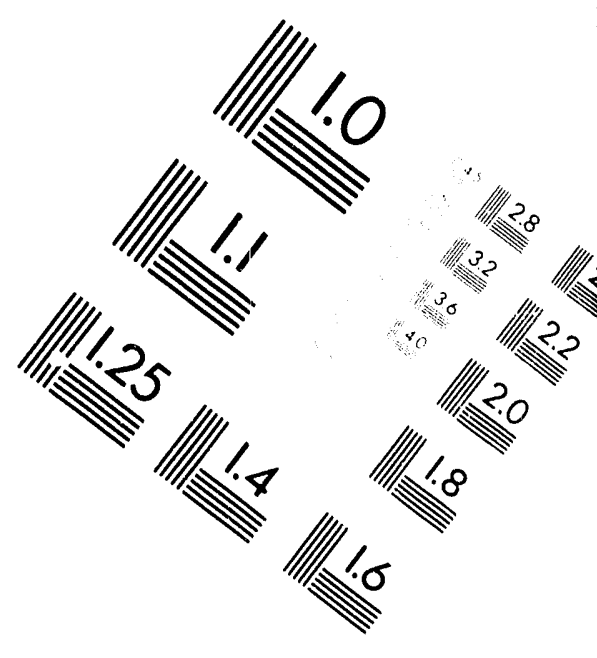

\title{
Centimeter
}

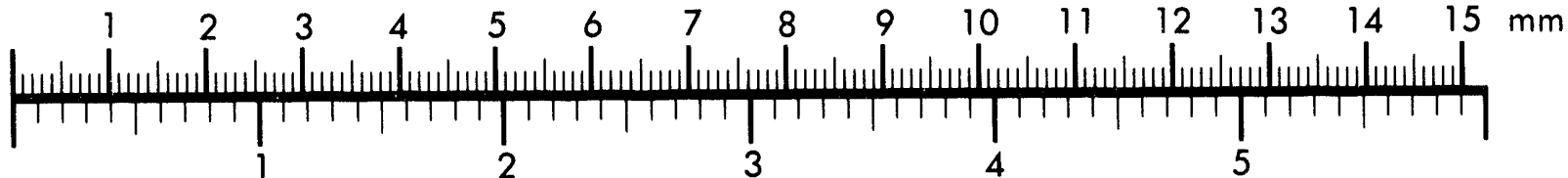

Inches
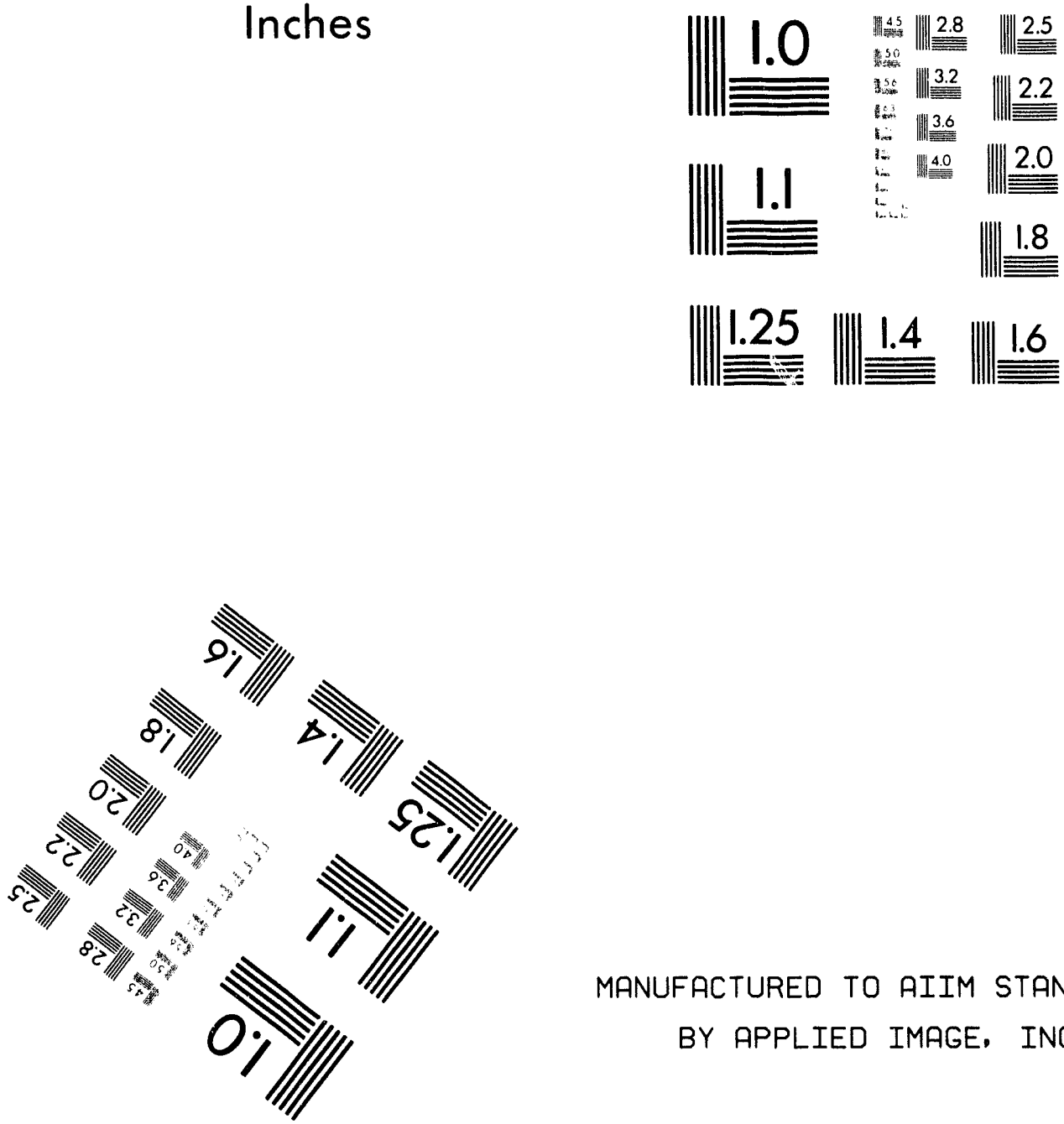

MANUFACTURED TO AIIM STANDARDS

BY APPLIED IMAGE, INC.

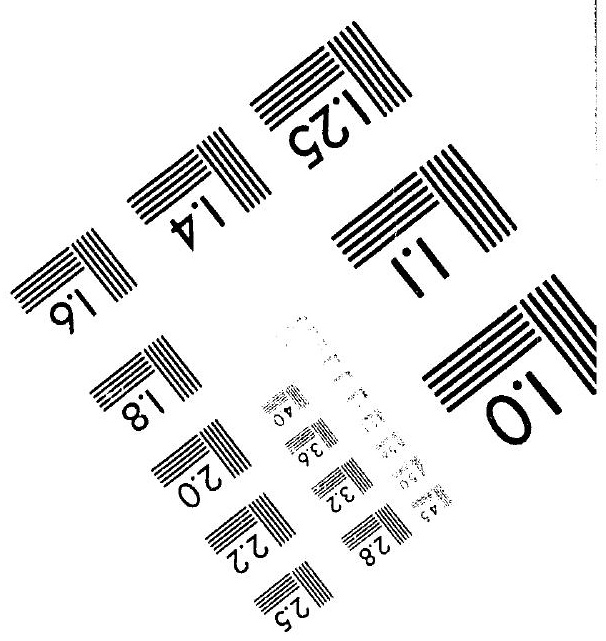



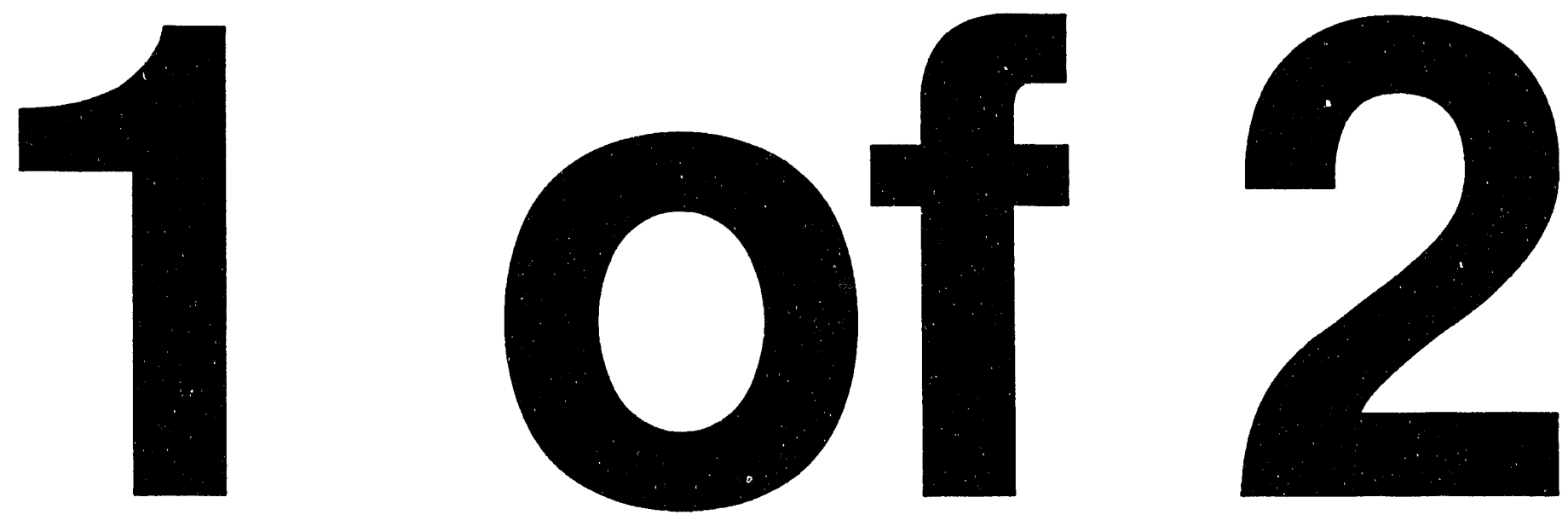
NUREG/CK-6223

ANL-94/13

\section{Review of the Proposed Materials of Construction for the SBWR and AP600 Advanced Reactors}

Manuscript Completed: March 1994

Date Published: June 1994

Prepared by

D. R. Diercks, W. J. Shack, H. M. Chung, T. F. Kassner

Argonne National Laboratory

9700 South Cass Avenue

Argonne, IL 60439

\section{Prepared for}

Division of Engineering

Office of Nuclear Regulatory Research

U.S. Nuclear Regulatory Commission

Washington, DC 20555-0001

NRC FIN L2257

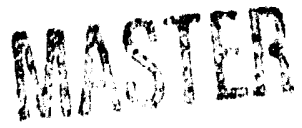




\section{Abstract}

Two advanced light water reactor (LWR) concepts, namely the General Electric Simplified Boiling Water Reactor (SBWR) and the Westinghouse Advanced Passive 600 MWe Reactor (AP600), were reviewed in detail by Argonne National Laboratory. The objectives of these reviews were to (a) evaluate proposed advanced-reactor designs and the materials of construction for the safety systems, (b) identify all aging and environmentally related degradation mechanisms for the materials of construction, and (c) evaluate from the safety viewpoint the suitability of the proposed materials for the design application.

Safety-related systems selected for review for these two LWRs included (a) reactor pressure vessel, (b) control rod drive system and reactor internals, (c) coolant pressure boundary, (d) engineered safety systems, (e) steam generators (AP600 only), (f) turbines, and (g) fuel storage and handling system. In addition, the use of cobalt-based alloys in these plants was reviewed.

The selected materials for both reactors were generally sound, and no major selection errors were found. It was apparent that considerable thought had been given to the materials selection process, making use of lessons learned from previous LWR experience. The review resulted in the suggestion of alternate and possibly better materials choices in a number of cases, and several potential problem areas have been cited. The review of the AP600 materials of construction was impaired by the fact that the materials designations given in the Standard Safety Analysis Report (SSAR) for this reactor were often too vague to identify the specific alloy to be used. With some notable exceptions, the SBWR SSAR generally gave more detailed materials information. 


\section{Contents}

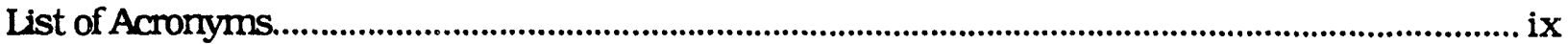

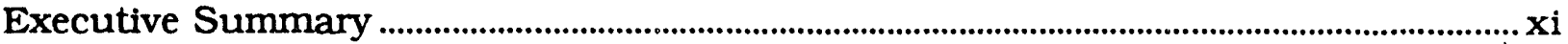

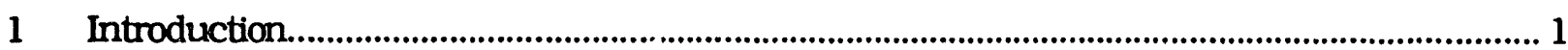

2 General Electric Simplified Boiling Water Reactor (SBWR)................................ 3

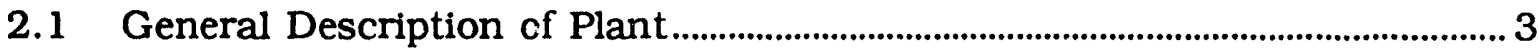

2.1.1 Reactor core, cooling system, and pressure vessel ............................... 3

2.1.2 Steam supply and turbine system ............................................................ 4

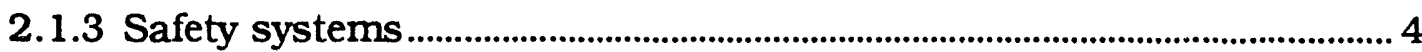

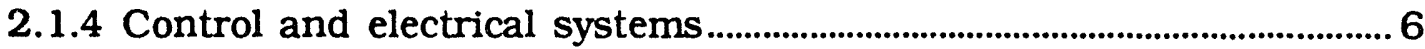

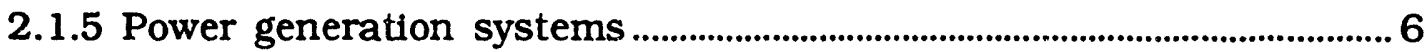

2.2 SBWR Reactor Pressure Vessel .............................................................................. 8

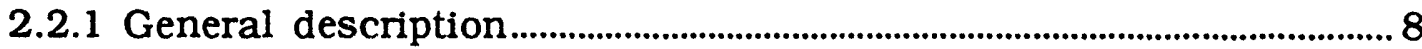

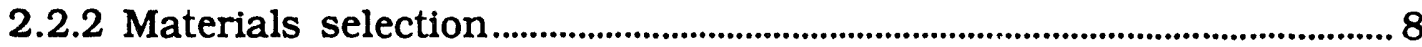

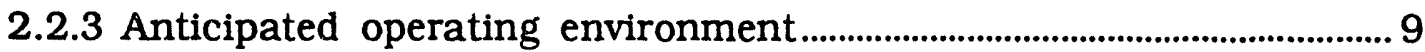

2.2.4 Potential material degradation an $\mathrm{i}$ failure modes............................... 9

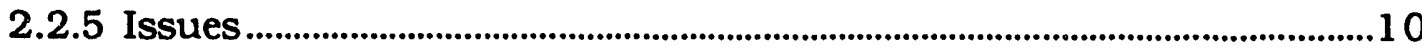

2.3 Control Rod Drive System and Reactor Internals.........................................13

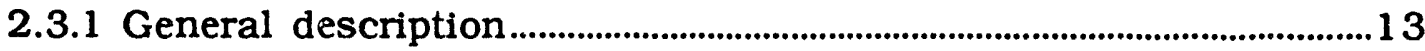

2.3.2 Materials selection ............................................................................................. 13

2.3.3 Anticipated operating environment................................................................13

2.3.4 Potential material degradation and failure modes...............................14

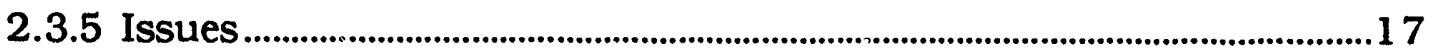

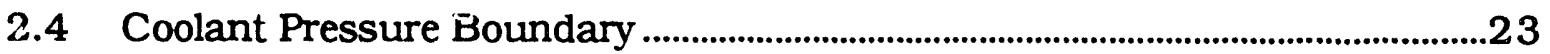

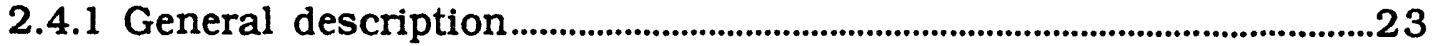

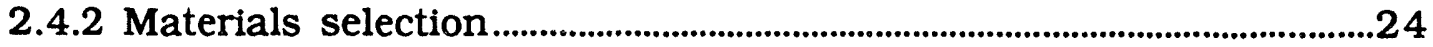

2.4.3 Anticipated operating environment.........................................................24

2.4.4 Potential material degradation and failure modes................................24

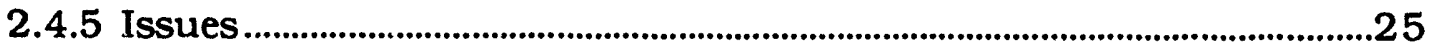

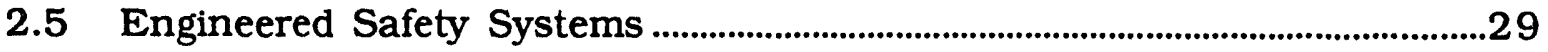

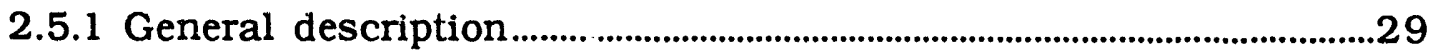

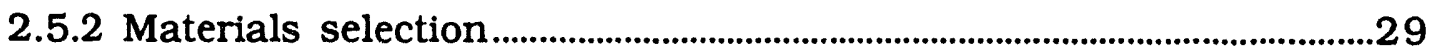

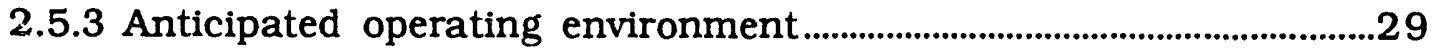

2.5.4 Potential material degradation and failure modes..............................30

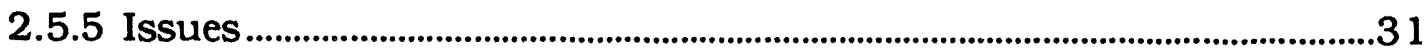

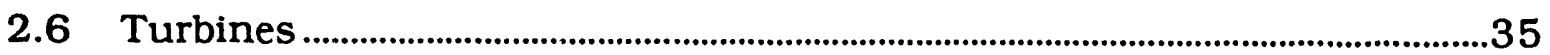

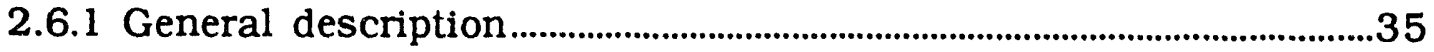




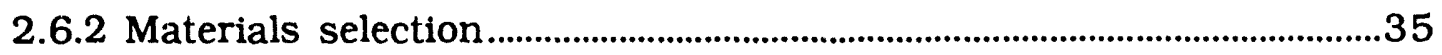

2.6.3 Anticipated operating environment.....................................................36

2.6.4 Potential material degradation and failure modes.............................36

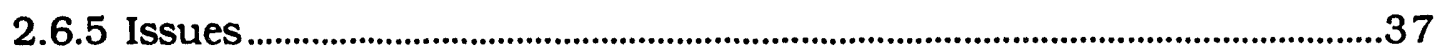

$2.7 \quad$ Fuel Storage and Handling System .............................................................................38

2.7.1 General description...........................................................................................38

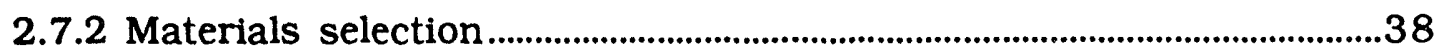

2.7.3 Anticipated operating environment........................................................38

2.7.4 Potential material degradation and failure modes.............................38

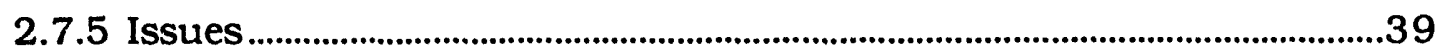

2.8 Use of Cobalt-Based Alloys......................................................................................42

3 Westinghouse Advanced Passive Pressurized Water Reactor (AP600) ..................44

3.1 General Description of Plant...........................................................................45

3.1.1 Reactor core, pressure vessel, and primary cooling circuit..............45

3.1.2 Steam generators and coolant pumps ............................................................46

3.1.3 Turbine, steam supply, feedwater, and condensate systems .............46

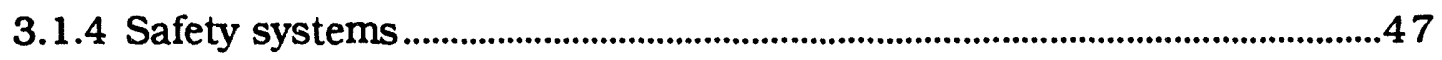

3.2 AP600 Reactor Pressure Vessel..................................................................48

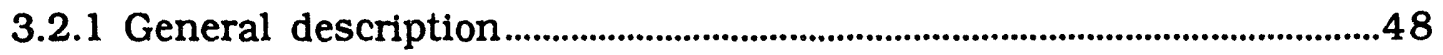

3.2.2 Materials selection..............................................................................................48

3.2.3 Anticipated operating envir jnment................................................................49

3.2.4 Potential material degradation and failure modes..............................49

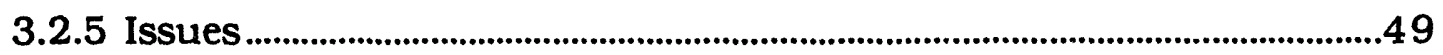

3.3 Control Rod Drive System and Reactor Internals.........................................53

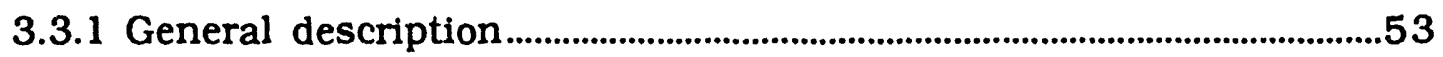

3.3.2 Materials selection.............................................................................................53

3.3.3 Anticipated operating environment....................................................53

3.3.4 Potential material degradation and failure modes.............................54

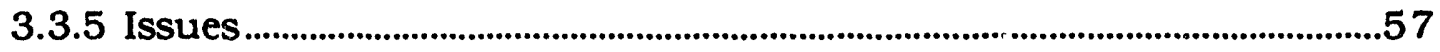

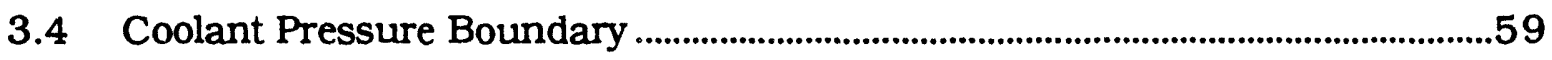

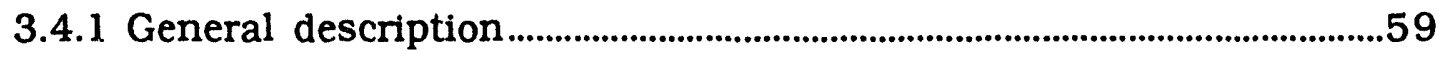

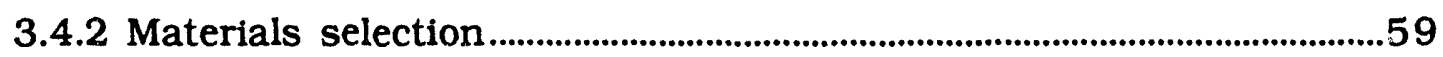

3.4.3 Anticipated operating environment..................................................................59

3.4.4 Potential material degradation and failure modes..............................60

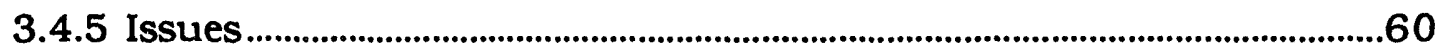

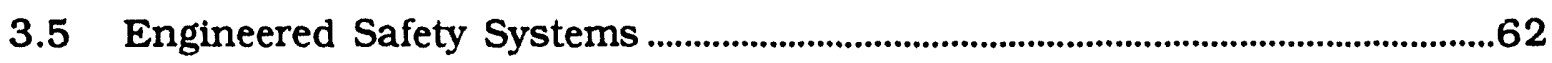

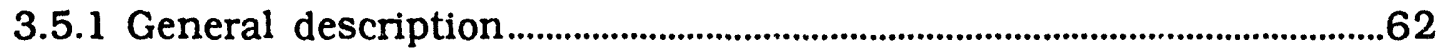

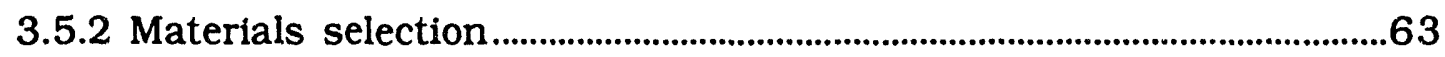


3.5.3 Anticipated operating environment............................................................63

3.5.4 Potential material degradation and failure modes.................................63

3.5.5 Issues ..........................................................................................................6

3.6 Steam Generators.................................................................................................70

3.6.1 General description ...............................................................................70

3.6.2 Materials selection..........................................................................................70

3.6.3 Anticipated operating environment..............................................................71

3.6.4 Potential material degradation and failure modes...................................7 7

3.6.5 Issues .................................................................................................................71

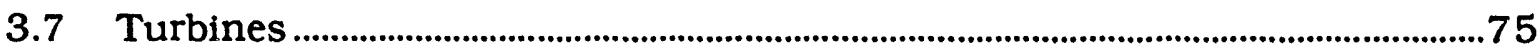

3.7.1 General description .........................................................................................75

3.7.2 Materials selection .....................................................................................75

3.7.3 Anticipated operating environment............................................................76

3.7.4 Potential material degradation and failure modes...................................76

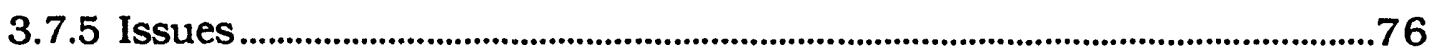

3.8 Fuel Storage and Handling System..........................................................................78

3.8.1 General description........................................................................................78

3.8.2 Materials selection ...............................................................................................78

3.8.3 Anticipated operating environment............................................................78

3.8.4 Potential material degradation and failure modes....................................78

3.8.5 Issues .................................................................................................................79

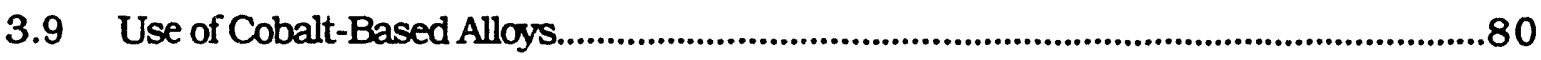

4 Summary and Conclusions ..............................................................................................82

4.1 Reactor Pressure Vessel ............................................................................................82

4.2 Control Rod Drive System and Reactor Internals.............................................83

4.3 Coolant Pressure Boundary ...........................................................................................84

4.4 Engineered Safety Systems ........................................................................................8

4.5 Steam Generators........................................................................................................86

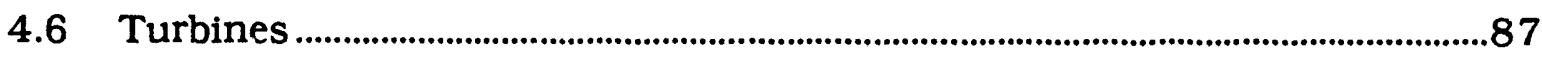

4.7 Fuel Storage and Handling System ...................................................................87

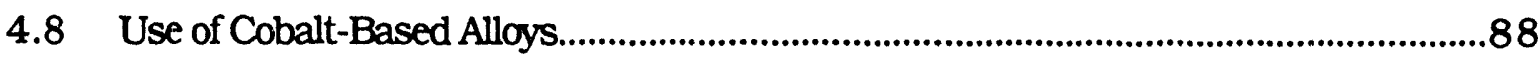

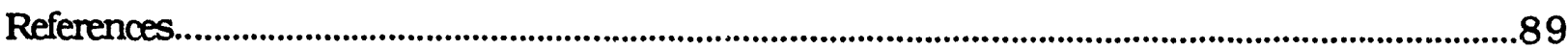




\section{List of Tables}

1. SBWR reactor pressure vessel component materials..............................................12

2. Materials of construction for SBWR control rod drive system.................................19

3. Materials of construction for SBWR reactor internals...............................................2 1

4. Expected SBWR water chemistry .......................................................................................22

5. Materials of construction for SBWR reactor coolant pressure boundary components

6. SBWR engineered safety-feature component materials and anticipated operating environment.

7. Summary of SBWR fuel and auxiliary pools cooling system water temperatures and chemistry requirements

8. Proposed use of cobalt-based hard-facing alloys for selected CRD system components in the SBWR.

9. Materials for AP600 reactor pressure vessel components

10. R.ecommended AP600 reactor coolant water chemistry specifications.

11. Materials for AP600 reactor control rod drive system and internal components

12. AP600 reactor coolant system materials.

13. AP600 engineered safety features component materials and anticipated operating environment.

14. Materials of construction for major AP600 steam generator components ...........73

15. Guidelines for normal AP600 secondary water chemistry

16. Specified limits for cobalt impurity levels in AP600 materials and components 


\begin{tabular}{|c|c|}
\hline $\mathrm{ABB}$ & ASEA Brown-Boveri \\
\hline ADS & Automatic depressurization system \\
\hline AISI & American Iron and Steel Institute \\
\hline ALARA & As low as reasonably achievable \\
\hline ANL & Argonne National Laboratory \\
\hline AP600 & Advanced Passive 600 MWe Pressurized Water Reactor \\
\hline ASME & American Society of Mechanical Engineers \\
\hline ASTM & American Society for Testing and Materials \\
\hline AVT & All volatile treatment \\
\hline BWR & Boiling water reactor \\
\hline CASCC & Crevice-assisted stress corrosion cracking \\
\hline CERT & Constant extension rate test \\
\hline CFR & Code of Federal Regulations \\
\hline CRD & Control rod drive \\
\hline DBTT & Ductile-to-brittle transition temperature \\
\hline ECP & Electrochemical potential \\
\hline EPRI & Electric Power Research Institute \\
\hline FATT & Fracture appearance transition temperature \\
\hline GE & General Electric Company \\
\hline HVS & High-velocity moisture separator \\
\hline IASCC & Irradiation-assisted stress corrosion cracking \\
\hline IGSCC & Intergranular stress corrosion cracking \\
\hline $\mathrm{K}_{\mathbf{I C}}$ & Plane-strain fracture toughness \\
\hline LWR & Light water reactor \\
\hline MSR & Moisture-separator reheater \\
\hline NOREM & $\begin{array}{l}\text { Family of cobalt-free hard-facing alloys designed to achieve } \\
\text { reduced activation and personnel radiation exposure ("no rem") }\end{array}$ \\
\hline NRC & Nuclear Regulatory Commission \\
\hline NSSS & Nuclear steam supply system \\
\hline ODSCC & Outer-diameter stress corrosion cracking \\
\hline ORNL & Oak Ridge National Laboratory \\
\hline PCCS & Passive containment cooling system \\
\hline PH & Precipitation hardening \\
\hline PWR & Pressurized water reactor \\
\hline PWSCC & Primary water stress corrosion cracking \\
\hline RCPB & Reactor coolant pressure boundary \\
\hline RCS & Reactor coolant system \\
\hline RPV & Reactor pressure vessel \\
\hline RTNDT $_{\text {ND }}$ & Reference temperature nil-ductility transition \\
\hline RTPTS & Reference temperature pressurized thermal shock \\
\hline SBWR & Simplified Boiling Water Reactor \\
\hline SHE & Standard hydrogen electrode \\
\hline SCC & Stress corrosion cracking \\
\hline SS & Stainless steel \\
\hline SSAR & Standard Safety Analysis Report \\
\hline STP & Standard temperature and pressure \\
\hline UNS & Universal (alloy) numbering system \\
\hline Y.S. & Yield strength \\
\hline
\end{tabular}




\section{Executive Summary}

Two advanced light water reactor (LWR) concepts, namely the General Electric Simplified Boiling-Water Reactor (SBWR) and the Westinghouse Advanced Passive 600 MWe Reactor (AP600), were reviewed in detail at Argonne National Laboratory (ANL). The objectives of tinese reviews were to (a) evaluate proposed advancedreactor designs and the materials of construction for the safety systems, (b) identify all aging and environmentally related degradation mechanisms for the materials of construction, and (c) evaluate from a safety viewpoint the suitability of the proposed materials for the design application.

The safety-related systems selected for review for these two LWRs were:

- Reactor pressure vessel.

- Control rod drive system and reactor internals.

- Coolant pressure boundary.

- Engineered safety systems.

- Steam generators (AP600 only).

- Turbines.

- Fuel storage and handling system.

In addition, the use of cobalt-based alloys in these plants was reviewed.

The materials selections for both reactors were generally sound, and no major selection errors were found. It was apparent that considerable thought had been given to the materials selection process, making use of lessons learned from previous LWR experience. The review resulted in the suggestion of alternate and possibly better materials choices in a number of cases, and several potential problem areas have been cited. The review of the AP600 materials of construction was impaired by the fact that the materials designations given in the Standard Safety Analysis Report (SSAR) for this reactor were often too vague to identify the specific alloy to be used. With some notable exceptions, the SBWR SSAR generally gave more detailed materials information.

Specific findings resulting from the reviews of these systems in the two reactor concepts are summarized below.

Reactor Pressure Vessel. Fabrication procedures and restrictions on copper and phosphorus appear to be adequate to preclude irradiation embrittlement in both the SBWR and the AP600 pressure vessels over their 60-year design life. The limit of $0.01 \mathrm{wt} . \%$ on sulfur content in the SA533, Grade B steel to be used to fabricate the SBWR vessel may not be sufficient to ensure no environmental enhancement of fatigue crack growth rates. The AP600 design calls for a $0.005 \mathrm{wt} \%$ limit on sulfur, and this limit was judged to be sufficiently low to avoid this problem. Both the SBWR and the AP600 designs call for the use of nickel-chromium-iron alloys for a number of applications inside the vessel, but the precise alloys are not identified. Some of these alloys, including Alloy 600 structural components and Alloy 182 weld butters, have experienced stress corrosion cracking (SCC) problems in conventional LWRs, 
and more information is needed to determine if the optimum alloys have been chosen for the two advanced reactors. In addition, the 17-4 $\mathrm{PH}$ precipitationhardening stainless steel (SS) chosen for the control rod drive (CRD) seal housing nuts in the SBWR is subject to severe SCC and hydrogen embrittlement if improperly heat treated, and stringent acceptance criteria are required for this component to avoid this potential problem. Finally, a number of ambiguities and apparent errors were noted in some of the materials specifications for the SBWR vessel.

Control Rod Drive System and Reactor Internals. The SSARs for both the SBWR and the AP600 were somewhat vague about the materials of construction for several important CRD and reactor internal components. Both designs call for the use of 17-4 $\mathrm{PH}$ precipitation hardened SS, and the possible susceptibility of this alloy to combined thermal aging and irradiation embrittlement at high fluence was noted. Components fabricated from Inconel X-750 and Types 304 and 316 SSs are susceptible to failure by irradiation-assisted stress corrosion cracking (IASCC), but this susceptibility has been found to exhibit significant heat-to-heat variation among steels of nominally similar chemical composition and fabrication history. No general guidelines for material selection to avoid this problem are currently avallable, and these components must be considered susceptible to IASCC for $\geq 5 \times 10^{20} \mathrm{n} / \mathrm{cm}^{2}$. Because the mechanism(s) of IASCC and origin of the heat-to-heat variation are not understood at present, material selection based upon general ASTM or ASME specification cannot assure resistance to IASCC failure. The hydrogen water chemistry specified for SBWR should help to control potential IASCC problems, but it may not be sufficient or practical to avoid problems in the top guide. The water chemistry parameters specified for the AP600 are quite sound, but it is not clear what specific additional steps have been taken to minimize effective stresses and eliminate crevices. Stress is an accelerant for the IASCC process and components should be designed to have the lowest possible applied and residual stress levels. Special attention should be paid to the reduction of the residual stresses due to fitup and welding processes. Where solution annealing is not possible, welding processes should be optimized to achieve low residual stresses.

Coolant Pressure Boundary. Few materials-related problems were seen for the SBWR coolant pressure boundary components. However, potential SCC problems were noted for Type 410 martensitic SS and Alloys 600 and 182 that were to be used for certain components. In addition, it was not clear that a nitrogen cover gas was to be used for the makeup water and condensate storage tanks, and questions were raised about the adequacy of the proposed $1 \%$ water cleanup reprocessing rate to maintain the high-quality coolant water chemistry specified for the SBWR. The materials specifications for the AP600 coolant pressure boundary components were generally much too vague to permit a detailed review. Assuming that most of the components were to be fabricated of materials similar to those used in conventional Westinghouse pressurized water reactors (PWRs) (an exception is the Type 316LN SS to be used for the coolant piping), no significant corrosion problems were foreseen. Aging embrittlement of the castings in the pump bodies was a possible concern. 
Engineered Safety System Components. Potential SCC problems were noted in SBWR depressurization valves, and it was not clear from the specifications that the desired " $L$ " grades of forged austenitic SS were to be used for this application. Potential aging embrittlement problems were noted for the cast valve bodies. In addition, the carbon steel to be used for the isolation condenser steam piping may be susceptible to excessive general corrosion and wastage if exposed to condensate over extended time periods. The review of the AP600 materials of construction was again impaired by a lack of detailed information. Alloy 82 was noted to be more resistant to SCC than Alloy 182 for the weld buttering in the core makeup tanks. The apparent proposed use of Inconel 600 for the passive residual-heat-removal heat exchanger tubes was considered satisfactory for the anticipated service conditions, although Inconel 690 would provide improved resistance to SCC. Finally, the need for a maximum specified ductile-to-brittle transition temperature (DBTT) for the carbon steel containment vessel was noted.

Steam Generators. The selection of Alloy 690 for the AP600 steam generator tubes instead of Alloy 600 should lead to greatly improved resistance to outerdiameter stress corrosion cracking (ODSCC) and primary-water stress corrosion cracking (PWSCC), although it is premature to assume that this selection will ensure a 60-year life. In addition, the use of the Type 405 ferritic SS trifoil tube support plate design, along with improved secondary water chemistry, should prevent tube denting and further reduce ODSCC problems. Fretting wear, flow-induced vibration, and thermal fatigue problems have apparently been corrected through improved design, and the flow-accelerated corrosion of the feedwater ring has been addressed by the use of more resistant alloys for the affected components. Virtually all of the design changes and materials proposed for the AP600 steam generators have been implemented with apparent success for replacement steam generators in current PWRs.

Turbines. The SSARs for both the SBWR and the AP600 make no explicit reference to the extensive work that has been performed on SCC and the optimization of fracture toughness in low-pressure turbine materials for nuclear power systems over the past decade. The specifications provided for turbine materials in both SSARs are insufficient to determine whether the materials actually conform to the "good practices" that are alluded to. The specification of $100 \%$ volumetric ultrasonic inspections, surface visual examinations, and magnetic-particle inspections of the finished, machined surfaces should ensure that fabrication defects will be detected. Potential SCC problems have been addressed in both designs, and the SBWR SSAR includes procedures for analyzing fatigue crack growth. Flowaccelerated corrosion problems, which tend to be more severe in PWRs, should be mitigated in the AP600 turbine through the use of morpholine rather than ammonia for $\mathrm{pH}$ control. Finally, that the specification of minimum fracture toughness for the AP600 turbine is incomplete because units were inadvertently omitted.

Fuel Storage and Handling System. It was recommended that the " $L$ " grades of austenitic SS be used to fabricate large, welded components in the SBWR fuel storage system to preclude possible SCC problems. It was also noted that carbon steels will apparently be used for several components that are in contact with the SBWR spent- 
fuel storage pool water, and general corrosion and wastage must be taken into account in these designs. The information provided in the AP600 SSAR was inadequate to permit a detailed review of the fuel storage and handling system materials, but the above comments would also apply.

Cobalt-Based Alloys. The SSARs for both the SBWR and the AP600 address the problem of controlling radiation levels proauced by the activation of cobalt. In the case of the SBWR, a relatively non-restrictive $0.15 \mathrm{wt} . \%$ average cobalt content is indicated for austenitic SSs used both inside and outside the core, and a $0.05 \mathrm{wt} . \%$ limit is given for the XM-19 alloy used in the CRD system. The AP600 SSAR gives detalled cobalt limits for alloys used to fabricate major components. However, cobalt-based alloys are used in hard-facing applications in both designs, and no mention is made of the possible use of any of the cobalt-free alternatives that have been developed. 
Several advanced nuclear reactor power plant concepts are under development in the U.S., including advanced light water reactors (LWRs) and, in the longer term, advanced high-temperature gas-cooled and liquid-metal-cooled reactors. These concepts generally feature simplified modular design and construction, passive safety systems, and projected improvements in reliability and maintainability. Sixty-year design lives have been proposed for some of these plants, in contrast to the typical 40-yr design lives of current-generation LWRs. It was planned to submit approximately four mid-size $(\approx 600 \mathrm{MWe})$ advanced concept water-cooled reactor designs to the U.S. Nuclear Regulatory Commission (NRC) for design certification by 1996, with gas- and sodium-cooled designs to follow.

Two advanced LWR concepts, namely the General Electric (GE) Simplified Boiling Water Reactor (SBWR) and the Westinghouse Advanced Passive 600 MWe Reactor (AP600), have been selected for detailed review by Argonne National Laboratory (ANL). The objectives of these reviews were to (a) evaluate proposed advanced reactor designs and the materials of construction for the safety systems, (b) identify all aging and environmentally related degradation mechanisms for materials of construction, and (c) evaluate from the safety viewpoint the suitability of the proposed materials for the design application. The reviews relied primarily upon information contained in the Standard Safety Analysis Reports (SSARs) for these two reactors, 1.2 with supplemental information obtained from NRC. U.S. Department of Energy (DOE), Electric Power Research Institute (EPRI), and foreign nuclear research programs, non-nuclear programs, and the general scientific and technical literature.

Detailed reviews of proposed designs, environments, and materials for the safety-related systems of advanced reactors were performed under this program, and potential materials degradation and failure were evaluated. The reviews included a detailed evaluation of relevant aging processes and the potential problems that might develop as a result of these processes; the suitability of the proposed design and materials of construction to mitigate these problems was also evaluated. The reviews were intended to be sufficiently detailed to provide NRC reviewers with an independent and technically defensible basis for evaluating the acceptability of materials selected for advanced reactors in the specific environment identified in the design.

Parallel reviews of these same two reactor concepts have been conducted concurrently by investigators at Oak Ridge National Laboratory (ORNL). The ANL reviews have been concerned primarily with environmental and metallurgical aging (aging ernbrittlement) effects. These included (a) stress corrosion cracking (SCC) of austenitic and duplex stainless steels (SSs) associated with coolant chemistry, sensitization and irradiation effects, (b) environmentally assisted fatigue and crack growth in ferritic and austenilic structural steels, (c) corrosion and intergranular attack of steam generator tubing, (d) corrosion and flow-accelerated corrosion of piping steels, and (e) metallurgical aging and embrittlement of cast duplex SSs. Consideration was also given to materials selection to minimize induced 
radioactivity, primarily through the reduced use of cobalt-containing alloys. The ORNL reviews focused on nonenvironmental mechanical properties, including tensile, fatigue, impact, fracture, and irradiation embrittlement behaviors, as well as fabrication and welding properties.

The results of the ANL reviews are summarized here, first for the SBWR and then for the AP600. Each reactor is reviewed on a system-by-system basis; the materials specified for each of the major components are first identified, and the suitability of these materials for service under the anticipated conditions is then critically evaluated. Potentially inappropriate materials selections are identified as issues for each system, and, where appropriate, alternative materials of construction are suggested. 


\section{General Electric Simplified Boiling-Water Reactor}

The proposed materials of construction were reviewed for the following reactor components and systems of the SBWR:

- Reactor pressure vessel.

- Control rod drive system and reactor internals.

- Coolant pressure boundary.

- Engineered safety systems.

- Turbines.

- Fuel storage and handling system.

Most of the information on the design and proposed materials of construction for the SBWR utilized in this study was obtained from the SBWR Standard Safety Analysis Report. 1 This information was supplemented by descriptions of the SBWR published in the technical literature. ${ }^{3-7}$ No direct contacts were made with GE personnel concerning the SBWR design or materials.

\subsection{General Description of Plant}

The SBWR is, as its name implies, a simplified version of the conventional GE BWR. The overall design the SBWR emphasizes simplicity and passive safety as a means of reducing costs and increasing inherent plant safety.

The key distinguishing features of the SBWR, when compared to the conventional BWR, are

- Lower power rating, namely $600 \mathrm{MWe}$, when compared to 1000-1300 MWe for a conventional BWR.

- Simplified operating plant, including natural convective flow through the coolant circuit.

- Passive safety system, including provisions for passive containment cooling and gravity-driven flooding of the core without active safety components or operator intervention.

The principal features of the various SBWR systems and the role of these features in achieving the SBWR design objective are summarized below, with an emphasis on safety-related components and systems.

\subsubsection{Reactor core, cooling system, and pressure vessel}

Significant simplifications in the reactor cooling circuit are achieved through the use of a natural-flow convective cooling system. Convective cooling depends upon gravity-induced circulation resulting from density differences between the water in regions outside the core and the steam-water mixture produced by normal 
boiling in the core. This design eliminates the need for recirculation cooling pumps and the associated recirculation loop piping, controls, restraints, and snubbers.

The natural recirculation design requires the use of a lower power density core compared with the conventional BWR. This, in turn, leads to lower fuel cycle costs and a 24-month operating cycle. In addition, lower power density results in larger thermal and hydrodynamic stability margins in the event of operating transients. Radiation embrittlement of the reactor pressure vessel has never been a significant problem for BWRs, and the lower power density of the SBWR core makes it of even less concern.

The natural recirculation design also requires a taller reactor pressure vessel for the SBWR to incorporate a "chimney" between the top of the core and the steam separator assembly for enhanced core flow. The diameter of the pressure vessel is greater at the top to increase the coolant inventory above the core, thereby reducing the need for additional emergency core cooling capacity. In addition to increasing the time available before the core is uncovered in a loss-of-coolant accident, the overall increase in the volume of the pressure vessel resuits in a substantial reduction in the pressurization rate that would occur after rapid isolation of the reactor from the normal heat sink. This characteristic permits considerable simplification of the pressure relief equipment.

\subsubsection{Steam supply and turbine system}

The direct-cycle BWR configuration, in which steam is generated directly in the core, is an inherent simplification over the indirect pressurized-water reactor (PWR) configuration, which requires a steam generator and secondary steam loop. In addition, the SBWR steam turbine operates on a two-flow approach that eliminates a low-pressure rotor and shell, simplifies the condenser, and cuts out piping, valves, and other equipment. The turbine system also makes use of adjustable-speed motor driven feedwater pumps, eliminates the separate steam seal system, and utilizes a single $100 \%$ feedwater heater string. These modifications result in a $45 \%$ reduction in the size of the turbine hall when compared with a conventional BWR of similar capacity.

\subsubsection{Safety systems}

The enhanced safety of the SBWR depends upon a combination of increased inherent safety margins built into the design and added passive safety systems that activate automatically without operator intervention.

Increased design safety margins. In addition to simplifying the reactor design and reducing capital costs, the natural-flow convective cooling system provides a simple approach to emergency core cooling. eliminating the need for pumps or backup diesel-powered generators. As noted above, the increased volume of the reactor pressure vessel above the core reduces the need for additional emergency core cooling capacity. Furthermore, no large pipes are attached to the vessel at or 
below the core elevation, so a large pipe-break accident cannot lead to uncovering of the core.

Isolation condenser system. Core decay heat produced in an accident situation in which the reactor is isolated from the turbine condenser is extracted from the core by convective cooling and is removed by three isolation condensers. These isolation condensers reject heat into pools located outside containment and then into the atmosphere. Steam produced by decay heat is channeled by natural circulation to the isolation condenser tube-side heat transfer surfaces, where it gives up its heat to the pool water on the other side of the tube wall and condenses. The condensate returns by gravity flow to the reactor, and radiolytically generated noncondensable gases are vented to the suppression pool. Heat transfer from the isolation condenser tubes to the pool water is accomplished by natural convection witiout pumped circulation, and the steam produced in the pools is vented to the atmosphere. The water inventory in the pools is sufficient for three days of decay heat removal, and addition of water to the pools after that time can provide passive decay hecat removal indefinitely.

Gravity-driven core cooling system. In the event of a loss-of-coolant accident, cr when the reserve coolant capacity in the pressure vessel is insufficient to maintain core cooling, additional cooling water can be supplied from three gravity-driven cooling-system pools located in the containment building at an elevation above the level of the core. As implied by the name, cooling water flows by gravity to the depressurized pressure vessel to keep the core covered, without the need for pumps or backup emergency power. Sufficient water is contained in the gravity-driven system cooling-system pools to flood the entire containment to a height of at least one meter above the active core. In the event of a severe accident in which molten core material penetrates the lower head of the pressure vessel and enters the drywell, the gravity-driven cooling system will flood the lower drywell region with the water inventory of the three system pools plus the suppression pool.

Automatic depressurization subsystem. The pressure in the reactor pressure vessel must first be relieved for the gravity-driven core cooling system to function. The automatic depressurization subsystem consists of eight safety relief valves and six depressurization valves. The safety relief valves are on the main steamlines between the reactor pressure vessel and the inboard main steamline isolation valve. They can function either in the automatic mode as overpressure safety valves, or they can be operator actuated to provide overpressure relief or system depressurization. The six depressurization valves, located on horizontal stub lines from the reactor pressure vessel or on lines branching from each main steamline, serve to reduce the pressure in the reactor pressure vessel to a sufficiently low level in an accident situation that the gravity-driven core cooling system can flood the core. As noted above, safety relief valves can be actuated manually to provide supplemental depressurization capacity in this situation.

The six depressurization valves are of a unique design in that they depend upon an explosive charge, or squib, to actuate a plunger that, in turn, shears off the inlet cap to the valve. The valves are actuated automatically after a preset time in the 
event of a loss-of-coolant signal from the reactor control system, or they can be manually actuated from the main control room.

Suppression pool. A water-filled suppression pool is located inside containment to serve as a heat sink during abnormal operations and accidents and to provide a supplemental source of cooling water in a severe accident situation. Specifically, the suppression pool serves to condense steam released by actuation of the safety relief valves and to condense steam released into the drywell in a loss-of-coolant accident. In the event of a severe accident in which molten core material penetrates the pressure vessel lower head and enters the drywell, the suppression pool supplies supplemental cooling water to the gravity-driven cooling system to flood the lower drywell region.

Passive containment cooling system. The passive containment cooling system removes the core decay heat rejected to containment after a loss-of coolant accident, thereby maintaining containment within pressure limits. The system consists of three independent loops, each containing a steam condenser, or passive containment cooling condenser, immersed in the same external pools as the isolation condensers. The system operates in the same manner as the isolation condenser system, i.e., steam present in the drywell in an accident situation is condensed in the cooling condensers, thereby rejecting its heat to the isolation pools. The resulting condensate is returned to the three gravity-driven cooling system pools, and noncondensable gases are vented to the suppression pool. The passive containment cooling system operates by natural circulation without the use of valves and is automatically activated when the drywell pressure exceeds that of the suppression pool.

\subsubsection{Control and electrical systems}

Space conditioning of the reactor control room is achieved by a passive, naturalcirculation air system. This feature, combined with the gravity-driven core cooling system, eliminates the need for safety-grade emergency diesel electrical generators and their associated reliability problems in the SBWR. The control rod drives (CRDs) are electrohydraulic rather than the conventional hydraulic design of the standard $B W R$, and the reactor instrumentation and controls are incorporated into a digitized multiplexed system that makes extensive use of microprocessor-based control and instrumentation modules.

\subsubsection{Power-generation systems}

The philosophy of system simplification carries over into the power generation system as well. A tandem, double-flow turbine with 52-in. last-stage buckets reduces the size of the turbine hall and simplifies the condenser and piping arrangement. The complexity and cost of the feedwater and condensate systems are reduced by the use of a single string of feedwater heaters. Variable-speed, motor-driven feed pumps reduce cost and simplify controls. The pumps used to pump forward the high-pressure drains in the conventional BWR have been eliminated by regulating the feed pump suction pressure to allow the drains to be pressure driven into the 
feedwater cycle, thus reducing capital and operating costs. The separate steam seal system of the conventional BWR has also been eliminated, because ts contribution to the concept of as low as reasonably achievable (ALARA) was judged to be insignificant. Finally, the main condenser is located under and to the side of the turbine, allowing the turbine pedestal to be lowered, thereby reducing capital costs. 


\subsection{SBWR Reactor Pressure Vessel}

\subsubsection{General description}

The reactor vessel is a vertical, cylindrical pressure vessel constructed from welded low-alloy steel forgings and plates. The vessel is designed, fabricated, tested, inspected, and stamped in accordance with ASME Code, Section III, Class 1 requirements. The interior of the vessel is clad with SS weld overlay, except for the head and nozzle weld zones. The bottom head is clad with a nickel-chromium-iron alloy. The shell is constructed of ring forgings made of ASME SA508, Class 3 material, joined by circumferential welds. Hence, the beltline region is a single forging, and there are no welds in the region of peak neutron flux. The length of the shell forgings is chosen to minimize the number of circumferential welds. The remainder of the vessel is constructed from SA533 Type $B$. Class 1 plates and SA508, Class 3 forgings. Gas tungsten arc welding, gas metal arc welding, shiel led metal arc welding, and submerged arc welding processes are used. Preheat and interpass temperatures during welding meet or exceed the values given in ASME Section III, Appendix D. Postweld heat treatment between a minimum temperature of $593^{\circ} \mathrm{C}\left(1099^{\circ} \mathrm{F}\right)$ and a maximum of $635^{\circ} \mathrm{C}\left(1175^{\circ} \mathrm{F}\right)$ are applied to all low-allny steel welds in accordance with ASME Code, Subsection NB-4620.

The vessel head is secured to the reactor vessel by studs and nuts. Shroud support brackets welded to the inside of the bottom head and are made of a nickelchromium-iron alloy and conform to ASME SB168 or SB166, though the precise alloy is not identified. These brackets support the steam separators, chimney, core plate, and peripheral fuel bundles.

There are penetrations in the bottom head of the reactor pressure vessel (RPV) for the CRDs. The CRD housings are welded to forged stub tubes that transmit loads from the CRD system to the bottom head of the reactor. Additional penetrations through the bottom head are provided for in-core neutron flux monitors. The housings of the in-core neutron flux monitors are also welded to forged stub tubes.

All reactor vessel nozzles are low-alloy steel forgings. Nozzles connecting to SS piping have safe ends of SS. The safe ends are welded to the nozzles after heat treatment of the RPV to avoid sensitization of the SS.

\subsubsection{Materials Selection}

The materials of construction specified by GE for the principal components of the RPV are summarized in Table 1. The RPV is fabricated from low-alloy steel plate and forgings. The plates are ASME SA533. Grade B, Class 1 material and the forgings are ASME SA508, Class 3 material. These are both low-alloy steels melted to fine grain practice and vacuum degassed to lower hydrogen content and improve cleanliness. They are used in the quenched and tempered condition. The maximum sulfur content for the base and weld materials is restricted to $0.01 \%$. Welding electrodes for the low-alloy steel welds are a low-hydrogen-type, ordered to ASME SFA-5.5. In addition, materials used in the core beltline region are restricted to a 
maximum of $0.05 \%$ copper and $0.012 \%$ phosphorous in base materials and a maximum of $0.08 \%$ copper and $0.012 \%$ phosphorous in weld materials.

The RPV is clad with weld-deposited austenitic stainless steel. No detailed specifications are given for the clad material. Presurnably, it follows current practice, i.e., Type 308L SS weld material laid down by the submerged-arc process. The bottom head of the vessel is clad with a nickel-chromium-iron alloy (apparently Inconel 600) instead of austenitic SS to minimize thermal stresses in the welds that join the shroud support brackets to the lower head. The shroud support brackets are also Inconel 600.

The studs, nuts, and washers for the head closure are AISI $4340 \mathrm{H}$ or 4340 modified low-alloy steels with a minimum yield strength of $893 \mathrm{MPa}(129.5 \mathrm{ksi})$. The modiffed grade refers to somewhat lower allowables for phosphorus and sulfur and a somewhat higher molybdenum level than in conventional 4340 steel. The maximum ultimate tensile strength of the bolting materials is specified not to exceed $1172 \mathrm{MPa}(170 \mathrm{ksi})$.

The CRD components are principally Type 304L or 316L SS, although the mounting bolts are AISI 4140 or related ste:els and the seal housing nuts are 17-4 PH martensitic SS.

\subsubsection{Anticipated operating environment}

The vessel design pressure is $8.62 \mathrm{MPa}(1250 \mathrm{psi})$ and the design temperature is $302^{\circ} \mathrm{C}\left(576^{\circ} \mathrm{F}\right)$. Because the welds are outside of the peak flux region, the peak fluence in the weld exposed to the highest radiation levels is only $1.41 \times 10^{18} \mathrm{n} / \mathrm{cm}^{2}$. The calculated shift in $\mathrm{RT}_{\mathrm{NDT}}$ for the worst weld is $29^{\circ} \mathrm{C}\left(52^{\circ} \mathrm{F}\right)$. The expected peak neutron fluence at the $1 / 4 \mathrm{~T}$ location that was used for evaluation is less than $5.8 \mathrm{x}$ $10^{18} \mathrm{n} / \mathrm{cm}^{2}$ for $60 \mathrm{yr}$. This corresponds to a stift in $\mathrm{RT}_{\mathrm{NDT}}$ of $16^{\circ} \mathrm{C}\left(29^{\circ} \mathrm{F}\right)$.

The reactor coolant is high-purity water, but it contains oxygen that is produced by radiolysis in the core. Although the SBWR uses a hydrogen-water chemistry to suppress dissolved-oxygen levels, the dissolved-oxygen content within the RPV is likely to vary considerably, being relatively high $(=0.2 \mathrm{ppm})$ in the upper part of the vessel and much lower in the lower part of the vessel. However, these are only generalizations; the actual distribution of dissolved oxygen level is a very complex function of the radiolytic reactions within the core and the internal circulation of the reactor coolant within the RPV by natural circulation.

\subsubsection{Potential material degradation and failure modes}

Adequate fracture toughness of the RPV is the critical requirement for safe operation of the reactor. The low-alloy steels used for the RPV do have high toughness in the proper metallurgical condition, but their toughness can decrease greatly under some conditions. However, as demonstrated by many years of successful experience, the requirements imposed by the ASME Code, 10 CFR 50 
Appendix G, and U.S. NRC Regulatory Guides $1.43^{8}$ and $1.50^{9}$ are sufficient to ensure that the as-fabricated vessel exhibits adequate fracture toughness.

In service, the primary factor leading to loss of fracture toughness is irradiation embrittlement. However, given the requirements for low copper and phosphorus levels in the low-alloy steels and the relatively low neutron flux levels associated with the SBWR design, the predicted loss in toughness is quite small, based on the correlations given in U.S. NRC Regulatory Guide 1.99.10 These correlations should be fully applicable to the SBWR RPV, Inasmuch as the operating temperature of the vessel is comparable to those which comprise the database upon which the correlations in Regulatory Guide 1.99 are based. Although no detalled information is available on the neutron spectrum for the SBWR (as compared with those of conventicinal BWRs and PWRs that are implicit in the correlations), the effects of the differences in spectra on the susceptibility to irradiation embrittlement would be expected to be extremely small.

\subsubsection{Issues}

In general, irradiation embrittlement is a critical issue for nuclear reactor pressure vessels. However, the fabrication procedures and restrictions on copper and phosphorus levels appear adequate to ensure that the loss in toughness over the 60 year life is acceptably low, particularly for the low fluence levels anticipated in the SBWR.

Current BWRs have experienced stress corrosion cracking (SCC) in nickelchromium-iron alloys such as Alloy 600 structural components and Alloy 182 weld butters. It has been demonstrated that the application of hydrogen-water chemistry in the SBWR can potentially reduce the probability that susceptible materials will actually undergo cracking. However, it is more difficult to assure that the hydrogenwater chemistry is effective in the RPV with the complex interaction of recombination driven by the hydrogen-water chemistry, radiolysis in the core, and recirculation by natural convection. Most of the nickel-chromium-iron alloys will be used in the lower head region of the vessel, where the hydrogen-water chemistry would be expected to be most effective. Nevertheless, it seems prudent to select alloys that are more resistant to SCC. Insufficient information is available on the actual composition and use of nickel-chromium-iron alloys to assess whether the most resistant materials have been selected or whether the design relies completely on the effectiveness of the hydrogen-water chemistry.

Another potential degradation mode for the vessel is fatigue crack growth. Extensive experimental data show that the primary determinant of accelerated, environmentally enhanced fatigue crack growth rates in low-alloy steels is the sulfur content of the steel.11.12 Although there is still some controversy over how to characterize the sulfur content of a low-alloy steel to ensure that it is not susceptible to environmentally assisted cracking, ${ }^{13}$ it appears that the limit of $0.01 \%$ on sulfur proposed for the SBWR is not sufficiently low to ensure that no environmental enhancement of the crack growth rate occurs. Although this limit ensures that the steels for the SBWR will be much cleaner than those used in current U.S. reactors, 
which typically range from $0.17-0.24 \%$ sulfur, lower levels are commonly found in the steels for new reactors in Europe and Japan. The steels for the Sizewell-B reactor in the U.K., for example, were limited to $0.005 \%$ sulfur. Thus, lower levels are well within the capability of commercial steel suppliers and should be specified here.

The use of 17-4 PH precipitation-hardening SS (SA564, Gr. 630 (H1100)) for the CRD seal housing nut also requires comment. This alloy is particularly susceptible to SCC and hydrogen embrittlement when heat treated to excessive hardnesses. 14 In the present application, the $\mathrm{H} 1100$ age-hardening treatment $(4 \mathrm{~h}$ at $\left.593^{\circ} \mathrm{C}\left(1100^{\circ} \mathrm{F}\right)\right)$ should produce a hardness of less than Rockwell $\mathrm{C} 35$. Severe susceptibility to cracking sets in for hardnesses of Rockwell C 40 or greater, which is associated with age-hardening heat treatments at less than $500^{\circ} \mathrm{C}\left(925^{\circ} \mathrm{F}\right)$. If the consequences of cracking are particularly severe for this component, the designers should require a verification of final hardness as one of the acceptance criteria.

Beyond these observations, the following apparent errors and ambiguities were noted in the materials specifications listed in Table 5.2-4 of the SSAR for the RPV and $\mathrm{CRD}$ components.

- The specification SA182, Type 316L, as called for in the RPV instrumentation nozzle forgings in Table 5.2-4, does not exist. It is assumed that the specification SA182. Grade F316 is intended, with the maximum carbon content of $0.02 \%$ indicated in the footnote to the table. Likewise, the specification SA336, Class F8 or F8M for the same component does not exist. It is assumed that the designers mean SA336. Class F316L. The F8 and F8M designations typically refer to the cast grades of Types 304 and 316 SS respectively, and the use of these grades for this application would be entirely inappropriate.

- SB166 and SB167 are indicated as alternative materials for the instrumentation nozzle forgings in Table 5.2-4. However, these specifications refer to Inconel 600 rather than the austenitic SSs indicated in the "Material" column of the table. It is assumed (as shown in Table 1) that the SB166 and SB167 specifications should, instead, refer to the instrument nozzle bars and seamless pipes, for which no specification is given. This is in agreement with the SB564, the forged grade of Inconel 600, that is specified for the stub tube material.

- For RPV drain nozzles, SA508, Class 1 is called for in Table 5.2-4. However, this is a carbon steel, and does not contain the $0.75 \%$ nickel and $0.5 \%$ molybdenum that is indicated in the "Material" column of the table. It is assumed that this should, instead, be SA508, Class 3.

- It is assumed that the SA194, B7 material specified for CRD mounting bolts actually means SA194, Grade 7. 
Table 1. SBWR reactor pressure vessel component materials

\begin{tabular}{|c|c|c|c|}
\hline Component & $\begin{array}{l}\text { Product } \\
\text { Form }\end{array}$ & $\begin{array}{l}\text { Material of } \\
\text { Construction }\end{array}$ & $\begin{array}{l}\text { Specification } \\
\text { (ASME) }\end{array}$ \\
\hline \multirow[t]{2}{*}{ Shells and heads } & Plate & $\begin{array}{l}\text { Low-alloy steel } \\
(0.5 \mathrm{Ni}, 0.5 \mathrm{Mo}, 0.2 \\
\text { C) }\end{array}$ & SA533, Gr. B, Class 1 \\
\hline & Forging & $\begin{array}{l}\text { Low-alloy steel }(0.75 \\
\mathrm{Ni}, 0.5 \mathrm{Mo}, 0.2 \mathrm{C})\end{array}$ & SA508, Class 3 \\
\hline Shell and head flange & Forging & $\begin{array}{l}\text { Low-alloy steel }(0.75 \\
\mathrm{Ni}, 0.5 \mathrm{Mo}, 0.2 \mathrm{C})\end{array}$ & SA508, Class 3 \\
\hline $\begin{array}{l}\text { Shroud support } \\
\text { brackets }\end{array}$ & - & $\begin{array}{l}\text { Nickel-chromium- } \\
\text { iron alloy }\end{array}$ & SB168 or SB166 \\
\hline Lower head cladding & - & $\begin{array}{l}\text { Nickel-chromium- } \\
\text { iron alloy }\end{array}$ & Not indicated \\
\hline $\begin{array}{l}\text { Head closure studs, } \\
\text { nuts, and washers }\end{array}$ & Various & $\begin{array}{l}\text { AISI } 4340 \mathrm{H} \text { or } \\
\text { modified } 4340 \text { low- } \\
\text { alloy steel }\end{array}$ & $\begin{array}{l}\text { SA540, Grade B23 or } \\
\mathrm{B} 24 \text { (min. Y.S. }=893 \\
\mathrm{MPa} \text { or } 129.5 \mathrm{ksi} \text { ) }\end{array}$ \\
\hline Nozzles & Forging & $\begin{array}{l}\text { Low-alloy steel }(0.75 \\
\text { Ni, } 0.5 \mathrm{Mo}, 0.2 \mathrm{C})\end{array}$ & SA508, Class 3 \\
\hline Drain nozzles & Forging & $\begin{array}{l}\text { Carbon steel }(0.2 \% \\
\text { carbon) (?) }\end{array}$ & SA508, Class 1 (?) \\
\hline \multirow[t]{2}{*}{$\begin{array}{l}\text { Instrumentation } \\
\text { nozzles }\end{array}$} & Forging & $\begin{array}{l}\text { Type } 316 \mathrm{~L} \\
\text { austenitic SS }\end{array}$ & $\begin{array}{l}\text { SA182, Type F316L } \\
\text { (0.02\% carbon max.), } \\
\text { or SA336, Class F8 or } \\
\text { F8M }\end{array}$ \\
\hline & $\begin{array}{l}\text { Bar, } \\
\text { Seamless } \\
\text { Pipes }\end{array}$ & Inconel 600 & SB 166 or SB167 \\
\hline Stub tubes & Forging & Inconel 600 & SB564 \\
\hline
\end{tabular}




\subsection{Control Rod Drive System and Reactor Internals}

\subsubsection{General description}

The SBWR CRD system and the reactor internal components are vital to the safe and reliable operation of the plant. The CRD system controls the reactor power level and provides the essential safety function of promptly shutting down, or "scramming," the reactor in the event of off-normal conditions. Reactor internal core support structures support the core and maintain proper core geometry and fuel subassembly spacing. Loss of core structural integrity could disrupt the coolant flow through the core or prevent proper functioning of the control rods and consequent loss of reactor control. Other reactor internal components direct coolant flow in the core region, position and protect in-core instrumentation, and provide for the injection and distribution of burnable poison for supplementary reactivity control. All of these functions are safety related, and the materials of construction for these components are reviewed here.

\subsubsection{Materials selection}

The CRD system and the reastor internal components are described in Chapters 3.0 and 4.0 of the SSAR, and detailed information on the proposed materials of construction is presented in Section 4.5. This information is summarized in Tables 2 and 3 for the major system components.

Inconel X-750 and 17-4 PH and Type 316L SS are the proposed materials of construction for the majority of the key components in the CRD system of the SBWR. Type 440 martensitic SS is used for the balls in the ball spindle assembly. Type 304L austenitic SS for the outer tube assembly flange, coated Type 321 austenitic SS for the CRD O-ring seal, and low-alloy steels for the CRD installation bolts. Cobalt-based alloys are specified for components that are subject to high wear conditions, such as the ball spindle assembly guide roller, roller pin, and guide shaft and bushing. However, unspecified non-cobalt alloys are to be used for the buffer assembly guide roller and pin.

For the reactor internal materials, Types 304L and 316L SS are specified for key structural components (i.e., safety-significant and hard-to-replace components such as the top guide, shroud, and core plate) in the SBWR. This is in contrast to the exclusive use of Type 304 SS to fabricate these components in conventional BWRs. The alloy XM-9 is suggested as an alternative material for several of these components. Less information and experience is available for this material, but it appears very resistant to environmentally assisted cracking in these environments. 15

\subsubsection{Anticipated operating environment}

The operating environment for these components will be reactor coolant at $\approx 288^{\circ} \mathrm{C}\left(550^{\circ} \mathrm{F}\right)$. The expected SBWR water chemistry, taken from Table 5.2-5 of the SSAR, is presented in Table 4. A significant radiation field is also present in the 
vicinity of the core, and the possible effects of this field on the proposed materials for the internal components will be considered here as well.

\subsubsection{Potential material degradation and failure modes}

A number of potential degradation and failure modes must be considered in specifying materials of construction or the CRD and reactor internal components. Inconel $X-750,17-4 \mathrm{PH}$ SS, and Type $304 \mathrm{~L}$ and $316 \mathrm{~L}$ SSs are all potentially susceptible to various modes of degradation and failure under the anticipated service conditions. Although an adequate database is not avallable to quantify the effects sufficiently, neutron irradiation in general aggravates the primary degradation processes that are known to affect these alloys in absence of irradiation, i.e., SCC of Inconel X-750, thermal aging of 17-4 PH, and IGSCC of Type 304 and 316 SSs.

17-4 PH SS, an austenitic-ferritic duplex SS, is subject to thermal aging and embrittlement. This phenomenon has been investigated extensively for cast duplex SSs in the absence of neutron irradiation, but only limited information is available on this process in the presence of irradiation. However, preliminary results indicate that irradiation leads to the enhanced aging degradation (i.e., reductions in initiation fracture toughness, Charpy upper-shelf energy, and DBTT) of duplex Type 308 SS welds as compared with thermal aging in the absence of irradiation.16-18 This neutron irradiation effect has not been well addressed in the SSAR.

Inconel $\mathrm{X}-750$ is known to be susceptible to SCC problems even in absence of irradiation if the composition and/or heat treatment are not properly controlled.19-23 As with SCC in the absence of irradiation, the susceptibility of Inconel X-750 to IASCC is reported to be sensitive to heat treatment during service in core. 24 Inconel. 718, a material known to be resistant to IASCC when annealed at low temperature, 24 should be considered as an alternative to Inconel X-750 where IASCC is a potential problem in the control rod drive system.

Because of the extended 60-year design life of the SBWR, the susceptibility of the $C R D$ and reactor internal components to irradiation-induced embrittlement and IASCC at high fluence is a greater concern than in conventional BWRs. The end-oflife fluence for the SBWR top guide is estimated to be as high as $\approx 10^{22} \mathrm{n} / \mathrm{cm}^{2}$. This substantially exceeds the commonly accepted threshold fluence of $\approx 5 \times 10^{20} \mathrm{n} / \mathrm{cm}^{2}$ (E > $1 \mathrm{MeV}$ ) for IASCC. 25.26 For this reason, considerable attention must be given to those factors that can contribute to IASCC susceptibility in the SBWR, including materials selection, water chemistry, stress control, and the elimination of crevices.

Materials selection. The mechanism(s) of IASCC are not well understood at present. In addition, a sufficient data base is not available for Types $304 \mathrm{~L}$ or $316 \mathrm{~L}$ SS. 27 Radiation-induced grain-boundary segregation of the impurity elements silicon, phosphorus, or sulfur has been suspected for many years to be the metallurgical process primarily responsible for intergranular cracking in solutionannealed austenitic SS at high fluence. However, results recently obtained in a number of laboratories and from in-reactor tests convincingly indicate that this 
hypothesis is incorrect.28-35 Contrary to earlier belief,24.36-38 higher levels of silicon and phosphorus seem to have no influence on the susceptibility of Type 304 and 316 SS to IASCC, 34.39 or in some cases, are beneficial in suppressing IASCC.28-33.35 Ongoing research is currently focusing on the role of radiation-induced depletion of chromium from grain boundaries and a synergism involving nitrogen, hydrogen, boron, or other unidentified impurity element(s).

Limited data are available on the performance of Types 304L and 316L SS as compared to the higher carbon Types 304 and 316 grades used in conventional BWRs and PWRs. According to data obtained by GE. Type 304L SS is generally more resistant to crack initiation than Type 304 SS, i.e., a somewhat higher fluence is required to initiate a crack in Type 304L, and crack growth rates at low fluence are significantly lower.27 However, crack growth rates in the two materials are similar for fluences $>1 \times 10^{21} \mathrm{n} / \mathrm{cm}^{2} .27$ Other results obtained from constant-extension-rate (ANL, Toshiba Electric Corporation), crack-growth-rate (ABB Atom), and tubeswelling tests (Siemens) indicate that the resistance of Type 304L SS to intergranular cracking is either similar to or worse than that of Type 304 SS.28-35.39 The exact cause of this large variation in susceptibility is not known at present, and there is no clear indication that carbon is the controlling element.

Thus, it cannot be automatically assumed that the lower carbon Type 304L SS will be significantly more resistant to SCC for high-fluence in-core components. A synergism involving impurity elements other than carbon apparently plays the crucial role in controlling the IASCC resistance of the Type 304 SS class. For example, one of the commercial-purity heats of Type 304 SS tested at ANL exhibited an unusually high resistance up to a fluence of $\approx 3 \times 10^{21} \mathrm{n} / \mathrm{cm}^{2}$, although the mechanism is not yet understood. 40

The low-carbon Type 316L SS appears to offer somewhat better resistance to IASCC than Type 316 SS in addition to its significantly greater resistance to stress corrcsion in the absence of a radiation field. However, control of impurities other than carbon agail appears crucial. Some modified heats of Type 316 SS have been reported to be resistant to IASCC, e.g., a high-purity Type 316L and low-nitrogen titanium-modified commercial-purity Type 316.31.39.41 Because of these observations, great attention has been focused on the role of nitrogen. However, some heats of commercial-purity Type 316 SS with normal levels of nitrogen and other elements have also been reported to be resistant to intergranular cracking.

Like the titanium-modified heats of Type 316 SS, a low-nitrogen high-purity Type 348 SS has been reported to exhibit resistance to IASCC both in BWR and PWR environments. 24 However, this resistance could not be reproduced in a subsequent investigation in which similar heats of high-purity Type 348 SS of virtually identical chemical composition containing somewhat higher nitrogen were tested in a PWR.34 Microstructural analyses conducted at ANL indicate that nitrogen atoms that segregate to grain boundaries and transmute to hydrogen during irradiation play an important role in determining the susceptibility to IASCC. 42 
In summary, it is not clear what metallurgical factors control IASCC in core components at high fluence. However, the specification of a low-carbon grade is neither a necessary nor a sufficient condition to prevent IASCC. Selection of the wrong heat of Type 304L SS (i.e., a heat containing an unfavorable combination of impurities other than carbon) would result in an increased susceptibility of safetysignificant SBWR components to IASCC.

High-purity Type 304 SS has been specified for the SBWR neutron absorber tubes rather than the commonly used commercial-purity material. The selection appears to be based on the performance of essentially one heat of high-purity Type 304 SS. However, other high-purity heats tested at ANL did not exhibit superior performance despite nominally similar compositions. ${ }^{32}$ This indicates that materials selection cannot be based upon general composition and ASTM- or AISI-designated class alone.

Water chemistry. Water chemistry parameters specified for normal operation of the SBWR are conductivity $<0.3 \mu \mathrm{S} / \mathrm{cm}$ (at $25^{\circ} \mathrm{C}$ ), $\mathrm{pH} \approx 7$, and electrochemical potential (ECP) <-230 mV SHE. Hydrogen-water chemistry will be used in the SBWR to suppress IASCC. The dissolved-oxygen content and the parameters for hydrogen-water chemistry are to be specified in the future.

IASCC is closely related to other forms of environmentally assisted cracking in high-temperature water in that the effect of water chemistry is similar in both unirradiated and irradiated materials. A strong effect of corrosion potential on the susceptibility to intergranular cracking of preirradiated materials has been reported.27,39,43 The effect appears to be independent of whether the potential was produced by water chemistry alone (e.g., by reducing dissolved oxygen 44,45 ) or in conjunction with irradiation. The effects of solution conductivity on the susceptibility of irradiated and unirradiated SS appear to be similar. The protection ECP necessary to suppress IGSCC during CERT tests of irradiated Type 304 SS has been reported to be $<-210 \mathrm{mV}$ SHE by GE investigators, a value similar to that for unirradiated and thermally sensitized material $(<-240 \mathrm{mV}$ SHE given for the design of SBWR). 43 However, some data obtained for a high-purity heat of Type 304 SS indicate significant crack growth rate for ECP values as low as $-450 \mathrm{mV}$ SHE. 27.39

Thus, the ranges of ECP and conductivity specified for the SBWR should, in principle, greatly suppress the susceptibility of the core internal components to IASCC. However, the effectiveness of hydrogen-water chemistry and the practicality of achieving a threshold ECP that is sufficient to mitigate IASCC in safety-significant components have not yet been established. This is particularly true for the top guide. Because of its position at the core upper level, it is not clear whether local ECP surrounding a top guide can be suppressed sufficiently (to <-230 mV SHE) by hydrogen-water chemistry. To achieve maximum resistance to IASCC, the sound water chemistry. approach proposed for the SBWR must be combined with careful attention to materials selection and stress and crevice control.

Stress control. One of the major concerns regarding the structural integrity of in-core components is the field failures of low-stress components such as the control 
blade sheath and handle. Design features aimed at mitigating LASCC of core components in the SBWR include maintaining the effective stress below a threshold level. This is an approach of potentially significant impact. The approach must, however, be described quantitatively and specifically for each safety-sis aificant component. Stress in an irradiated component could be produced from a variety of sources, i.e., applied load, weld residual stresses, fit-up stresses, thermal expansion during operation, irradiation creep (stress relief), and irradiation-induced swelling. During a well-defined constant-load test in hot-cell, the applied stress is the only major stress component present, assuming the swelling-induced stress is negligible. Results from such tests indicate that the IASCC failure threshold is influenced strongly by applied stress and fluence. 46

Therefore, minimizing the applied load in a given component would certainly be beneficial if it is practical. However, the situation during actual service is complex because there is no assurance that applied stress is the major component of overall stress. There are many reports of field experience in which components have failed under minimal applied load (e.g., cracking in BWR core shrouds and control blade sheaths). Therefore, special attention should be paid to the reduction of the residual stresses due to fit-up and welding. Where solution annealing is not possible, welding procedures should be optimized to produce the lowest possible residual stresses. This problem has not been well addressed in the SBWR SSAR document.

Crevice control. The greatest threat to the integrity of the SBWR safetysignificant reactor internal components is failure by the combined processes of IASCC and crevice-assisted stress corrosion cracking (CASCC). This also applies to other components such as neutron absorber tubes. The systematic elimination of crevices in the design of the top guide of the SBWR represents a very important improvement over top guides in conventional BWRs.

\subsubsection{Issues}

Although several potential degradation and failure modes exist for the materials specified for the $C R D$ and reactor internal components, available data and information are often insufficient to make a definitive judgment on the selection of materials. However, the following issues should be raised:

- Accelerated thermal aging under neutron irradiation is possible in the 17-4 PH SS specified for several $\hat{i} i$ the CRD system components. The data available are not sufficient to provide a basis to determine the significance of this potential mode of degradation.

- Both Inconel X-750 and Type 316 SS, which are specified for numerous CRD and reactor internal components, are susceptible to IASCC. Heat-to-heat variations, probably associated with minor variations in chemistry and microstructure, appear to play an important role, and materials selection cannot be based upon general ASTM or ASME specifications. 
- The water chemistry parameters specified for the SBWR, including the use of hydrogen-water chemistry, should greatly suppress the susceptibility of the core internal components to IASCC. However, for the top guide in particular, it is not clear that the local ECP can be maintained sufficiently low by hydrogen-water chemistry to prevent IASCC. The proposed water chemistry approach, while very good, must be combined with careful attention to materials selection and stress and crevice control. 
Table 2. Materials of construction for SBWR control rod drive system

\begin{tabular}{|c|c|c|}
\hline Component & Material of Construction & $\begin{array}{c}\text { Specification } \\
\text { (ASME or ASTM) }\end{array}$ \\
\hline \multicolumn{3}{|l|}{ Spool Piece Assembly } \\
\hline Spool piece housing & Type 304L SS & SA182, Gr. F304L \\
\hline Seal housing & Type $304 \mathrm{~L}$ SS & SA182, Gr. F304L \\
\hline Drive shaft & Austenitic SS & SA479, Gr. XIM-19 \\
\hline Ball bearings & Type 440 SS & A276. Type $440 \mathrm{C}$ \\
\hline Separation spring & Inconel X-750 & - \\
\hline \multicolumn{3}{|l|}{ Ball Spindle Assembly } \\
\hline Spool piece housing & 17-4 PH SS & $\begin{array}{l}\text { A564, TP630 (17-4), } \\
\text { Condition H-1 } 100\end{array}$ \\
\hline Ball nut & $17-4$ PH SS & $\begin{array}{l}\text { A564, TP630 (17-4), } \\
\text { Condition H-1 } 100\end{array}$ \\
\hline Balls & Type 440 SS & A276. Type $440 \mathrm{C}$ \\
\hline Guide roller & Stellite No. 3 & - \\
\hline Guide roller pin & Haynes Alloy No. 25 & - \\
\hline Guide shaft & Stellite No. 6 & - \\
\hline Guide shaft bushing & Stellite No. 12 & - \\
\hline \multicolumn{3}{|l|}{ Buffer Assembly } \\
\hline Buffer spring & Inconel X-750 & - \\
\hline Buffer sleeve & $\begin{array}{l}\text { Type 316L SS, hard faced } \\
\text { with Colmonoy } 6\end{array}$ & - \\
\hline Guide roller and pin & Non-cobalt Alloys & - \\
\hline Stop piston & $\begin{array}{l}\text { Type 316L SS, hard faced } \\
\text { with Stellite } 6\end{array}$ & - \\
\hline \multicolumn{3}{|l|}{ Hollow Piston } \\
\hline Piston tube & $\mathrm{XM}-19$ & - \\
\hline Piston head & $\begin{array}{l}\text { Type 316L SS, hard faced } \\
\text { with Stellite } 3\end{array}$ & - \\
\hline Latch and latch spring & Inconel X-750 & - \\
\hline $\begin{array}{l}\text { Bayonet coupling } \\
\text { (CRD spud) }\end{array}$ & Inconel X-750 & - \\
\hline
\end{tabular}


Table 2. (Cont'd)

\begin{tabular}{llc}
\hline \multicolumn{1}{c}{ Component } & Material of Construction & $\begin{array}{c}\text { Specification } \\
\text { (ASME or ASTM) }\end{array}$ \\
\hline $\begin{array}{l}\text { Guide Tube Assembly } \\
\text { Guide tube }\end{array}$ & Type 316L SS & - \\
$\begin{array}{l}\text { Outer Tube Assembly } \\
\text { Outer tube }\end{array}$ & $\begin{array}{l}\text { XM-19 } \\
\text { Flange }\end{array}$ & Type 304L SS \\
$\begin{array}{l}\text { Bayonet coupling } \\
\text { (CRD blowout support) }\end{array}$ & Inconel X-750 & - \\
& & - \\
$\begin{array}{l}\text { Miscellaneous Parts } \\
\text { Ball for check valve } \\
\text { O-Ring seal (between CRD } \\
\text { housing and CRD) } \\
\text { CRD installation bolts }\end{array}$ & $\begin{array}{l}\text { Haynes Alloy } \\
\text { Type 321 SS, coated with } \\
\text { qualified metal }\end{array}$ & - \\
& $\begin{array}{l}\text { AISI 4140, 4142, 4145, } \\
4140 \mathrm{H}, 4142 \mathrm{H}, \text { or }\end{array}$ & SA193, Gr. B7 \\
& $4145 \mathrm{H}$ steel & \\
\hline
\end{tabular}


Table 3. Materials of construction for SBWR reactor internals

\begin{tabular}{|c|c|c|}
\hline Component & Material of Construction & $\begin{array}{c}\text { Specification } \\
\text { (ASME or ASTM) }\end{array}$ \\
\hline Shroud support & $\begin{array}{l}\text { Nickel-chromium-iron } \\
\text { alloy }\end{array}$ & SB166 or SB168 \\
\hline $\begin{array}{l}\text { Shroud, core plate, and } \\
\text { top guide }\end{array}$ & Type $304 \mathrm{~L}$ or $316 \mathrm{~L}$ SS & $\begin{array}{l}\text { SA240, SA182, } \\
\text { SA479, SA312, } \\
\text { SA249, or SA213 }\end{array}$ \\
\hline $\begin{array}{l}\text { Core plate and top guide } \\
\text { studs }\end{array}$ & $\begin{array}{l}\text { Type } 304 \text { or } 316 \text { SS or } \\
\text { XM-19 }\end{array}$ & $\begin{array}{l}\text { SA479 or SA193, } \\
\text { Gr. B8 }\end{array}$ \\
\hline $\begin{array}{l}\text { Core plate and top guide } \\
\text { nuts }\end{array}$ & $\begin{array}{l}\text { Type } 304 \text { or } 316 \text { SS or } \\
\text { XM-19 }\end{array}$ & $\begin{array}{l}\text { SA } 479 \text { or SA194, } \\
\text { Gr. } 8\end{array}$ \\
\hline $\begin{array}{l}\text { Core plate and top guide } \\
\text { sleeves }\end{array}$ & $\begin{array}{l}\text { Type } 304,304 \mathrm{~L}, 316 \text { or } \\
316 \mathrm{~L} \text { SS or XM-19 }\end{array}$ & $\begin{array}{l}\text { SA479; SA182, Gr. } \\
\text { F304L or 316L; } \\
\text { SA213, Type 304L, } \\
\text { 316, or 316L; or } \\
\text { SA249, Type 304L, } \\
\text { 316, or 316L }\end{array}$ \\
\hline $\begin{array}{l}\text { Peripheral single-assembly } \\
\text { fuel support }\end{array}$ & Type $304 \mathrm{~L}$ or $316 \mathrm{~L}$ SS & $\begin{array}{l}\text { SA312, Gr. } 304 \mathrm{~L} \text { or } \\
316 \mathrm{~L}\end{array}$ \\
\hline Control rod drive housing & Type $304 \mathrm{~L}$ or $316 \mathrm{~L}$ SS & $\begin{array}{l}\text { SA312, Gr. TP304L or } \\
\text { 316L; SA182, Gr. } \\
\text { F304L or 316L; and } \\
\text { SA351, Type CF3 or } \\
\text { CF3A }\end{array}$ \\
\hline Control rod guide tube & Type $304 \mathrm{~L}$ or $316 \mathrm{~L}$ SS & $\begin{array}{l}\text { SA351, Type CF3 or } \\
\text { CF3A; or SA312 or } \\
\text { SA249, Type } 304 \mathrm{~L} \text { or } \\
316 \mathrm{~L}\end{array}$ \\
\hline Orificed fuel support & $\begin{array}{l}\text { Type } 304 \mathrm{~L} \text { SS } \\
\text { or XM-19 }\end{array}$ & $\begin{array}{l}\text { SA351, Type CF3 or } \\
\text { XM-19 }\end{array}$ \\
\hline $\begin{array}{l}\text { Chimney and partitions, } \\
\text { chimney head and separ- } \\
\text { ator assembly, and steam } \\
\text { dryer assembly }\end{array}$ & Type $304 \mathrm{~L}$ or $316 \mathrm{~L}$ SS & $\begin{array}{l}\text { A240, Type 304L or } \\
\text { 316L; A182, Gr. 304L; } \\
\text { A276, Type 316L; } \\
\text { A312, Gr. TP-304L; } \\
\text { A269, Gr. TP-304L; or } \\
\text { A351, Gr. CF3 or CF3A }\end{array}$ \\
\hline
\end{tabular}


Table 4. Expected SBWR water chemistry

\begin{tabular}{|c|c|c|c|c|c|c|c|c|}
\hline \multirow[b]{2}{*}{ Parameter } & \multicolumn{5}{|c|}{ Concentration (ppb)a } & \multirow{2}{*}{$\begin{array}{c}\text { Conduc- } \\
\text { tivity } \\
(\mu \mathrm{S} / \mathrm{cm} \text { at } \\
\left.25^{\circ} \mathrm{C}\right)\end{array}$} & \multirow{2}{*}{$\begin{array}{c}\mathrm{pH} \\
\text { at } 25^{\circ} \mathrm{C}\end{array}$} & \multirow{2}{*}{$\begin{array}{c}\mathrm{ECP} \\
\left(\mathrm{V} \text { at } \mathbf{2 5}^{\circ} \mathrm{C}\right)\end{array}$} \\
\hline & Fe & $\mathbf{a r}$ & Chloride & Sulfate & Oxygen ${ }^{b}$ & & & \\
\hline Condensate treatment & $<20$ & $<2$ & $<4$ & $<4$ & $<10$ & $\approx 0.075$ & - & - \\
\hline $\begin{array}{l}\text { Condensate treatment } \\
\text { Effluent and feedwater }\end{array}$ & $<2.2$ & $<0.1$ & $<0.32$ & $<0.32$ & $20-50$ & $\approx 0.059$ & - & - \\
\hline \multicolumn{9}{|l|}{ Reactor water: } \\
\hline Normal operation & $<20$ & $<1$ & $<20$ & $<20$ & $\mathbf{b}$ & $<0.3$ & $\approx 7$ & $<-0.23$ \\
\hline Shutdown & $<20$ & $<1$ & $<20$ & $<20$ & - & $<1.2$ & $\approx 7$ & - \\
\hline Hot standby & $<20$ & $<1$ & $<20$ & $<20$ & $<200$ & $<0.3$ & $\approx 7$ & - \\
\hline Depressurized & $<20$ & $<1$ & $<20$ & $<20$ & $\begin{array}{l}1000- \\
8000\end{array}$ & $<1.2$ & $5.6-8.6$ & - \\
\hline $\begin{array}{l}\text { Control rod drive } \\
\text { cooling water }\end{array}$ & $<2.2$ & $<0.1$ & $<0.32$ & $<0.32$ & $20-50$ & $\approx 0.059$ & - & - \\
\hline
\end{tabular}

aThese limits should be met at least $90 \%$ of the time.

bSome revision of dissolved-oxygen values may be established after hydrogen-water chemistry has been established. 


\subsection{Coolant Pressure Boundary}

\subsubsection{General description}

The SBWR coolant pressure boundary is made up of all of the pressurecontaining components that are a part of the reactor coolant system (RCS) or are connected to the RCS. The reactor coolant pressure boundary (RCPB) includes the reactor pressure vessel; steam, condensate, and feedwater system piping; and associated pumps and valves. Simplifications in the design of the SBWR as compared with a conventional BWR have resulted in the elimination of considerable external piping, including the recirculation loop piping, a portion of the steam supply piping. valves, and other components. Nonetheless, the coolant boundary comprises a significant part of the SBWR plant, and its structural integrity is a fundamental safety consideration.

Because the pressure vessel is discussed separately, the present section will focus on the steam supply and condensate and feedwater systems. The function of the steam supply system, 1.e., the main steam lires, the steamline flow limiter, and the main steam isolation valves, is to convey steam generated in the reactor to the turbine plant. The condensate and feedwater system receives condensate from the condenser hotwells, supplies it to the purification system, and delivers high-purity, heated feedwater to the reactor in a closed steam cycle that utilizes regenerative feedwater heating. The drains from each stage of the feedwater heaters are cascaded through successively lower pressure feedwater heaters to the main condenser. This allows the water to be purified by the full-flow condensate purification system before it returns to the reactor. This feature will reduce the amount corrosion-product iron that enters the final feedwater that flows through the reactor. Operation of the condensate purification system incorporates state-of-the-art practice to minimize sulfate ingress and transport of resin fines into the reactor coolant, which could promote SCC of system materials. Instrumentation is provided to monitor system influent and effluent water quality and the pressure drop across each of the four condensate polisher vessels. Other instrumentation for water quality measurements will be provided but they were not identified.

The SBWR has a reactor water cleanup/shutdown system cooling system designed to remove dissolved and undissolved impurities from the coolant that can become activated in the core and lead to high radiation fields in the piping. Though not specifically stated, this system also presumably serves to remove dissolved impurities that would otherwise build up in the coolant and create potential corrosion problems. The system processes reactor water at a rate of $1 \%$ of the rated feedwater flow.

The steam supply and condensate and feedwater system components are designed and constructed in accordance with applicable ASME Codes and U.S. NRC Regulatory Guides. 


\subsubsection{Materials selection}

The proposed materials of construction for the principal components in the SBWR coolant pressure boundary are summarized in Table 5 . The austenitic SS piping used in conventional BWRs for the recirculation piping is not present here Lecause the piping has been eliminated through the use of natural convective coolant circulation through the core. Most of the remaining RCPB components, including the main steam piping, nozzles, valve bodies, and flanges, as well as the feedwater and isolation condenser piping, are to be made of various grades of $0.3 \%$ carbon steel. The only significant exceptions are the isolation condenser condensate piping. which is to be made of Type $316 \mathrm{~L}$ austenitic SS $(0.02 \%$ carbon max.), and selected steam line piping internal components, which are to be made of various low-alloy steels or SSs.

In discussing the RCPB materials for the SBWR, the SSAR states (in Section 5.2.3.2.2) that "for the SBWR, IGSCC resistance has been achieved through the use of IGSCC resistant materials such as Type 316 Nuclear Grade stainless steel and stabilized nickel-base Alloy 600M and 182M." However, the materials of construction list in Table 5.2-4 of the SSAR do not specifically indicate the use of Type 316NG SS, unless that is what is meant by the Type $316 \mathrm{~L}$ SS $10.02 \%$ carbon max.) specified for the isolation condenser condensate piping. The stabilized nickelbase alloys are also not specifically called out, except for the use of SB564 for the reactor pressure vessel stub tubes discussed in Section 3.1 above. The SB564 specification refers to Alloy 600 tubes in general, but could be taken to mean the stabilized " $M$ " grade in this case.

\subsubsection{Anticipated operating environment}

The expected SBWR water chemistries for the condensate treatment effluent and feedwater; reactor water under normal operation, shutdown, hot standby, and depressurization; and CRD cooling water (Table 5.2-5 in the SSAR) are consistent with good practice based on BWR Water Chemistry Guidelines. The conductivity value for the condensate treatment efluent and feedwater and the CRD cooling water at $25^{\circ} \mathrm{C}$ is given as $<0.059 \mu \mathrm{S} \cdot \mathrm{cm}^{-1}$, which is below the theoretical minimum value for pure water. High water purity could be designated as water with a conductivity of $\approx 0.06$ or $<0.07 \mu \mathrm{S} \cdot \mathrm{cm}^{-1}$. The materials, construction, and preservice and inservice inspection of the coolant pressure boundary are covered by every applicable ASTM Standard/Specifi-cation, ASME Code, and U.S. NRC Regulatory Guide.

\subsubsection{Potential material degradation and failure modes}

The elimination of the recirculation piping in the SBWR also eliminates the intergranular stress corrosion cracking (IGSCC) problems that have plagued these components in the conventional BWR. The use of carbon steel for the main steam piping and feedwater piping is consistent with conventional BWR practice and should cause no problems. The only other significant potential SCC problems in the RCPB components are associated with the martensitic Type 410 and 17-4 PH SSs to 
be used for certain valve internals and with the possible use of Alloys 600M and $182 \mathrm{M}$. The martensitic stainless steels are very susceptible to SCC when hardened to levels higher than $\approx R_{c} 35$, and care must be taken to ensure proper heat treatment of these components. Alloys 600 and 182, even for the "M" grades, can crack in oxygenated water, particularly under crevice conditions. Proper controls of dissolved-oxygen levels in the coolant and avoldance of crevice geometries in component design are essential.

The SSAR states that vented tanks with delonized or demineralized water with no control of dissolved oxygen will be used for final cleaning and flushing of the feedwater system. This will not lead to any corrosion problems. However, the SSAR does not state whether the makeup water and the condensate storage tanks will have an inert nitrogen cover gas to maintain low dissolved-oxygen levels and prevent pickup of carbon dioxide from the air. This feature should be adopted to further minimize impurity ingress into the reactor coolant system.

As noted above, the SBWR has a reactor water cleanup/shutdown system cooling system designed to remove dissolved and undissolved impurities from the coolant that would otherwise build up and create potential radiation field and corrosion problems. However, the system reprocessing rate of $1 \%$ of the rated feedwater flow is rather low, and it is not clear if this rate is adequate to maintain the high-quality water chemistry that GE has specified for the SBWR.

\subsubsection{Issues}

Few materials problems are foreseen in the RCPB components. However, the following points should be reiterated:

- The SSAR states that "IGSCC resistance has been achieved through the use of IGSCC resistant materials such as Type 316 Nuclear Grade stainless steel and stabilized nickel-base Alloy 600M and 182M." However, the SSAR materials of construction list does not specifically indicate the use of Type 316NG SS, unless that is what is meant by the Type $316 \mathrm{~L}$ SS $10.02 \%$ carbon max.) specified for the isolation condenser condensate piping.

- The stabilized nickel-base alloys are also not specifically called out for the SBWR, except for the use of SB564 for the reactor pressure vessel stub tubes. The SB564 specification refers to Alloy 600 tubes in general, but could be taken to mean the stabilized " $M$ " grade in this case.

- The martensitic SSs specified for selected valve internals in the main steam piping system are very susceptible to SCC when hardened to levels higher than $\approx R_{c} 35$. Care must be taken to ensure proper heat treatment of these components.

- Alloys 600 and 182, even for the "M" grades, can crack in oxygenated water, particularly under crevice conditions. Proper control of coolant dissolved- 
oxygen levels and avoidance of crevice geometries in component design are essential.

- The SSAR does not state whether the makeup water and the condensate storage tanks used for final cleaning and flushing of the feedwater system will have an inert nitrogen cover gas to maintain low dissolved-oxygen levels and prevent pickup of carbon dioxide from the air. This feature should be adopted to further minimize impurity ingress into the reactor coolant system.

- The reactor water cleanup/shutdown system cooling system processing rate of $1 \%$ of the rated feedwater flow is rather low, and it is not clear if it is adequate to maintain the high-quality water chemistry that GE has specified for the SBWR. 
Table 5. Materials of construction for SBWR reactor coolant pressure boundary components

\begin{tabular}{|c|c|c|c|}
\hline Component & Form & Material & $\begin{array}{c}\text { Specification } \\
\text { (ASME or ASTM) }\end{array}$ \\
\hline \multicolumn{4}{|l|}{ Main Steam Piping } \\
\hline Pipe & Seamless pipe & $0.3 \%$ carbon steel & SA333, Gr. 6 \\
\hline Contour nozzle & Forging & $0.3 \%$ carbon steel & SA350, Gr. LF2 \\
\hline $\begin{array}{l}200 A 1500 \# \text { large } \\
\text { groove flange }\end{array}$ & Forging & $0.3 \%$ carbon steel & SA350, Gr. LF2 \\
\hline 50A special nozzle & Forging & $0.3 \%$ carbon steel & SA350, Gr. LF2 \\
\hline Elbow & Seamless pipe & $0.3 \%$ carbon steel & SA420, Gr. WPL6 \\
\hline $\begin{array}{l}\text { Head fitting/pene- } \\
\text { tration piping }\end{array}$ & Forging & $0.3 \%$ carbon steel & SA350, Gr. LF2 \\
\hline \multicolumn{4}{|l|}{ Main Steam Valve } \\
\hline Valve body & Cast & $0.3 \%$ carbon steel & SA352, Gr. LCB \\
\hline Cover & Forged & $0.3 \%$ carbon steel & SA350, Gr. LF2 \\
\hline Poppet & Forged & $0.3 \%$ carbon steel & SA350, Gr. LF2 \\
\hline Valve stem & Rod & $17-4$ PH SS & $\begin{array}{l}\text { SA564, Type } 630 \\
\text { (H1100) }\end{array}$ \\
\hline Body bolt & Bolting & $\begin{array}{l}\text { AISI } 4340 \mathrm{H} \text { low- } \\
\text { alloy steel }\end{array}$ & $\begin{array}{l}\text { SA540, Gr. B23, } \\
\text { Cl } 5\end{array}$ \\
\hline Hex nuts & Bolting nuts & $\begin{array}{l}\text { AISI } 4140 \text { low- } \\
\text { alloy steel }\end{array}$ & SA194, Gr. 7 \\
\hline \multicolumn{4}{|c|}{ Main Steam Line Safety Rellef Valve } \\
\hline Body & $\begin{array}{l}\text { Forging or } \\
\text { casting }\end{array}$ & $0.3 \%$ carbon steel & SA350, Gr. LF2 \\
\hline Bonnet (yoke) & $\begin{array}{l}\text { Forging or } \\
\text { casting }\end{array}$ & $0.3 \%$ carbon steel & $\begin{array}{l}\text { SA350, Gr. LF2 or } \\
\text { SA352, LCB }\end{array}$ \\
\hline Nozzle (seat) & $\begin{array}{l}\text { Forging or } \\
\text { casting }\end{array}$ & $\begin{array}{l}\text { Type } 316 \text { L SS (C } \leq \\
0.02 \% \text { ) or } 0.3 \% \\
\text { carbon steel }\end{array}$ & $\begin{array}{l}\text { SA182, Gr. F316 } \\
\text { (carbon } \leq 0.02 \% \text { ) or } \\
\text { SA350, LF2 }\end{array}$ \\
\hline $\begin{array}{l}\text { Body-to-bonnet } \\
\text { stud }\end{array}$ & Bar/rod & $\begin{array}{l}\text { AISI } 4140 \text { low- } \\
\text { alloy steel }\end{array}$ & SA194, Gr. 7 \\
\hline Disk & $\begin{array}{l}\text { Forging or } \\
\text { casting }\end{array}$ & $\begin{array}{l}\text { Inconel } 718 \text { or } \\
\text { CF3A cast duplex } \\
\text { SS }\end{array}$ & $\begin{array}{l}\text { SB637, Gr. } 718 \text { or } \\
\text { SA351, Gr. CF3A }\end{array}$ \\
\hline Spring washer & Forging & $0.3 \%$ carbon steel & SA105 \\
\hline Adjusting screw & Forging & $\begin{array}{l}\text { Type } 410 \text { marten- } \\
\text { sitic SS }\end{array}$ & SA193, Gr. B6 \\
\hline $\begin{array}{l}\text { Setpoint adjust- } \\
\text { ment assembly }\end{array}$ & Forgings & $\begin{array}{l}\text { Carbon and alloy } \\
\text { steel parts }\end{array}$ & (Multiple) \\
\hline
\end{tabular}


Table 5. (Cont'd.)

\begin{tabular}{|c|c|c|c|}
\hline Component & Form & Material & $\begin{array}{c}\text { Specification } \\
\text { (ASME or ASTM) }\end{array}$ \\
\hline \multicolumn{4}{|c|}{ Main steam Line Safety Relief Valve (Cont'd.) } \\
\hline Spindle (stem) & Bar & Type 630 PH SS & $\begin{array}{l}\text { SA564, Gr. } 630 \\
(\text { H } 1100)\end{array}$ \\
\hline Spring & $\begin{array}{l}\text { Wire or Belle- } \\
\text { ville washers }\end{array}$ & $\begin{array}{l}\text { Alsi } 4161 \mathrm{H} \text { low- } \\
\text { alloy steel or } 0.45 \\
\text { C-1.4 Ni-0.7 Mo- } \\
0.3 \mathrm{~V} \text { low-alloy } \\
\text { steel }\end{array}$ & $\begin{array}{l}\text { A304, Gr. } 4161 \mathrm{H} \\
\text { or 45CrMoV6.7 } \\
\text { (German grade) }\end{array}$ \\
\hline Feedwater Piping & Seamless pipe & $0.3 \%$ carbon steel & SA333, Gr. 6 \\
\hline \multicolumn{4}{|c|}{ Isolation Condenser } \\
\hline $\begin{array}{l}\text { Steam pipe } \\
\text { Condensate pipe }\end{array}$ & $\begin{array}{l}\text { Seamiess pipe } \\
\text { Seamless pipe }\end{array}$ & $\begin{array}{l}0.3 \% \text { carbon steel } \\
\text { Type } 316 \mathrm{~L} \text { SS } \\
\text { (carbon } \leq 0.02 \% \text { ) }\end{array}$ & $\begin{array}{c}\text { SA333, Gr. } 6 \\
-\end{array}$ \\
\hline
\end{tabular}




\subsection{Engineered Safety Systems}

\subsubsection{General description}

The engineered safety systems of the SBWR include the containment and fission-product removal systems, the emergency core cooling systems, and the control room habitability systems. Of these, the first two are a concern from a materials performance point of view, and the materials of construction for these two systems will be reviewed here.

The containment and fission-product removal systems include containment, the passive containment cooling system (PCCS), the containment isolation system, the safety envelope, and the flammability control system. The emergency core cooling system includes the gravity-driven cooling system and the automatic depressurization subsystem. These systems are critical to reactor safety in that they provide for core cooling and nuclear materials containment in an accident situation. In addition, the automatic depressurization system (ADS) forms a part of the reactor primary pressure boundary.

\subsubsection{Materials selection}

These systems, the specified materials of construction, and anticipated operating conditions for these systems are described in Chapter 6.0 of the SSAR, with most of the materials information contained in Section 6.1. This information is summarized in Table 6 for the major system components.

The general materials selection philosophy for these systems appears to be one of specifying the low-carbon grades of austenitic SS (Types 304L or 316L) for components normally operating in contact with reactor coolant or emergency cooling water. Other components are typically made of carbon or low-alloy steel. Demineralized water is specified for the SBWR core cooling water and the containment sprays, and the authors of the SSAR state that chloride leaching from concrete components in contact with the water is insignificant.

\subsubsection{Anticipated operating environment}

Containment. The containment system surrounding the reactor pressure vessel normally operates in a dry nitrogen atmosphere $\left(<4 \% \mathrm{O}_{2}\right)$ at temperatures below $150^{\circ} \mathrm{C}$.

Isolation and passive containment cooling systems. The principal components in the isolation and fassive containment cooling systems are the condensers and the associated piping. The isolation condenser tubing and piping also comprise a part of the reactor pressure boundary. The isolation condensers will normally operate in contact with condensate on the primary side and isolation pool water on the secondary side, both at temperatures well below $100^{\circ} \mathrm{C}$. The PCCS condensers will have the same conditions on the secondary side, but the primary side will normally be dry. The isolation condenser steam piping will contain saturated steam at 
$\leq 288^{\circ} \mathrm{C}$, and the condensate lines will normally be dry. The PCCS piping will normally be dry and will operate at temperatures $<100^{\circ} \mathrm{C}$.

Automatic depressurization systern. The automatic depressurization system consists of eight safety relief valves and six depressurization valves. These valves serve to relieve excess system pressure during off-normal situations and to completely depressurize the system in a loss of coolant accident situation, thereby enabling the gravity-driven cooling system to flood the core. The safety relief valves are mounted on top of the main steam lines in the reactor drywell and discharge through lines routed to quenchers located in the suppression pool. Four of the depressurization valves are mounted on horizontal stub lines connected to the reactor pressure vessel at about the elevation of the main steam lines. The remaining two depressurization valves are mounted on horizontal lines branching from each main steam line.

The four depressurization valves located on stub lines from the reactor pressure vessel operate with their interior surfaces nominally in continuous contact with saturated steam at $=288^{\circ} \mathrm{C}$. However, their location in stub lines somewhat removed from the pressure vessel means that they will probably be at a slightly lower temperature, and continuous condensation and refluxing of the reactor coolant is likely to occur inside the valves and stub lines.

Gravity-driven cooling system. The components of the gravity-driven cooling system largely operate in contact with deionized water at temperatures well below $100^{\circ} \mathrm{C}$, similar to the suppression-pool components.

\subsubsection{Potential material degradation and failure modes}

Containment. Corrosion is not expected to be a problem under the benign conditions present in the containment system, and the carbon steel specified for most of the containment components should perform satisfactorily. The suppression pool liner and vents operate in contact with deionized water at temperatures well below $100^{\circ} \mathrm{C}$. These components are specified to be made of Type 304L SS, and this material should be satisfactory for this application.

Isolation and passive containment cooling systems. The Type 304L SS specified for the PCCS components should provide satisfactory service. However, it is not clear that the high corrosion resistance of Type 304L SS is needed for the inlet piping to this condenser. In the case of the isolation condenser, the SSAR does not specifically spell out the material of construction for the condenser tubing. Type 304L or Type 316L SS would be the preferred material to avoid excessive general corrosion and wastage in this normally wet environment. The Type 316L SS specified for the condensate piping should be satisfactory. However, the carbon steel for the steam piping may suffer excessive general corrosion and wastage if condensation occurs in this line.

Automatic depressurization system. The four depressurization valves on stub lines from the reactor pressure vessel are particularly susceptible to SCC because of 
their expected operating environment, i.e., continuous condensation and refluxing of the reactor coolant on the inside surfaces. The designers of the SBWR apparently recognized this potential problem, and Table 6.1-1 of the SSAR specifies that the forged valve parts are to be made of Type 304L or Type 316L SS. The valve bodies are to be made of the equivalent CF3 (304L) or CF3M (316L) casting alloys. However, this specification is contradicted to some extent by a statement in Section 6.3.3.2 of the SSAR that "the valve bodies are made of 304 or 316 stainless steel $(304 \mathrm{~L}$ or $316 \mathrm{~L}$ stainless steel where welding is employed)." The severe operating environment present here clearly calls for the use of the lcw-carbon " $\mathrm{L}$ " grades for all components in these valves, welded or not. The case valve bodies similarly should be fabricated of the equivalent " $\mathrm{L}$ " grade (CF3 and CF3M rather than CF8 and CF8M). Data recently obtained at ANL suggest that CF3 is somewhat more resistant to environmentally assisted crack growth than CF3M.47

Another concern in the materials specification for these valves is the potential for aging embrittlement of the cast bodies during the 60-year design life at temperatures on the order of $288^{\circ} \mathrm{C}$. Extensive studies conducted at ANL have found that the CF3 alloy is, in general, more resistant to embrittlement than CF3M, and that the detailed chemistry within the range permitted by the CF3 specification is important. In particular, the carbon and nitrogen levels should be held as low as possible.

Gravity-driven cooling system. Essentially all of the major components in this system are to be fabricated of Type 304L or Type 316L stainless steel, and either of these alloys should perform satisfactorily in this benign environment.

\subsubsection{Issues}

- The SBWR depressurization valves will operate in a wet-steam reactor-coolant environment that creates a significant potential for SCC problems. All valve components should be fabricated of the "L" grades of austenitic SS (Types $304 \mathrm{~L}$ and $316 \mathrm{~L}$ ) for maximum resistance to SCC.

- Long-term exposure to the reactor coolant temperatures creates a potential for both SCC and aging embrittlement in the cast depressurization valve bodies. Casting alloy CF3 is somewhat more resistant to both degradation modes than CF3M. Lower carbon and lower nitrogen heats of CF3 are more resistant to aging embrittlement than higher carbon and nitrogen heats.

- The carbon steel specified for the isolation condenser steam piping may suffer excessive general corrosion and wastage if condensation occurs in this line. 


\begin{tabular}{|c|c|c|c|c|}
\hline Component & $\begin{array}{l}\text { Product } \\
\text { Form }\end{array}$ & $\begin{array}{l}\text { Material of } \\
\text { Construction }\end{array}$ & $\begin{array}{l}\text { Specification } \\
\text { (ASME or ASTM) }\end{array}$ & $\begin{array}{l}\text { Operating Environment } \\
\text { (Normal/Accident) }\end{array}$ \\
\hline \multirow[t]{4}{*}{$\begin{array}{l}\text { Containment } \\
\text { Containment vessel } \\
\text { liner }\end{array}$} & Plate ( $\leq 64 \mathrm{~mm}$ ) & Carbon Steel & $\begin{array}{l}\text { SA285, Gr. A } \\
\text { (0.17\% carbon) }\end{array}$ & $\begin{array}{l}<150^{\circ} \mathrm{C} \text { in nitrogen atmosphere } \\
(<4 \% \text { oxygen }) / \leq 167^{\circ} \mathrm{C} \text { in contact } \\
\text { with reactor coolant and PCCS water }\end{array}$ \\
\hline & Plate $(>64 \mathrm{~mm})$ & Carbon Steel & $\begin{array}{l}\text { SA516, Gr. } 60 \text { or } 70 \\
(0.25 \% \text { carbon })\end{array}$ & \\
\hline & Plate & SS & SA240, Type 304L & \\
\hline & Cladding & SS & SA264 & \\
\hline \multirow[t]{2}{*}{ Penetrations } & Plate & Carbon Steel & $\begin{array}{l}\text { SA516, Gr. } 60 \text { or } 70 \\
(0.25 \% \text { carbon } \\
\text { steel })\end{array}$ & \\
\hline & Pipe & Carbon Steel & $\begin{array}{l}\text { SA333, Gr. } 6 \\
(0.3 \% \text { carbon })\end{array}$ & \\
\hline Pool liner & Sheet & SS & $\begin{array}{l}\text { SA240, Type } 304 \mathrm{~L} \\
\text { or A167. Type } 304 \mathrm{~L}\end{array}$ & \\
\hline $\begin{array}{l}\text { Drywell head, } \\
\text { Personnel lock, } \\
\text { Equipment hatch }\end{array}$ & Plate & Carbon Steel & $\begin{array}{l}\text { SA516, Gr. } 70 \text { or } \\
\text { SA537, Class } 1 \\
(0.25 \% \text { carbon })\end{array}$ & \\
\hline Structural steel & Shapes & Carbon Steel & $\begin{array}{l}\text { A36; A572, Gr. } 50 \\
(0.25 \% \text { carbon })\end{array}$ & \\
\hline Vent pipe & Plate & SS & $\begin{array}{l}\text { SA240, Type 304L } \\
\text { or A167, Type } \\
304 L^{a}\end{array}$ & \\
\hline
\end{tabular}


Table 6. (Cont'd)

\begin{tabular}{|c|c|c|c|c|}
\hline Component & $\begin{array}{l}\text { Product } \\
\text { Form }\end{array}$ & $\begin{array}{l}\text { Material of } \\
\text { Construction }\end{array}$ & $\begin{array}{l}\text { Specification } \\
\text { (ASME or ASTM) }\end{array}$ & $\begin{array}{l}\text { Operating Environment } \\
\text { (Normal/Accident) }\end{array}$ \\
\hline \multicolumn{5}{|c|}{ Isolation Condenser } \\
\hline $\begin{array}{l}\text { Steam pipe } \\
\text { Condensate pipe }\end{array}$ & $\begin{array}{l}\text { Seamless pipe } \\
\text { Seamless pipe }\end{array}$ & Carbon steel & $\begin{array}{l}\text { SA333, Gr. } 6 \\
\text { Type } 316 \mathrm{~L}\end{array}$ & $\begin{array}{l}\text { Saturated steam at } 288^{\circ} \mathrm{C} \text { in steam } \\
\text { pipe and condensate at }<100^{\circ} \mathrm{C} \text { in } \\
\text { condensate pipe } / \text { steam and } \\
\text { condensate at } 288^{\circ} \mathrm{C} \text { in both pipes }\end{array}$ \\
\hline \multicolumn{5}{|c|}{ Passive Containment Coolling System } \\
\hline Condenser & $\begin{array}{l}\text { Forging } \\
\text { Tube } \\
\text { Pipe }\end{array}$ & $\begin{array}{l}\text { SS } \\
\text { SS } \\
\text { SS }\end{array}$ & $\begin{array}{l}\text { SA182, Gr. F304L } \\
\text { SA213, Gr. TP304L } \\
\text { SA312, Gr. TP304L }\end{array}$ & $\begin{array}{l}\text { Ambient temperature in contact } \\
\text { with passive containment cooling } \\
\text { pool water } / 134^{\circ} \mathrm{C} \text { in contact with } \\
\text { saturated steam from drywell }\end{array}$ \\
\hline Piping & Pipe & SS & SA312, Gr. TP304L & \\
\hline Flanges & & SS & SA182, Gr. F304L & \\
\hline Nuts and bolts & Bar & SS & $\begin{array}{l}\text { SA194, Gr. 8; } \\
\text { SA193, Gr. B8 }\end{array}$ & \\
\hline \multicolumn{5}{|c|}{ Gravity-Driven Cooling System } \\
\hline Piping & Seamless pipe & SS & $\begin{array}{l}\text { SA376, Gr. TP304L } \\
\text { or TP316L } \\
\text { SA312, Gr. TP304L } \\
\text { or TP316L }\end{array}$ & $\begin{array}{l}57^{\circ} \mathrm{C} \text { in contact with emergency } \\
\text { cooling water }\end{array}$ \\
\hline Fittings & Forging & SS & $\begin{array}{l}\text { SA182, Gr. F304L or } \\
\text { F316L }\end{array}$ & \\
\hline
\end{tabular}




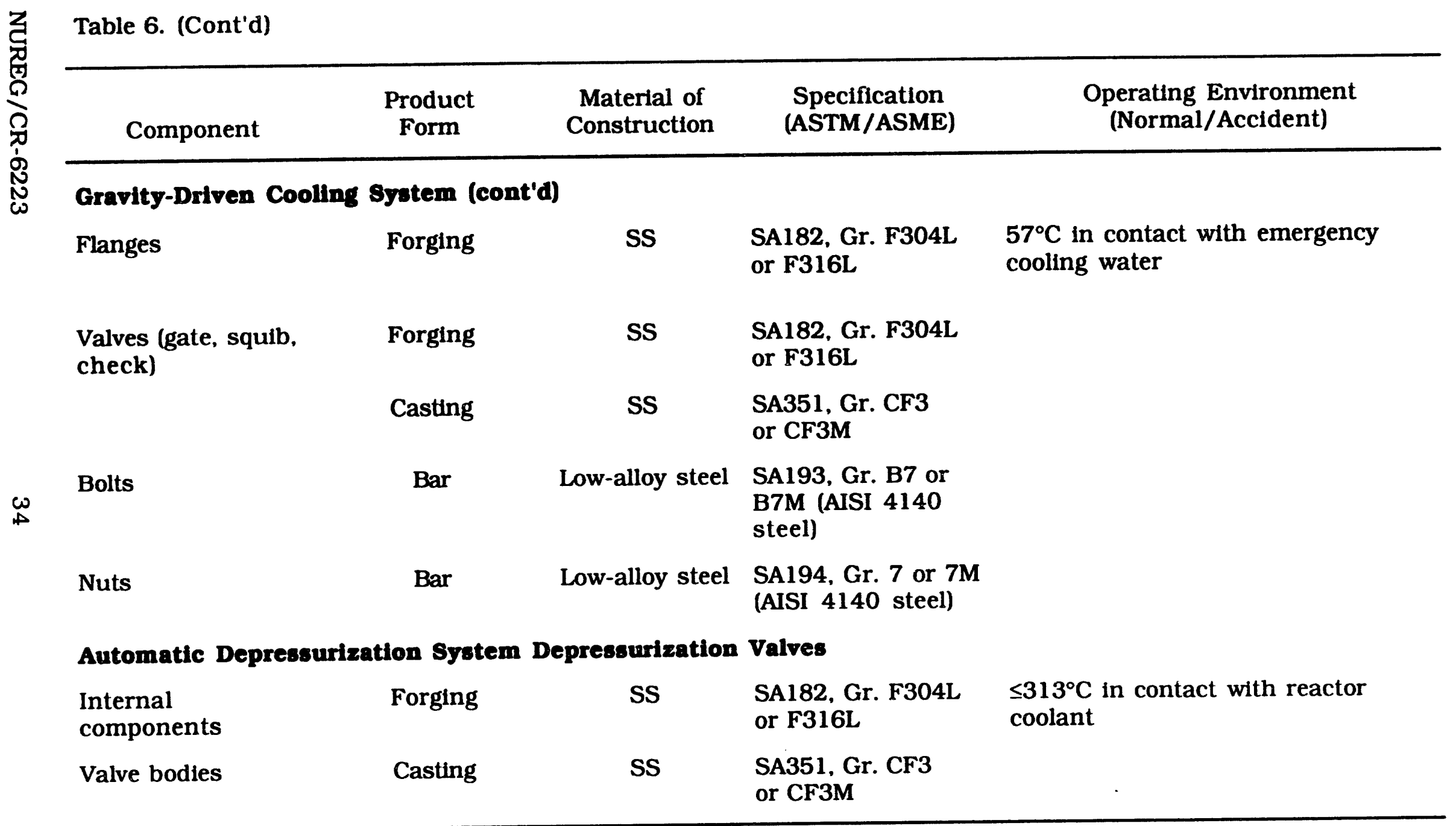

aCarbon content not to exceed $\mathbf{0 . 0 2 0 \%}$ 


\subsection{Turbines}

\subsubsection{General description}

The turbine-generator consists of an 1800-rpm turbine; in-line, high-velocity moisture separators (HVSs); generator; exciter; controls; and associated subsystems. The turbine consists of a double-flow, high-pressure unit, and a double-flow, lowpressure unit in tandem. The high-pressure unit has two stages of steam extraction. The steam passes through the low-pressure turbine, which has four extraction points for the four low-pressure stages of feedwater heating, and exhausts into the main condenser. In addition to the external high-velocity separators, the turbine is designed to separate water from the steam and drain it to the next lowest extraction point. The generator is a direct-driven, three-phase, $60-\mathrm{Hz}, 1800-\mathrm{ppm}$ synchronous unit with a water-cooled stator and hydrogen-cooled rotor.

The high-pressure turbine receives steam through four steam leads, one from each control valve outlet. The steam is expanded axially across several stages of stationary and moving blades. Four cylindrical-shell, in-line HVSs are installed in the steam path between the high- and low-pressure turbines. The HVSs serve to dry the high-pressure turbine steam exhaust (crossaround steam), before it enters the lowpressure turbine. In the low-pressure turbine, the steam is expanded axially across several stages of stationary and moving buckets.

The generator rotor is manufactured from a one-piece forging and includes layers of field windings embedded in milled slots. The rotor body and shaft are machined from a single, solid steel forging. Material properties are checked on test specimens taken from the forging, and the microstructure is examined metallographically. The rotor is checked for defects by magnetic particle and ultrasonic examination. Surface finish tests are performed on the slots to detect stress risers.

\subsubsection{Materials selection}

The materials for the turbine rotor and parts are identified only as nickelchromium-molybdenum-vanadium alloy steels. The most widely used steels of this type are the $3.5 \mathrm{Ni}-\mathrm{Cr}-\mathrm{Mo}-\mathrm{V}$, but presumably the description is left sufficiently general so that other materials in this class could be considered. The SSAR specifies that the steels will be vacuum melted or vacuum degassed by processes that minimize flaw occurrence and provide adequate fracture toughness. No detailed specifications or references are given. Instead, the material characteristics are described only in general terms that are certainly unexceptionable, but vague. The following paragraph is from Section 10.2.3.1 of the SSAR.

"Tramp elements are controlled to the lowest practical concentrations consistent with good scrap selection and melting practice, and consistent with obtaining adequate initial and long-life fracture toughness for the environment in which the parts operate. The turbine materials have the lowest fracture appearance 
transition temperatures (FATTs) and highest Charpy V-notch energies obtainable. on a consistent basis, from water-quenched $\mathrm{Ni}-\mathrm{Cr}-\mathrm{Mo}-\mathrm{V}$ material at the sizes and strength levels used."

\subsubsection{Anticipated operating environment}

The operating environment for the high-pressure turbine and the first stages of the low-pressure turbine will be dry steam. As energy is removed from the steam, it will begin to condense. The exact characteristics of this process will depend on the detailed thermodynamics of the turbine, but in a typical nuclear low-pressure turbine, the steam begins to condense at the third stage of the low-pressure rotor. ${ }^{48}$ At this point the steam contains $3-5 \%$ water and its temperature is $160-170^{\circ} \mathrm{C}$. At the last stage, the water content in the steam is $<13 \%$, and the temperature is below $90^{\circ} \mathrm{C}$. Based upon the proposed operating water chemistry for the SBWR, which is summarized in Table 4, the impurity levels should be very low, but the dissolvedoxygen level could be 0.1-2 ppm. Although the hydrogen-water chemistry proposed for the SBWR should be very effective in maintaining low dissolved-oxygen levels in the reactor vessel and associated piping, radiolysis still occurs in the core, and the steam tends to remain relatively high in dissolved oxygen. 49 It is in the wet steam environment that SCC of the turbines is most likely to occur. 48.50 Although dissolved oxygen is detrimental for SCC of the turbine alloys, it is beneficial in preventing flowaccelerated corrosion in the high-velocity moisture separators.

\subsubsection{Potential material degradation and failure modes}

It is well known that in this class of materials cleanliness is critical to achieving high fracture toughness and resistance to temper embrittlement. 51 The minimum values cited for the fracture-appearance-transition temperature (50\% FATT) of less than $-18^{\circ} \mathrm{C}\left(0^{\circ} \mathrm{F}\right)$ and for the Charpy $\mathrm{V}$-notch energy at the minimum operating temperature of each low-pressure disk of at least $81.3 \mathrm{~N}-\mathrm{m}(60 \mathrm{ft}-\mathrm{lb})$ are typical of those reported for modern rotor steels, 50 although they are not necessarily consistent with the claim in Subsection 10.2.3.1 of the SSAR that

"The turbine materials have the lowest fracture appearance transition temperatures (FATTs) and highest Charpy $V$-notch energies obtainable, on a consistent basis, from water-quenched $\mathrm{Ni}-\mathrm{Cr}-\mathrm{Mo}-\mathrm{V}$ material at the sizes and strength levels used."

Inasmuch as actual levels of FATT and Charpy V-notch energy will vary with the size of the part and the location within the forging, these variations must be considered in the acceptance of a specific forging. Adequate fracture toughness is to be ensured by Charpy V-notch tests on selected samples which are then correlated by the method of Longsdon and Begley. 52 In addition to obtaining high fracture toughness, it is important to avold defects. The p-oposed preservice inspections include $100 \%$ volumetric (ultrasonic) inspections and surface visual examinations. All subsurface indications will be either removed or evaluated to ensure that they will not grow to a size which will compromise the integrity of the unit during 
service. All finished, machined surfaces will be subjected to a magnetic-particle test with no flaw indications permissible.

The operating temperature of the high-pressure rotor is below the stress rupture range for the proposed materials. Therefore, creep-rupture is not considered a significant failure mechanism. However, basic stress and creep-rupture data will be obtained at appropriate temperatures with equipment and procedures consistent with ASTM recommendations. 53

Stress corrosion cracking of steam turbine rotors has been a world-wide problem in the nuclear power industry.48,50.54.55 The problem has been extensively studied and a technology has been developed to deal with cracking. 56.57 Several mitigating features have been identifled: good water chemistry, welded or monoblock designs instead of shrink-fit disks, and lower yield strength. 50.57 However, it is difficult to eliminate the problem completely.

Fatigue is another potential method of degradation. Cyclic stresses are unavoidable in rotating machinery, and fatigue life is governed by the inherent fatigue crack growth characteristics of the material and the size of the largest undetectable defects in the rotor. The growth of these defects can be analyzed by fracturemechanics procedures completely analogous to those used for analyzing the growth of stress corrosion cracks. 56.57

Flow-induced corrosion in wet steam piping associated with turbine systems has occurred in a number of operating reactors. 58-60 The problem tends to be more severe in PWRs because of the incentive to reduce dissolved-oxygen levels for the purpose of minimizing steam generator corrosion; however, it has also been observed in some BWRs. 58

\subsubsection{Issues}

The SSAR makes virtually no reference to the extensive work that has been done on SCC and the optimization of fracture toughness in low-pressure turbine materials for nuclear power systems over the past decade: The differences between a lowtoughness material that is relatively susceptible to SCC and a high-toughness material that is resistant to SCC are due to changes in impurity levels and fabrication practices that are quite subtle. In vague, general terms, the material specification for the rotors (and the monoblock design) reflect the "good practices" resulting from this work, but the specifications provided for the materials are insufficient to determine whether the materials really conform to these "good practices." 


\subsection{Fuel Storage and Handling System}

\subsubsection{General description}

The fuel storage and handling system for the SBWR does not constitute a part of the reactor pressure boundary. Nonetheless, fallure of critical components in this system could have significant safety implications, and selection of appropriate materials of construction for these components is an important safety consideration. The principal safety concerns associated with the fuel storage and handling system are (1) maintaining proper cooling of the stored spent fuel to prevent overheating and cladding damage, and (2) maintaining proper spacing of stored fuel elements, both new and spent, to prevent accidental formation of a critical geometry. The water in the spent fuel storage pool also provides radiological shielding.

\subsubsection{Materials selection}

The fuel storage and handling system for the SBWR is described in Chapter 9, Section 9.1 of the SSAR. However, the proposed materials of construction for critical components are given only in general terms. An unspecified SS is to be used for constructing the spent fuel pool liner, fuel pool heat exchangers (tube side), pump internals, and prefilter, demineralizer, and strainer housings. The new and spent fuel storage racks are to be made of aluminum. Most of the remaining components are presumably to be fabricated of an unspecified carbon steel.

\subsubsection{Anticipated operating environment}

The as-received new fuel assemblies are initially stored dry in storage racks in the new fuel storage vault in the reactor building. After inspection, the assemblies are moved to the new fuel storage pool to await loading into the reactor. The spent fuel elements are stored in the spent-fuel storage pool.

The anticipated water temperature and chemistry conditions for the spent-fuel storage and handling system components are summarized in Table 7, with water chemistry maintained through the use of demineralizers in the circulating cooling system. Most of the critical components will operate for extended periods of time in contact with the spent-fuel storage pool water or the isolation condenser/passive containment cooling pool water.

\subsubsection{Potential material degradation and failure modes}

The greatest threat to the integrity of these components under the anticipated conditions is failure by corrosion-related processes. Such processes could take the form of either general corrosion or localized effects such as crevice corrosion or SCC. The susceptibility of the three categories of proposed materials of construction, namely SS, aluminum, and carbon steel, to failure by corrosion in the anticipated range of operating environments will be discussed here. 
Stainless steel. It is assumed here that the "stainless steel" identified as the material of construction for several of the components in the fuel storage and handling system is an "18-8" austenitic SS such as Type 304 and Type 316. These steels would be expected to be quite resistant to general corrosion in the range of operating environments identified in Table 4, and no problems are anticipated. Stress corrosion cracking in chloride-containing solutions is a potential problem for these steels, particularly in the vicinity of welds where a sensitized microstructure

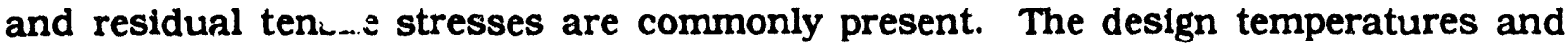
dissolved chloride levels are low relative to the values typically associated with severe chloride-induced SCC, although SCC failures have been observed under similar conditions in highly susceptible microstructures. The use of the low-carbon grades Types 304L and 316L would greatly reduce the likelihood of SCC problems in these components, particularly in large weldments such as the spent-fuel pool liner.

Another form of localized corrosion that poses a potential problem in austenitic SS components in this environment is crevice corrosion. This problem can best be prevented by avoiding the creation of crevice geometries in the design of the components. Without more detailed design information on the various components, more specific guidance cannot be provided.

Aluminum. Aluminum and aluminum-base alloys are resistant to general corrosion in water, but the alloys are susceptible to crevice and pitting corrosion as well as stress-corrosion and hydrogen-induced cracking in aqueous environments. Because pure aluminum has very little strength, it is alloyed with $\mathrm{Cu}, \mathrm{Mg}, \mathrm{Zn}, \mathrm{Li}$ and other elements, which in some instances, increase the likelihood of pitting corrosion and cracking. Pitting corrosion can be more prevalent in stagnant as opposed to flowing water. The design and materials selection for fuel storage racks must address issues related crevice and pitting corrosion of aluminum-base alloys for the water chemistry in the low-flow environment of a storage pool.

Carbon steel. Although carbon steels are not particularly susceptible to SCC in the anticipated environment, their general corrosion rates will be significantly higher than those of the SSs or aluminum. This does not rule out their use in the construction of fuel storage and handling system components, but it does require that corrosion be taken into account in the design process. For example, carbon steel probably would not be a good choice for spent-fuel storage racks, because progressive wastage would eventually threaten the structural integrity of these

components. The use of aluminum for the racks, as proposed in the SSAR, represents a better materials choice.

\subsubsection{Issues}

- The low-carbon grades of austenitic SS (e.g.. Types 304L and 316L) should be used to fabricate large weldments such as the spent-fuel pool liner, to reduce the likelihood of SCC. 
- The general corrosion rates of the carbon steels are sufficiently high in the anticipated environment that corrosion wastage must be taken into account in the design of components to be fabricated of carbon steel.

- The design and materials selection for fuel storage racks must address issues related crevice and pitting corrosion of aluminum-based alloys for the water chemistry in the low-flow environment of a storage pool. 
Table 7. Summary of SBWR fuel and auxiliary pools cooling system water temperatures and chemistry requirements

\begin{tabular}{|c|c|c|c|}
\hline Parameter & $\begin{array}{l}\text { Operating } \\
\text { Target }\end{array}$ & $\begin{array}{l}\text { System } \\
\text { Design }\end{array}$ & $\begin{array}{l}\text { Maximum } \\
\text { Value }\end{array}$ \\
\hline Spent fuel storage pool water temperature $\left({ }^{\circ} \mathrm{C}\right)$ & - & 48.9 & $\begin{array}{c}60.0^{\mathrm{a}} \\
82.2^{\mathrm{b}} \\
100^{\mathrm{c}}\end{array}$ \\
\hline $\begin{array}{l}\text { Isolation condenser/passive containment } \\
\text { cooling pool water temperature }\left({ }^{\circ} \mathrm{C}\right)\end{array}$ & - & - & 100 \\
\hline Suppression pool water temperature $\left({ }^{\circ} \mathrm{C}\right)$ & - & $40.6^{d}$ & 48.9 \\
\hline Chloride content (ppb) & 10 & 20 & 100 \\
\hline Sulfate content (ppb) & 10 & 20 & 100 \\
\hline Fluoride content (ppb) & - & - & $<150$ \\
\hline Conductivity at $25^{\circ} \mathrm{C}(\mu \mathrm{S} / \mathrm{cm})$ & 1.0 & 1.2 & 2.0 \\
\hline Silica (as $\left.\mathrm{SiO}_{2}\right)(\mathrm{ppb})$ & - & - & $<100$ \\
\hline $\mathrm{pH}$ at $25^{\circ} \mathrm{C}$, minimum & 5.9 & 5.6 & 5.3 \\
\hline $\mathrm{pH}$ at $25^{\circ} \mathrm{C}$, maximum & 8.3 & 8.6 & 8.9 \\
\hline $\begin{array}{l}\text { Fe corrosion product (insoluble }+ \text { soluble) } \\
\text { (ppb) }\end{array}$ & 10 & 20 & 100 \\
\hline $\mathrm{Cu}$ total (ppb) & 0.5 & 1.0 & 5.0 \\
\hline All other metals (ppb) & 4.5 & 9.0 & 45.0 \\
\hline Total corrosion product metals (ppb) & 15 & 30 & 150 \\
\hline Total suspended solids (ppb) & - & - & $<1000$ \\
\hline
\end{tabular}

aSingle active failure with normal maximum heat load, or abnormal maximum heat load with no failure.

bSingle active fallure with maximum abnormal heat load.

cNo active cooling system; heat removal by boil-off.

dHigh-water-temperature alarm set-point. 


\subsection{Use of Cobalt-Based Alloys}

Cobalt-based alloys have historically been used in nuclear reactor applications where high resistance to abrasive and corrosive wear is required. These applications include weld-deposited hard facing on the sealing surfaces of valves and high-wear surfaces on CRD components. Problems arise when small amounts of cobalt from these alloys are carried by the coolant to the core and activated by neutrons to form ${ }^{60} \mathrm{Co}$, a strong gamma emitter. The ${ }^{60} \mathrm{Co}$ is subsequently transported through the cooling loop and deposited on component surfaces or incorporated into the oxdde films forming on these surfaces. The resulting radiation field can create exposure problems for maintenance and repair personnel.

No mention is made in the SSAR of the use of cobalt-based alloys in the SBWR valve trim, and it is not clear what alloys are used for these applications. In the CRD system, an attempt has been made to minimize the presence of cobalt-containing alloys in the vicinity of the core. The SSAR (Section 12.3.1) indicates that the average cobalt content of the austenitic SSs used both inside and outside the core is 0.15 wt.\%, a level that is not particularly stringent. In the case of the XM-19 alloy that is used for the CRD system piston tubes, the cobalt level is limited to $0.05 \%$.

However, cobalt-base alloys continue to be specified as hard-facing materials for selected CRD components in the SBWR where high resistance to wear is required. The alloys used include the traditional Haynes 25 and Stellite 6, as well as the less commonly used Stellites 3 and 12. In addition, the cobalt-free hard facing alloy Colmonoy 6 is used in at least one application in the CRD system. The use of these alloys is summarized in Table 8.

The EPRI has sponsored a considerable amount of work in recent years on the development and evaluation of cobalt-free alternatives to the standard hard facing alloys. 61-65 Several promising hard-facing alloys have resulted from this research effort, including the NOREM family of $\mathrm{Fe}-\mathrm{Mo}-\mathrm{Cr}-\mathrm{Ni}-\mathrm{C}$ alloys that can be cast or welddeposited as a hard facing. A number of experimental studies have demonstrated that, in the weld-deposited form, these alloys offer wear and corrosion resistances comparable to that of Stellite 6 . When applied as a weld deposit to gate valve sealing surfaces and tested in a simulated PWR environment, for example, three of the NOREM alloys showed somewhat better wear resistance than did the Stellite 6 standard. 62

Despite these encouraging results, no mention is made of the NOREM and other cobalt-free alloys or their possible use in the SBWR SSAR. Because of the increasing emphasis on AlARA in nuclear plant design and operation. it is recommended that the NOREM alloys be considered as replacements for the cobalt-base hard facing materials currently specified for the SBWR CRD system components listed in Table 8. 
Table 8. Proposed use of cobalt-based hard-facing alloys for selected CRD system components in the SBWR

\begin{tabular}{|c|c|}
\hline Component & Material of Construction \\
\hline Ball spindle assembly guide roller & Stellite 3 \\
\hline Ball spindle assembly guide roller pin & Haynes 25 \\
\hline Ball spindle assembly guide shaft & Stellite 6 \\
\hline $\begin{array}{l}\text { Ball spindle assembly guide shaft } \\
\text { bushing }\end{array}$ & Stellite 12 \\
\hline Buffer assembly sleeve & $\begin{array}{c}\text { Type 316L SS hard-faced with } \\
\text { Colmonoy } 6^{a}\end{array}$ \\
\hline $\begin{array}{l}\text { Buffer assembly guide roller stop } \\
\text { piston }\end{array}$ & $\begin{array}{c}\text { Type 316L SS hard-faced with } \\
\text { Stellite } 6\end{array}$ \\
\hline Hollow piston head & $\begin{array}{c}\text { Type 316L SS hard-faced with } \\
\text { Stellite } 3\end{array}$ \\
\hline Check valve ball & Haynes Alloy (unspecified) \\
\hline
\end{tabular}

acobalt-free alloy 
The proposed materials of construction were reviewed for the following reactor components and systems in the Westinghouse Advanced Passive 600 MWe Pressurized Water Reactor (AP600):

- Reactor pressure vessel.

- Control rod drive (CRD) system and reactor internals.

- Reactor coolant system.

- Engineered safety systems.

- Steam generators.

- Turbines.

- Fuel storage and handling systems.

Most of the information on the design and proposed materials of construction for the AP600 utilized in this study was obtained from the AP600 SSAR. ${ }^{2}$ This information was supplemented by descriptions of the AP600 published in the technical literature.66-73 No direct contact was made with Westinghouse personnel concerning the AP600 design or materials. 


\subsection{General Description of Plant}

The AP600 is an advanced LWR design that features reduced size, simplified design, and passive safety. The objectives of the design are to reduce construction time and costs, achieve greater component reliability, and attain a high degree of inherent safety.

The key distinguishing features of the AP600, compared with a conventional PWR, are

- Lower power rating, namely $600 \mathrm{MWe}$, compared to $1000-1300 \mathrm{MWe}$ for a conventional PWR.

- Simplified operating plant, including the elimination of $75 \%$ of the nuclear steam supply system (NSSS) piping, more than half of the NSSS valves, and the requirement for safety-grade backup diesel generators.

- Passive safety system, including provisions for passive containment cooling and gravity-driven flooding of the core without active safety components or operator intervention.

The principal features of the various AP600 systems and the role of these features in achieving the AP600 design objective are summarized here, with an emphasis on safety-related components and systems.

\subsubsection{Reactor core, pressure vessel, and primary cooling circuit}

The AP600 utilizes a low-power-density core with an average linear power of 4.1 $\mathrm{kW} / \mathrm{ft}$, as compared with $5.4 \mathrm{~kW} / \mathrm{ft}$ in a conventional PWR. This results in increased thermal and hydrodynamic safety margins in the event of operating transients. In conjunction with the core neutron reflector, this core design also reduces the irradiation field at the pressure vessel, with a calculated fast-neutron fluence of $<2 \mathrm{x}$ $10^{19} \mathrm{n} / \mathrm{cm}^{2}$ at the vessel over its 60-year design life. The core is designed for an 18-month fuel cycle, assuming an $85 \%$ capacity factor, but it is capable of operating on a 24-month cycle.

The core is located low in the vessel to minimize the probability of core uncovering during loss-of-coolant accidents, and there are no vessel penetrations below the top of the core. This means that bottom mounted in-core instrumentation is not used. An integrated head package that contains the CRD mechanisms, integrated head cooling fans, instrument columns, insulation, seismic support, and package lift rig is employed. A permanent welded seal flange is used to provide the seal between the vessel flange and the refueling cavity floor.

The coolant system consists of two heat-transfer circuits, each with a steam generator, two reactor coolant pumps, a single hot leg, and two cold legs. The system also includes a pressurizer, interconnecting piping, valves, and instrumentation required for operational control and actuation of safeguards. All 
coolant system components are located in containment. An oversized pressurizer is used to increase transient operation margins and to eliminate the need for poweroperated relief valves.

The reactor coolant circuits and pressurizer function in the same manner as in a conventional PWR. Overpressure protection for the coolant system is provided by spring-loaded safety valves installed on the pressurizer. These valves discharge to the containment atmosphere. The valves for the first three stages of automatic depressurization are also mounted on the pressurizer. These valves discharge steam through spargers into the in-containment refueling water storage tank of the passive core cooling system. The discharge steam is condensed and cooled by mixing with water in the tank.

The reactor cooling system is also served by several auxiliary systems, including the chemical and volume control system, the passive core cooling system, the spent fuel pit cooling system, the primary sampling system, the liquid rad-waste system, and the component cooling-water system. 2

\subsubsection{Steam generators and coolant pumps}

The AP600 steam generators are designed to be readily accessible for inspection and repair. They include a steam separator area sludge trap with cleanout provisions. The steam generator channel head is designed for the direct attachment of two reactor coolant pumps. In addition, the channel head is accessible for both manual and robotic inspection, plugging, sleeving, and nozzle dam placement.

The coolant pumps are hermetically sealed and directly attached to the steam generator channel head. Each pump includes sufficient internal rotating inertia to provide a flow coastdown and thereby avoid departure from nucleate boiling following a loss-of-coolant accident. The pumps are designed to withstand a loss of all cooling water for at least $10 \mathrm{~min}$ without damage. The pump and motor designs also incorporate features to reduce the deposition of radioactive crud. ${ }^{2}$

\subsubsection{Turbine, steam supply, feedwater, and condensate systems}

The 1800-rpm turbine consists of a double-flow high-pressure section and two double-flow low-pressure sections. The high-pressure turbine has extraction connections for two stages of feedwater heating. The high-pressure exhaust steam provides for one stage of feedwater heating in the deaerator. The low-pressure turbines have extraction connections for four stages of feedwater heating. Moisture separator reheaters, which extract moisture from and reheat the steam, are an integral component of the turbine system. The turbines are oriented to minimize potential interaction between turbine missiles and safety-related structures and components.

The main steam system supplies steam from the steam generators to the highpressure turbine. The system is also designed to dissipate heat generated by the steam supply system to the condenser through steam dump valves or to the 
atmosphere through power-operated relief valves or spring-loaded main steam safety valves when either the turbine generator of the condenser is not avallable. Three steam generator safety valves are utilized in each of the two steam headers.

The main feedwater system supplies condensate from the deaerator storage vessel to the steam generators. The condensate system condenses and collects steam from the low-pressure turbines and turbine steam bypass systems and transfers it from the main condenser to the deaerator. Both systems are designed for improved control of dissolved oxygen. ${ }^{2}$

\subsubsection{Safety systems}

Similar to the General Electric SBWR, the AP600 concept incorporates a number of passive safety system features. These include the following:

- Core decay heat is removed by a passive residual-heat-removal heat exchanger located in the in-containment refueling water storage tank, which serves as a heat sink. The system is actuated by opening two normally closed, fail-open, air-operated valves, and circulation is by convection.

- Coolant makeup for small leaks is provided by two core makeup tanks filled with borated water and located above the reactor cooling system (RCS) loop piping. The system is actuated by isolation valves that open automatically in the event of low water level in the pressurizer, and makeup flow is by gravity.

- Coolant makeup for large leaks (including loss-of-coolant accidents) is provided by the two core makeup tanks described above, plus two gaspressurized accumulators. Additional makeup water is provided by an incontainment refueling water storage tank located above the RCS. An automatic RCS depressurization system reduces system pressure to permit gravity (hydrostatic head) flow from the tank.

- Borated water and pressurized nitrogen tanks located outside the containment provide core spray to reduce iodine and cesium concentrations in the containment atmosphere in the event of a core release. The system is actuated by the automatic opening of a normally closed valve between the nitrogen and borated-water tanks.

- Containment cooling to carry RCS sensible and core decay heat away from the containment structure is provided by natural air circulation between the containment structure and the surrounding concrete shield building.

- A low-power-density core provides increased design margins of safety and extends the life of the reactor vessel by reducing the radiation levels at the vessel beltline.

- An oversized pressurizer is used to increase the transient operating margins and to eliminate the need for power-operated relief valves. 


\subsection{AP600 Reactor Pressure Vessel}

\subsubsection{General description}

The reactor vessel is a vertical, cylindrical pressure vessel constructed from welded low-alloy steel forgings and plates. The vessel is designed, fabricated, tested, inspected, and stamped in accordance with ASME Code, Section III, Class 1 requirements. The interior of the vessel is clad with SS weld overlay. The shell is constructed of ring forgings made of SA508, Class 3 material, joined by circumferential welds. The beltline region is a single forging, and there are no welds in the peak region of neutron flux. The remainder of the vessel is constructed from SA533 Type B. Class 1 plates and SA508, Class 3 forgings. The welding materials conform to the applicable ASME specifications for low-alloy steels and are qualified to the requirements of ASME Code Section III. The welding procedures are qualified in accordance with the requirements of ASME Sections III and IX. The vessel head is secured to the reactor vessel by studs and nuts.

There are 68 penetrations in the reactor pressure vessel (RPV) head for the CRDs and instrumentation. Detailed descriptions of these penetrations are not provided, but it appears that they will consist of tubes secured by partial-penetration welds in a design similar to that used in current PWRs.

All reactor vessel nozzles are low-alloy steel forgings. Nozzles connecting to SS piping have safe ends of SS. The safe ends are welded to the nozzles after heat treatment of the RPV to avoid sensitization of the SS.

\subsubsection{Materials selection}

The materials of construction specified for the AP600 reactor pressure vessel components are summarized in Table 9. The specifications are vague or incomplete in some cases, and it is not always possible to identify the precise alloy to be used. The RPV is fabricated from low-alloy steel plates and forgings. The plates are ASME SA533, Type B, Class 1 material and the forgings are ASME SA508, Class 3 material. Materials used in the core beltline region are restricted to a maximum of $0.05 \%$ copper and $0.01 \%$ phosphorous in base materials and in as-deposited weld materials. Sulfur levels in the steels are restricted to $0.005 \%$ maximum. Vanadium and nickel are limited to 0.05 and $0.8 \%$, respectively.

The RPV is clad with weld-deposited Type 308 or 308L austenitic SS that conforms to ASME specification Stainless Steel Weld Metal Analysís A-8.

The studs, nuts, and washers for the head closure are ASME SA540. No grade or class is specified. The minimum yield strength is $130 \mathrm{ksi}$. The minimum tensile strength is $145 \mathrm{ksi}$. The maximum ultimate tensile strength of the bolting materials cannot exceed $170 \mathrm{ksi}$. No toughness requirements are specified. They would be required for some grades and classes that meet the given tensile requirements, but not for others. 
"Appurtenances" to the CRDs and instrument penetrations are specified as either SB166 or SB167 and SA182. The SA182 specification covers literally dozens of low-alloy steels and SSs; however, based on current practice, the critical components will be the tubes, which are probably covered by the SB167 specification, and hence, are either Alloy 600 or Alloy 690, both of which are covered by the specification. Welds between the low-alloy steels and austenitic or nickel alloys will be made with nickel-chromium-iron Weld Metal F-Number 43.

\subsubsection{Anticipated operating environment}

The vessel design pressure is $2485 \mathrm{psi}$ and the nominal design temperature at the pressure vessel outlet is $343^{\circ} \mathrm{C}\left(650^{\circ} \mathrm{F}\right)$. The reactor coolant chemistry (Table 10) is consistent with that used in current PWRs and the EPRI PWR Primary Water Chemistry Guidelines. ${ }^{74}$

\subsubsection{Potential material degradation and failure modes}

Adequate fracture toughness of the RPV is the critical requirement for safe operation of the reactor. The low-alloy steels used for the RPV do have high toughness in the proper metallurgical condition, but under some conditions, the toughness can be greatly reduced. However, as demonstrated by many years of successful experience, the requirements imposed by the ASME Code, 10 CFR 50 Appendix G, and U.S. NRC Regulatory Guides 1.43 and 1.50 are adequate to ensure that the as-fabricated vessel has adequate fracture toughness.

In service, the primary factor leading to loss of fracture toughness is irradiation embrittlement. However, given the requirements for low copper and phosphorus levels in the low-alloy steels and the controls on other alloying elements, the predicted loss in toughness based on the correlations given in U.S. NRC Regulatory Guide $1.99 \mathrm{Rev} .2^{10}$ should be conservative because the operating temperature of the vessel is comparable to temperatures that comprise the database upon which the correlations in the Regulatory Guide are based. Although no detailed comparison of the neutron spectrum for the AP600 with that of conventional PWRs is provided, the effects of any differences in the spectra (in terms of effects on irradiation embrittlement) would be expected to be extremely small. The estimated RTpTs at the end of the design life is only $51^{\circ} \mathrm{F}$, far below the screening criterion in $10 \mathrm{CFR}$ 50.61. The calculated upper-shelf values at the end of life are above $50 \mathrm{ft}-\mathrm{lb}$.

\subsubsection{Issues}

Although irradiation embrittlement is a critical issue for the RPV, the fabrication procedures and restrictions on copper and phosphorus levels appear adequate to assure that the loss in toughness over the 60-year life is acceptable.

Another potential degradation mode for the vessel is fatigue crack growth. Extensive experimental data show that the primary determinant of accelerated, environmentally enhanced fatigue crack growth rates in low-alloy steels is the sulfur 
content of the steel. Although there is still some controversy over how to characterize the sulfur content of a low-alloy steel to ensure that it is not susceptible to environmentally assisted cracking, it is very likely that the limit of $0.005 \%$ on sulfur proposed for the AP600 is sufficiently low to ensure that no environmental enhancement of the crack growth rate occurs, and it is consistent with the requirements for new PWRs operating in Europe and Japan.

Current PWRs have experienced SCC in nickel-chromium-iron alloys such as Alloy 600 structural components and Alloy 182 weld butters. It seems prudent to select alloys that are more resistant to SCC. Insufficient information on the actual composition and use of nickel-chromium-iron alloys is given to ascertain that the most resistant materials have been selected. Based on current experience, use of Alloy 600 should be avoided and Alloy 690 should be used instead. 
Table 9. Materials for AP600 reactor pressure vessel components

\begin{tabular}{|c|c|c|c|}
\hline Component & $\begin{array}{l}\text { Product } \\
\text { Form }\end{array}$ & $\begin{array}{c}\text { Material of } \\
\text { Construction }\end{array}$ & $\begin{array}{l}\text { Specification } \\
\text { (ASME or ASTM) }\end{array}$ \\
\hline Head plates & Plate & $\begin{array}{l}\text { Low-alloy steel } \\
(0.5 \mathrm{~N} 1,0.5 \mathrm{Mo} \text {, } \\
0.2 \mathrm{C})\end{array}$ & SA533, Gr. B, Class 1 \\
\hline Shell courses & Forging & $\begin{array}{l}\text { Low-alloy steel (0.75 } \\
\text { Ni, } 0.5 \text { Mo, } 0.2 \mathrm{C})\end{array}$ & SA508, Class 3 \\
\hline $\begin{array}{l}\text { Shell flange and } \\
\text { nozale forgings }\end{array}$ & Forging & $\begin{array}{l}\text { Low-alloy steel }(0.75 \\
\text { Ni, } 0.5 \text { Mo, } 0.2 \mathrm{C})\end{array}$ & SA508, Class 3 \\
\hline $\begin{array}{l}\text { Head closure studs, } \\
\text { nuts, and washers }\end{array}$ & Various & Low-alloy steel & $\begin{array}{l}\text { SA540, (min. Y.S. = } \\
130 \mathrm{ks} 1)\end{array}$ \\
\hline Nozzles & Forging & $\begin{array}{l}\text { Low-alloy steel }(0.75 \\
\text { Ni, } 0.5 \mathrm{Mo}, 0.2 \mathrm{C})\end{array}$ & SA508, Class 3 \\
\hline Nozzle safe ends & - & Not identified & SA182 \\
\hline \multirow{2}{*}{$\begin{array}{l}\text { Instrumentation tube } \\
\text { and control rod drive } \\
\text { appurtenances }\end{array}$} & Forging & Not identified & SA182 \\
\hline & $\begin{array}{l}\text { Bar, seam- } \\
\text { less pipe }\end{array}$ & Alloy 600 or 690 & SB166 or SB 167 \\
\hline Core support pads & - & Alloy 600 or 690 & SB166 \\
\hline $\begin{array}{l}\text { Monitor tubes and } \\
\text { vent tube }\end{array}$ & $\begin{array}{l}\text { Seamless } \\
\text { pipe }\end{array}$ & Not identified & $\begin{array}{l}\text { SA312, SA376, SB166, } \\
\text { SB167, or SA182 }\end{array}$ \\
\hline Seal ledge & - & Not identified & SA616 or SA533 \\
\hline $\begin{array}{l}\text { Vessel supports and } \\
\text { head lift lugs }\end{array}$ & - & Low-alloy steel & SA533 \\
\hline $\begin{array}{l}\text { Cladding and } \\
\text { buttering }\end{array}$ & - & $\begin{array}{l}\text { Type } 308 \text { or } 308 \mathrm{~L} \\
\text { SS; Ni-Cr-Fe weld } \\
\text { metal }\end{array}$ & ASME A-8/ASME F-43 \\
\hline
\end{tabular}


Table 10. Recommended specifications for AP600 reactor coolant water chemistry

\begin{tabular}{ll}
\hline \multicolumn{1}{c}{ Parameter } & \multicolumn{1}{c}{ Specification } \\
\hline Electrical conductivity & $<1$ to $40 \mu \mathrm{mhos} / \mathrm{cm}$ at $25^{\circ} \mathrm{C}$ \\
Solution pH & $4.2 \leq 10.5$ at room temperature; \\
& $>5.0$ at operating temperature \\
Dissolved oxygen & Controlled to $\leq 0.1 \mathrm{ppm}$ for $\mathrm{T}>200^{\circ} \mathrm{C}$ \\
& with hydrazine additions prior to \\
& operation; controlled to $<0.005 \mathrm{ppm}$ \\
& with hydrogen additions during power \\
Chlorides & operations \\
Fluorides & $\leq 0.15 \mathrm{ppm}$ \\
Hydrogen & $\leq 0.15 \mathrm{ppm}$ \\
Suspended solids & 25 to $50 \mathrm{~cm}{ }^{3}$ (STP)/kg $\mathrm{H}_{2} \mathrm{O}$ \\
pH control agent $\left({ }^{7} \mathrm{LiOH}\right)$ & $\leq 0.2 \mathrm{ppm}$ \\
Boric acid & Coordinated with boron additions \\
Silica & 0 to $400 \mathrm{ppm}$ as boron \\
Aluminum & $\leq 1.0 \mathrm{ppm}$ \\
Calcium + magnesium & $\leq 0.05 \mathrm{ppm}$ \\
Magnesium & $\leq 0.05 \mathrm{ppm}$ \\
\hline & $\leq 0.025 \mathrm{ppm}$ \\
\hline &
\end{tabular}




\subsection{Control Rod Drive System and Reactor Internals}

\subsubsection{General description}

The AP600 CRD system and the reactor internal components are vital to the safe and reliable operation of the plant. The CRD system provides control of the reactor power level, as well as the essential safety function of promptly shutting down, or "scramming," the reactor in the event of off-normal conditions. Reactor internal core support structures support the core and maintain proper core geometry and fuel subassembly spacing. Loss of core structural integrity could disrupt the coolant flow through the core or prevent proper functioning of the control rods and consequent loss of reactor control. Other reactor internal components direct coolant flow in the core region, position and protect in-core instrumentation, and provide for the injection and distribution of burnable absorbers for supplementary reactivity control. All of these functions are safety related, and the materials of construction for these components are reviewed below.

\subsubsection{Materials selection}

The proposed materials of construction for the reactor CRD system and selected reactor components for the AP600 reactor are summarized in Table 11, based upon information extracted from Section 4.5 of the AP600 SSAR. Although the materials of construction for these systems are specified in somewhat more detail than for many of the other systems in the AP600 design, several vague references are made to unidentified materials, including "Ni-Cr-Fe alloy," "stainless steel," "Co alloy or qualified substitute," and "suitable hard-facing." The bulk of the components are to be fabricated of Type 304 SS, with some use of Type 316 SS. To avoid thermal sensitization and to prevent IGSCC, the austenitic SSs are to be fabricated according to Regulatory Guide 1.44, "Control of the Use of Sensitized Stainless Steel."75 Types 403 and 410 martensitic SSs are specified for applications where greater strength is required or ferromagnetic properties are needed. The control drive assembly coil housing is exposed to the containment atmosphere and a ferromagnetic material is required, so an unspecified "low-C cast steel or ductile iron" (nickel plated) is called for. The internal latch assembly springs are to be made of "Alloy $750, "$ which is presumably Inconel $X-750$. Aside from these occasional vague materials specifications, no major problems in materials selection are noted.

\subsubsection{Anticipated operating environment}

The CRD system and reactor internal components will see the same operating environment as the inside surface of the pressure vessel, namely coolant at a design pressure of $2485 \mathrm{psi}$ and a design outlet temperature of $343^{\circ} \mathrm{C}\left(650^{\circ} \mathrm{F}\right)$. The reactor coolant chemistry has already been summarized Table 10. In addition, the reactor internal components, particularly those located near the core, will receive a substantial neutron radiation fluence. 


\subsubsection{Potential material degradation and fallure modes}

The only primary degradation process for core internal components addressed in the AP600 SSAR is thermal sensitization and IGSCC. The methods specified for the prevention of intergranular attack of the Type 304 and 316 SS appear to be adequate; namely, control of primary reactor coolant water chemistry (Table 10), use of proper solution annealing. prohibition of subsequent heat treatment at temperatures from 430 to $820^{\circ} \mathrm{C}\left(800\right.$ to $\left.1500^{\circ} \mathrm{F}\right)$ to avoid sensitization, control of welding procedure, and confirmation of nonsensitizing welding in heat-affected zones.

However, other potential degradation processes applicable to core internal components irradiated to high fluences have been not addressed at all in the design. These include (a) IASCC of nonsensitized steels, (b) irradiation-induced degradation in toughness and embrittlement near end of life, and (c) the integrity of weldments at high fluence.

Although most of the useful data and field experience information are proprietary and little has been reported in literature, failure of core internal components fabricated from nonsensitized Type 304 and 316 SSs after accumulation of high fluence has been well established for PWR service. The exact nature of the fallure mechanism is still subject to debate, i.e., IASCC or irradiation-assisted cracking. However, most investigators believe that fallure is by the former process, suggesting that coolant water plays an important role. 27

Both Inconel X-750 and 316L SS are susceptible to IASCC. Researchers at Siemens have found that the IASCC susceptibility of Inconel X-750 is quite sensitive to prior heat treatment, and, in particular, to the annealing conditions during fabrication. 24 Inconel 718, a material known to be resistant to IASCC when annealed at low temperatures, should be considered as an alternative to Inconel X-750 in situations where IASCC is a potential problem in the CRD system. 24

In addition, 17-4 PH SS can undergo accelerated thermal aging in the presence of neutron irradiation. This phenomenon has been studied in detail for the cast duplex SSs in the absence of irradiation, but only limited information is available for 17-4 PH SS, particularly in the presence of neutron irradiation. 32.47 .48

Because of the extended design life of the AP600, the susceptibility of the CRD and reactor internal components to irradiation-induced embrittlement and IASCC at high fluence is a greater concern than in conventional PWRs. The end-of-life fluence for the AP600 internal components near the core is estimated to be $=6 \times 10^{22} \mathrm{n} / \mathrm{cm}^{2}$ (80 dpa). This substantially exceeds the commonly accepted threshold fluence of $\approx 2-3 \times 10^{21} \mathrm{n} / \mathrm{cm}^{2}$ ( $\mathrm{E}>1 \mathrm{MeV}$ ) for LASCC. For this reason, considerable attention must be given to those factors that can contribute to IASCC susceptibility in the AP600, including materials selection, water chemistry, stress control, and the elimination of crevices. 
Materials selection. The mechanism(s) of IASCC are not well understood at present, nor is a sufficient data base avallable for Types 304L or 316L SS. Radiationinduced grain-boundary segregation of the impurity elements silicon, phosphorus, and sulfur has been suspected for many years to be the metallurgical process primarily responsible for intergranular cracking in solution-annealed austenitic SS at high fluence. However, results obtained recently at several laboratories and from inreactor tests indicate convincingly that this hypothesis is incorrect.28.35 Contrary to earlier thinking, higher levels of silicon and phosphorus seem, in fact, to be beneficial in suppressing IASCC. Ongoing research is currently focusing on the role of radiation-induced depletion of chromium from grain boundaries and a synergism involving nitrogen, hydrogen, boron, or other unidentified impurity element(s).

Limited data are avallable on the performance of Types 304L and 316L SS, compared with the higher-carbon Types 304 and 316 grades used in conventional BWRs and PWRs. According to data obtained by GE. Type 304L SS is generally more resistant to crack initiation than Type 304 SS, i.e., a somewhat higher fluence is required to initiate a crack in Type $304 \mathrm{~L}$, and crack growth rates at low fluence are significantly lower.27 However, crack growth rates in the two materials are similar for fluences $>1 \times 10^{21} \mathrm{n} / \mathrm{cm}^{2}$. Other results obtained from constant-extension-rate (ANL, Toshiba Electric Corporation), crack-growth-rate (ABB Atom), and tubeswelling tests (Siemens) indicate that the resistance of Type 304L SS to intergranular cracking is either similar to or worse than that of Type 304 SS. $30-35,39$ The exact cause of this large variation in susceptibility is not known at present. and there is no clear indication that carbon is the controlling element.27.42

Thus, it cannot automatically be assumed that the lower carbon Type 304L SS will be significantly more resistant to SCC for high-fluence in-core components. A synergism involving impurity elements other than carbon apparently plays the crucial role in controlling the IASCC resistance of the Type 304 SS class. For example, one of the commercial-purity heats of Type 304 SS tested at ANL exhibited an unusually high resistance up to a fluence of $\approx 3 \times 10^{21} \mathrm{n} / \mathrm{cm}^{2}$, although the mechanism is not understood yet. 42

The low-carbon Type 316L SS appears to offer somewhat better resistance to IASCC than Type 316 SS in addition to its signiffcantly greater resistance to stress corrosion in the absence of a radiation field. However, control of impurities other than carbon again appears crucial. Some modified heats of Type 316 SS have been reported to be resistant to IASCC, e.g., a high-purity Type 316L and low-nitrogen titanium-modified commercial-purity Type 316.31.39.41 Because of these observations, great attention has been focused on the role of nitrogen. However, some heats of commercial-purity Type 316 SS with normal levels of nitrogen and other elements have also been reported to be resistant to intergranular cracking.

Like the titanium-modified heats of Type $316 \mathrm{SS}$, a low-nitrogen high-purity Type 348L SS has been reported to exhibit greatly improved resistance to intergranular cracking. 24 Microstructural analyses conducted at ANL suggests that nitrogen atoms that segregate to grain boundarles and transmute to hydrogen during irradiation play an important role. 42 
At present, it is fair to say that an established solution that can be used to mitigate the IASCC fallure on the basis of material selection is not avallable, nor is the mechanism itself understood. It is not clear which factor(s) is(are) necessary or sufficient to suppress degradation of core internal components at high fluence, i.e., control of nitrogen, carbon, or other impurities (such as silicon, phosphorus, boron, and sulfur), or the addition of alloying elements such as molybdenum, titanium, or nioblum. However, limited data indicate that some heats of modifled Type 304 and 316 SS are more resistant than others to this type of degradation. It is commonly observed that heat-to-heat variations are very significant even among the same types of SSs having nominally similar chemical composition within the limits of ASTM specifications. The best information avallable today indicates that resistance to IASCC can best be achieved by using either high-purity, titanium-modified, lownitrogen Type 316 SS or high-purity, low-nitrogen Type 348 SS. It is very important to keep the AP600 design updated with respect to this issue, with the objective of avoiding inappropriate materials selection.

Water chemistry. Water chemistry parameters specified for normal operation of the AP600 are specified in Table 10. IASCC is closely related to other forms of environmentally assisted cracking in high-temperature water in that the effect of water chemistry is similar in both unirradiated and irradiated materials. The strong effect of corrosion potential on the susceptibility to intergranular cracking of preirradiated materials is well established. The effect appears to be independent of whether the potential was produced by water chemistry alone (e.g., by reducing dissolved oxygen) or in conjunction with irradiation. The effects of solution conductivity on the susceptibility of irradiated and unirradiated SS appear to be similar.

Thus, the conductivities specified for the AP600 in conjunction with the naturally low dissolved-oxygen levels in a PWR should, in principle. greatly suppress the susceptibility of the core internal components to IASCC. Nonetheless, the core internal components will see a high neutron fluence over the design life. To achieve maximum resistance to IASCC. the sound water chemistry approach proposed for the AP600 must be combined with careful attention to materials selection and stress and crevice control.

Stress control. One of the major concerns regarding the structural integrity of in-core components is the field fallures of low-stress components. Although the mechanical design of the reactor internals is described in Section 3.9.5 of the SSAR, it is not clear what specific steps, if any, have been taken to maintain the effective stresses on internal components to levels below the threshold for IASCC. This approach is potentially significant when applied to each safety-significant component.

Crevice control. The greatest threat to the integrity of the AP600 safetysignificant reactor internal components is fallure by the combined processes of IASCC and crevice-assisted stress corrosion cracking (CASCC). Again, the SSAR is 
not specific as to what steps have been taken to eliminate crevices in the design of the AP600 internal components.

\subsubsection{Issues}

Potential degradation processes other than thermal sensitization and IGSCC applicable to core internal components irradiated to high fluences are not addressed in the AP600 SSAR. These processes include (a) IASCC of nonsensitized steels, (b) irradiation-induced degradation in toughness and embrittlement near end of life, and (c) the integrity of weldments at high fluence.

Unforturately, available data and information are often insufficient to make a definitive judgment on the materials selections to avoid these potential degradation and failure processes. However, sufficient information is available to raise the following issues:

- Accelerated thermal aging under neutron irradiation is possible in the 17-4 PH SS specified for a number of the rod cluster control spider assembly retainers. The available data are not adequate to provide a basis for determining the suitability of this alloy for this application.

- Both Inconel X-750, which is specified for the CRD internal latch assembly springs, and Types 304 and 316 SS, which are specified for numerous CRD and reactor internal components, are susceptible to IASCC. Heat-to-heat variations, probably associated with minor variations in chemistry and microstructure, appear to play an important role, and materials selection cannot be based upon general ASTM or ASME specifications.

- It is not clear what specific steps, if any, have been taken to maintain the effective stresses on AP600 reactor internal components to levels below the threshold for IASCC. Similarly, the SSAR does not specify what steps have been taken to eliminate crevices in the design of the AP600 internal components. 
Table 11. Materials for AP600 Reactor control rod drive system and internal components

Component

Materials of Construction

Control Rod and Drive System

Pressure-containing materials

Type 304 austenitic SS;

"Ni-Cr-Fe alloy" for reactor vessel

head penetrations

Control rod assemblies

Drive rod

Drive rod coupling

Springs

Locking button

Other components

Internal latch assembly

Magnetic pole pieces

Link pins

Springs

Latch arm tips

Type 410 martensitic SS

Type 403 martensitic SS

"Ni-Cr-Fe alloy"

"Co alloy or qualified substitute"

Type 304 austenitic SS

Type 410 martensitic SS

"Co alloy or qualified substitute"

"Alloy 750" (Inconel X-750?)

"Clad with suitable hard facing"

(equivalent to Stellite-6 or low- or zero-Co substitute)

Other components

Type 304 austenitic SS

Rod control cluster assembly

Absorber rodlets

Absorber material clad in "stainless

Other rodlets

Hub

Coil housing

Reactor Internals

steel" (Cr plated)

"Stainless steel" (Cr plated)

Type 316 austenitic SS

"low-C cast steel or ductile iron" (Ni plated)

Bolts and dowel pins

Type 316 austenitic SS

Holddown spring

Type 403 martensitic SS

Rod control cluster assembly

Absorber rod end plugs

Spider assembly

Spider assembly retainer

Spider assembly springs

Type 308 austenitic SS

Types 304 and 308 SS

17-4 PH SS

Alloy 718

Other internal components

Type 304 austenitic SS 


\subsection{Coolant Pressure Boundary}

\subsubsection{General description}

The reactor coolant pumps, primary coolant piping, and pressurizer, along with the pressure vessel (discussed in Section 4.1) form the primary-coolant pressure boundary of the AP600 reactor. Two hermetically sealed, canned-motor-reactorcoolant pumps are mounted in the inverted position at the bottom of each of the two steam generators. The pump suction nozzles are welded to vertical channel-head outlet nozzles, effectively combining the steam generator and reactor coolant pumps into a single structure, thereby eliminating the need for a separate set of pump supports. The pumps are of a high-rotational-inertia design, with the incorporation of a heavy depleted-uranium disk into the rotor configuration.

The pumps are connected to the pressure vessel by the primary coolant piping, consisting of a single hot leg (31-in. ID piping) and two cold legs (22-in. ID piping) for each of the two heat-transfer circuits. Also included in the reactor coolant system are the pressurizer, interconnecting piping, valves, and instrumentation for operational control and safeguards actuation. All reactor coolant system equipment is located in the reactor containment. Because these components comprise the primary pressure boundary of the plant and must contain an internal pressure of $2250 \mathrm{psi}$, their structural integrity is a fundamental safety consideration.

\subsubsection{Materials selection}

The materials of construction for the AP600 reactor coolant system components, as presented in the SSAR, are summarized in Table 12. Unfortunately, in most cases the specifications are hopelessly vague for the purpose of reviewing the suitability of the materials of construction. As an example, the SA182 specification for the pressure forgings in the coolant pumps includes 43 different low-alloy, austenitic, and austenitic/ferritic SSs, and the SA336 specification covers 33 different alloys. The SA312 and SA376 specifications for the reactor coolant piping likewise include numerous austenitic and precipitation-hardening SSs, and the specific material of construction cannot be identified without an indication of grade or type. In the case of the coolant piping, the specific material is fortuitously identified almost as an afterthought in Section 3B.2.1 (Leak Before Break Evaluation) of the SSAR as Type 316LN austenitic SS.

\subsubsection{Anticipated operating environment}

The design pressure of the AP600 primary coolant loop is 2250 psi and the nominal design temperature at the hot-leg inlet from the pressure vessel is $343^{\circ} \mathrm{C}$ $\left(650^{\circ} \mathrm{F}\right)$. The reactor coolant chemistry (Table 10$)$ is consistent with that used in current PWRs and the EPRI PWR Primary Water Chemistry Guidelines. ${ }^{74}$

A chemical and volume control system is included in the primary-coolant loop and provides a means for controlling the chemistry and $\mathrm{pH}$ of the coolant. Control of $\mathrm{pH}$ is accomplished by additions of $\mathrm{LiOH} \cdot \mathrm{H}_{2} \mathrm{O}$ enriched in the ${ }^{7 \mathrm{Li}}$ isotope to $99.9 \%$. 
Hydrazine is used as an oxygen scavenger during reactor startup, and the coolant is treated with dissolved hydrogen to control the net decomposition of water by radiolysis in the core region. Boron in the form of boric acid is added to the coolant for long-term reactivity control. In addition, suspended solid and other impurity concentrations are maintained below specified limits (Table 10) by controlling the quality of the makeup water through chemical additives and by purification of the reactor coolant in the chemical and volume control system.

\subsubsection{Potential material degradation and failure modes}

Because the specifications for the materials of construction for the reactor coolant system components are generally too vague to identify the specific alloy to be used, the approach taken here has been to assume that the materials are similar to those used in conventional Westinghouse PWRs. A notable exception is the coolant piping, for which Type 316LN austenitic SS is to be used. Under these assumptions, no corrosion problems are foreseen for the reactor coolant system components as long as the recommended water chemistry of Table 10 is maintained.

However, aging embrittlement of the castings in the pump bodies is a possible concern. It is assumed that these components are to be made of a cast duplex austenitic/ferritic SS such as CF-3, CF-3M, CF-8, or CF-8M. In general, the molybdenum-containing grades such as $C F-3 M$ and $C F-8 M$ are more susceptible to embrittlement, and a 60 -yr design life at $315^{\circ} \mathrm{C}$ is likely to produce severe embrittlement in heats with an unfavorable chemistry or a relatively high deltaferrite level. A grade like CF-8 is less susceptible, but it too can suffer substantial embrittlement if the chemistry or delta-ferrite level is unfavorable. The authors of the AP600 SSAR are referred to NUREG/CR-451376 for detailed information on the aging embrittlement behavior of the cast duplex SSs.

\subsubsection{Issues}

The materials of construction for the AP600 reactor coolant system components presented in the SSAR are, in general, much too vague for the purpose of reviewing the suitability of the materials of construction. An exception is the coolant piping, for which the material is identified as Type 316LN austenitic SS elsewhere in the document. Assuming that the materials for the remaining components are similar to those used in conventional Westinghouse PWRs, the following issues are identified:

- No corrosion problems are foreseen for the reactor coolant system components as long as the recommended water chemistry of Table 10 is maintained.

- Aging embrittlement of the castings in the pump bodies is a possible concern. The authors of the AP600 SSAR are referred to NUREG/CR-451376 for detailed information on the aging embrittlement behavior of the cast duplex SSs. 
Table 12. AP600 reactor coolant system materials

\begin{tabular}{|c|c|c|}
\hline Component & Material of Construction & $\begin{array}{l}\text { Specification } \\
\text { (ASME or ASTM) }\end{array}$ \\
\hline \multicolumn{3}{|l|}{ Reactor Coolant Pumps } \\
\hline Pressure forgings & $\begin{array}{l}\text { Low-alloy, austenitic, \& } \\
\text { austenitic/ferritic SSs }\end{array}$ & SA182 or SA336 \\
\hline Pressure castings & $\begin{array}{l}\text { Duplex SS or carbon and } \\
\text { low-alloy steel }\end{array}$ & SA351 or SA352 \\
\hline Tube and pipe & Ferritic \& austenitic SSs & $\begin{array}{l}\text { SA213; SA376 or } \\
\text { SA312 }\end{array}$ \\
\hline Pressure plates & $\begin{array}{l}\text { Austenitic, duplex, ferritic, \& } \\
\text { martensitic SSs }\end{array}$ & SA240 \\
\hline Bar material & $\begin{array}{l}\text { Austenitic, duplex, ferritic, \& } \\
\text { martensitic SSs }\end{array}$ & SA479 \\
\hline Closure bolting & $\begin{array}{l}\text { Alloy, ferritic, austenitic, \& } \\
\text { precipitation-hardening SSs }\end{array}$ & $\begin{array}{l}\text { SA193; SA320, SA540, } \\
\text { or SA453 }\end{array}$ \\
\hline \multicolumn{3}{|l|}{ Reactor Coolant Piping } \\
\hline Coolant loop piping & $\begin{array}{l}\text { Austenitic \& precipitation- } \\
\text { hardening SSs }\end{array}$ & SA376 \\
\hline $\begin{array}{l}\text { Coolant fittings; branch } \\
\text { nozzles }\end{array}$ & $\begin{array}{l}\text { Austenitic \& precipitation- } \\
\text { hardening SSs }\end{array}$ & SA376 \\
\hline Surge line & $\begin{array}{l}\text { Austenitic \& precipitation- } \\
\text { hardening SSs }\end{array}$ & SA376 \\
\hline $\begin{array}{l}\text { Piping other than loop } \\
\text { and surge line }\end{array}$ & $\begin{array}{l}\text { Austenitic \& precipitation- } \\
\text { hardening SSs }\end{array}$ & SA312 and SA376 \\
\hline \multicolumn{3}{|l|}{ Prescuxizer } \\
\hline Pressure plates & Low-alloy steel plate & SA533 \\
\hline Pressure forgings & Low-alloy steel forgings & SA508 \\
\hline Nozzle safe ends & (not stated) & SA182 \\
\hline Cladding and buttering & $\begin{array}{l}\text { Type } 308 \text { or } 308 \mathrm{~L} \text { SS; } \mathrm{Ni}-\mathrm{Cr}-\mathrm{Fe} \\
\text { weld metal }\end{array}$ & ASME A-8; ASME F-43 \\
\hline Closure studs/nuts & (not stated) & SA193, SA194 \\
\hline
\end{tabular}




\subsection{Engineered Safety Systems}

\subsubsection{General description}

The engineered safety systems in the AP600 Reactor that are considered here include the passive containment cooling and passive core cooling systems. The function of the passive containment cooling system is to reduce containment temperature and pressure following a loss-of-coolant accident or main steam line break inside containment. In reducing containment pressure during such events, it also limits releases of post-accident radioactivity to the external environment. The system is designed with a minimum number of active components, all of which can be tested during plant operation, and the loss of any single active component does not impair the functioning of the system.

The passive containment cooling system relies upon the natural circulation of air between the containment structure and the concrete building surrounding containment. During an accident, cooling is enhanced by the draining of water onto the steel containment shell. This water flows by gravity from a 350,000-gal annular tank on the roof of the shield building. This amount of water is sufficient for three days of cooling, and additional water can be added after that time. The main components of the passive containment cooling system are the passive containment cooling water storage tank; an air baffle that defines the flowpath of the cooling air (located between the steel containment vessel and the concrete shield building); an air inlet and exhaust, also incorporated in the shield building; and a water distribution system located on the outside surface of the steel containment vessel.

The passive core cooling system provides emergency core cooling following an accident event. Depending upon the situation, the system is designed to perform the following specific functions: (a) provide emergency removal of core decay heat, (b) provide reactor coolant system makeup and boration, (c) provide safety injection to the reactor coolant system during loss-of-coolant accidents, and (d) control the containment sump $\mathrm{pH}$ to provide for radioactivity control and prevent corrosion. The passive core cooling system is designed to operate without the use of active components such as pumps and ac power sources. However, it does require a onetime alignment of valves upon actuation of the specific components.

The passive core cooling system performs these functions by providing for the injection of cooling water into the core and containment sump from large reservoirs located in containment. It consists of two core makeup tanks, two accumulators, the in-containment refueling water storage tank, two passive residual heat-removal heat exchangers, the $\mathrm{pH}$ adjustment tank, and associated piping, valves, instrumentation, and other related equipment. The automatic depressurization system valves and spargers, which are part of the reactor coolant system, also provide important passive core cooling functions. 


\subsubsection{Materials Selection}

The proposed materials of construction for the major components in the passive containment and core cooling systems are summarized in Table 13. Unfortunately, the specifications are again very general, and the specific materials of construction cannot be definitively determined in most cases.

\subsubsection{Anticipated operating environment}

The anticipated operating environments for the various components of the engineered safety systems are also summarized in Table 13. The environments range from relatively benign $\left(<100^{\circ} \mathrm{C}\right.$ at $1 \mathrm{~atm}$ pressure in contact with borated water) to more challenging $\left(315^{\circ} \mathrm{C}\right.$ at 2250 psi pressure in contact with reactor coolant). In several cases, the component is exposed to benign conditions for the vast majority of its life, with more severe conditions imposed only in an accident or other off-normal situation. In these cases, the materials of construction must be compatible with the more severe conditions, but time-dependent processes such as IGSCC and aging embrittlement are of less concern.

\subsubsection{Potential material degradation and failure modes}

Core makeup tanks. The core makeup tanks are part of the passive core cooling system and provide coolant makeup for small leaks. They are filled with borated water and located above the loop piping of the reactor cooling system. The system is actuated by isolation valves that open automatically in the event of low water level in the pressurizer, and makeup flow is by gravity. The AP600 SSAR calls for the tank to be made of SA533 and SA508, and the cladding and buttering of ASME Code Section IX weld metal A-8 and F-43.

Unfortunately, none of these specifications is specific enough to identify the precise alloys to be used in fabrication. The ASME specification SA533 includes four different manganese-molybdenum and manganese-molybdenum-nickel steels, and the actual alloy to be used cannot be identified without further information as to the material type and class. The intended alloy is believed to be SA533, Type B, Class 2 , an alloy commonly used in the fabrication of nuclear pressure vessels. This alloy should give good service in this application, and the remaining three alloys included under the SA533 specification would probably also be satisfactory.'

Specification SA508 includes eight different carbon and low-alloy steels, and the authors of the SSAR again fail to identify the specific alloy. SA508, Class 2, a nickelchromium-molybdenum low-alloy steel, is commonly used for forgings in nuclear applications, and it is believed that this is the alloy intended here. This alloy, as well as most of the other SA508 alloys, would again probably be satisfactory here, depending upon the strength requirements.

Similar uncertainties are encountered in identifying the specified cladding and buttering alloys. The ASME Code Section IX weld metal alloy A-8 encompasses nickel compositions from 14.5 to $30 \mathrm{wt} \%$ and chromium compositions from 7.5 to 
15 wt.\%. Any of the weld cladding alloys in this composition range should be satisfactory, but the alloy to be used is probably Type 316 or 316L austenitic SS filler metal. The Section IX Specification F-43 includes no fewer than 15 nickel-base alloys, but the alloy to be used here is believed to be IN 82 or IN 182. Both of these alloys are satisfactory for this application, with IN 82 probably providing better resistance to SCC. The suitability of some of the other F-43 alloys is uncertain.

Passive residual heat removal heat exchanger. Removal of core decay heat is provided by a passive residual heat removal heat exchanger located in the incontainment refueling-water storage tank, which serves as a heat sink. The system is actuated by the opening of two normally closed, fail-open, air-operated valves, and circulation is by convection. The materials specified for the plates, forgings, cladding, and buttering in this component are identical to those discussed above for the core makeup tanks, and the same comments apply. In addition, the heat exchanger tubing is to be made of an SB163 nickel-iron-chromium alloy or an unspecified SS. The SB163 specification covers eight alloy compositions, but the one intended here is believed to be Inconel 600 (UNS N06600). This alloy has experienced cracking problems in PWR steam generator service, but this failure mode would not be expected under normal operating conditions at temperatures $<100^{\circ} \mathrm{C}$. Exposures to higher temperatures where cracking is possible would only occur briefly during accident conditions, and sufficient time at temperature to induce cracking is very unlikely. Nonetheless, Inconel 690 (N06690) would be a better choice for the heat exchanger tubing in this respect. The use of SB163 alloys N02200 and N02201 (nominally pure nickel) as well as N04400 (nickel-copper) is not recommended for this application. The performance of the remaining SB163 alloys (N08810 and N08825) would probably be satisfactory.

In-containment refueling water storage tank. The refueling-water storage tank is located above the reactor coolant system (RCS) and provides additional coolant makeup water as a part of the passive core cooling system. An automatic depressurization system reduces system pressure to permit gravity (hydrostatic head) flow from! the tank. The SSAR does not give an ASME specification for the materials of construction for this tank except to identify it as SS (austenitic?) plate stiffened with structural sections. It appears that structural steel modules will also form a part of the tank wall. Because the tank will normally operate at well below $100^{\circ} \mathrm{C}$, SCC should not be a problem and SS should be satisfactory. Carbon and lowalloy structural steels in contact with the refueling water will suffer general corrosion and wastage with time, and this effect must be taken into account in the design.

Passive containment cooling system water storage tank. This tank is located on the roof of the containment building and holds $1300 \mathrm{~m}^{3}(350,000 \mathrm{gal})$ of water for enhanced cooling of the containment shell in an accident situation. The materials of construction are identified only as an SS liner on reinforced concrete walls. Because of the benign nature of the operating environment, no materials problems are foreseen here.

Spargers. For makeup water from the in-containment refueling-water storage tank to flow into the reactor cooling system in an accident situation, the cooling 
system must first be depressurized. Two sets of valves connected to the pressurizer provide for staged depressurization of the system, and these valves, in turn, discharge into the in-containment refueling-water storage tank through spargers. The spargers thus operate in the relatively benign environment of the incontainment refueling-water storage tank, and the unidentified austenitic SS specified for their construction should be satisfactory.

Containment vessel. The containment vessel is to be constructed of an ASME SA537, Class 2 carbon steel with an inorganic zinc coating on the inner surface, plus an additional phenolic coating up to $8 \mathrm{ft}$ above the operating floor. The containment vessel normally operates at moderate temperatures $\left(138^{\circ} \mathrm{C}\right.$ design) in contact with air, and no problems are anticipated at temperatures in this range. However, the SSAR does not specify a maximum ductile-to-brittle transition temperature (DBTT) for the containment vessel steel. A maximum DBTT should be specified, based upon the minimum temperature expected for this component during a shutdown under severe winter conditions.

Valves. A number of depressurization and isolation valves are used in the engineered safety systems, and many of them operate in continuous contact with the reactor coolant at the reactor operating temperature of $315^{\circ} \mathrm{C}$. This temperature is sufficiently high to produce adverse thermal aging effects in certain materials over extended periods of time. Furthermore, some of these valves are located at dead legs in the piping, where stagnant coolant conditions can lead to the build-up of impurities and possible SCC in susceptible materials.

Unfortunately, the materials specifications for the valve components, which are summarized in Table 13, are again rather vague. The valve bodies and bonnets are to be made of an unspecified grade of SA182 or SA351. The SA182 specification includes no less than 52 different types of ferritic, austenitic stainless, and ferriticaustenitic SSs. Similarly, the SA351 specification includes 27 varieties of cast austenitic and duplex SSs. The specifications for the remaining valve components are similarly vague. Thus, it is impossible to comment in specific terms on the materials choices for the valve components, but some general observations can be made.

The biggest concern for valve bodies in particular is possible aging embrittlement in the cast duplex SSs. In general, the molybdenum-containing grades such as CF-3M and CF-8M are more susceptible to embrittlement, and a 60-yr design life at $315^{\circ} \mathrm{C}$ is likely to produce severe embrittlement in heats with an unfavorable chemistry or a relatively high delta-ferrite level. A grade like CF-8 is less susceptible, but it too can suffer substantial embrittlement if the chemistry or deltaferrite level is unfavorable. The authors of the AP600 SSAR are referred to NUREG/CR-451376 for detailed information on the aging embrittlement behavior of the cast duplex stainless steels.

Stress corrosion cracking is most likely to be a problem where the valve is in extended contact with stagnant coolant at temperatures $>150^{\circ} \mathrm{C}$. Though dissolved oxygen levels are generally quite low in PWR coolant, levels of oxygen and other 
impurities can build up in these stagnant regions. Where these conditions exist, the designers are advised to eliminate any crevices in the valve design and avoid the use of sensitized or otherwise susceptible material. The " $L$ " grades of austenitic stainless steel should be used in all cases.

\subsection{5 lssues}

The review of the proposed materials of construction for the engineered safety system components is hampered by lack of detailed information on the precise alloy to be used for many of the components. Nonetheless, the following issues have been Identified:

- The weld buttering alloy to be used in the fabrication of the core makeup tanks is believed to be Alloy 82 or 182 . Either of these alloys should give satisfactory service; however Alloy 82 would provide better resistance to SCC.

- Inconel 600, which is believed to be the alloy selected for the passive residual heat removal heat exchanger tubes, will probably give satisfactory service under the anticipated operating conditions, but Inconel 690 would provide improved resistance to SCC.

- A maximum DBTT should be specified for the containment vessel steel, based upon the minimum temperature expected for this component during a shutdown under severe winter conditions. 
Table 13. AP600 engineered safety features component materials and anticipated operating environments

\begin{tabular}{lccc}
\hline Component & $\begin{array}{c}\text { Material of } \\
\text { Construction }\end{array}$ & $\begin{array}{c}\text { Specification } \\
\text { (ASME or ASTM) }\end{array}$ & $\begin{array}{c}\text { Operating Environment } \\
\text { (Normal and Accident) }\end{array}$ \\
\hline
\end{tabular}

\section{Core Makeup Tanke}

Pressure plates

$0.25 \%$ carbon low-alloy SA533 steel

Pressure forgings

Carbon or low-alloy steel

Cladding and

buttering

?

Passive Residual Heat Removal Heat Exchnnger
Pressure plates

Pressure forgings

Cladding and

录

Tubing
$0.25 \%$ carbon low-alloy SA533 steel

ER308Mo, ER316, or ER316L (?); IN82 (?)

\section{SA508}

SS weld metal analysis

A-8; $\mathrm{Ni}-\mathrm{Cr}$-Fe weld metal F-number 43
Operating temperature $<100^{\circ} \mathrm{C}$; operating pressure $=15.5 \mathrm{MPa}(2250 \mathrm{psia})$ : inner surface in contact with borated water.
Operating temperature $<100^{\circ} \mathrm{C}$ under normal conditions(?), $315^{\circ} \mathrm{C}$ under accident conditions.

Design pressure $<0.7 \mathrm{MPa}$ (100 psig) (?) under normal conditions, $20 \mathrm{MPa}(2900$ psig) under accident conditions.

Outer surface in contact with refuelingwater storage tank water, inner surface in contact with reacior coolant.
Inconel $600(?)$ or SS
SB163 Ni-Fe-Cr-Alloy

or SS 
Table 13. (Cont'd)

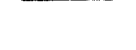

Component

Material of

Specification

Construction

(ASME or ASTM)

Operating Environment

(Normal and Accident)

In-Containment Refueling-Water Storage Tank

Tank wall

SS plate stiffened with Not identified structural steel

sections; structural

steel modules

Pasdive Containment Cooling Syatem Water Storage Tank

Tank wall

SS liner on reinforced concrete walls

$\infty$

\section{Spargers}

Spargers

Austenitic SS

Not identified

\section{Containment Vessel}

Containment vesse]

$0.24 \%$ carbon $(\max$. steel
Not identified

Design temperature $<100^{\circ} \mathrm{C}$; design pressure <0.7 MPa (100 psig); surface in contact with borated water.

Design temperature $<100^{\circ} \mathrm{C}$ in contact with borated water.

SA537, Class 2 with inorganic zinc coating: phenolic top coat on inner surface up to $8 \mathrm{ft}$ above operating floor
Design temperature $=138^{\circ} \mathrm{C}$; design

pressure $=310 \mathrm{kPa}$ (45 psig); max. pressure $=662 \mathrm{kPa}$ (96 psig)
Operating temperature $<100^{\circ} \mathrm{C}^{\circ}$; operating pressure <0.7 $\mathrm{MPa}$ (100 psig); surface in contact with borated water. 
Table 13. (Cont'd)

\begin{tabular}{|c|c|c|c|}
\hline Component & $\begin{array}{l}\text { Material of } \\
\text { Construction }\end{array}$ & $\begin{array}{c}\text { Specification } \\
\text { (ASME or ASTM) }\end{array}$ & $\begin{array}{l}\text { Operating Environment } \\
\text { (Normal and Accident) }\end{array}$ \\
\hline \multicolumn{4}{|l|}{ Valves } \\
\hline Bodies & $\begin{array}{l}\text { Forged austenitic or } \\
\text { cast duplex SS(?) }\end{array}$ & SA182 or SA351 & \multirow{6}{*}{$\begin{array}{l}\text { Operating temperatures up to } 315^{\circ} \mathrm{C} \text {; } \\
\text { operating pressures up to } 20 \mathrm{MPa}(2900 \\
\text { psig); contact with reactor coolant or other } \\
\text { borated water }\end{array}$} \\
\hline Bonnets & $\begin{array}{l}\text { Forged austenitic or } \\
\text { cast duplex SS(?) }\end{array}$ & SA182 or SA351 & \\
\hline Discs & $\begin{array}{l}\text { Forged austenitic, age- } \\
\text { hardening. or cast } \\
\text { duplex SS(?) }\end{array}$ & $\begin{array}{l}\text { SA182, SA564, } \\
\text { or SA351 }\end{array}$ & \\
\hline Stems & $\begin{array}{l}\text { Forged austenitic or } \\
\text { age-hardening SSs (?) }\end{array}$ & SA182 or SA564 & \\
\hline $\begin{array}{l}\text { Pressure retaining } \\
\text { bolting }\end{array}$ & Martensitic SS & SA453 & \\
\hline $\begin{array}{l}\text { Pressure retaining } \\
\text { nuts }\end{array}$ & $\begin{array}{l}\text { Martensitic SS or } \\
\text { carbon, low-alloy, or } \\
\text { austenitic SS }\end{array}$ & SA453 or SA194 & \\
\hline
\end{tabular}




\subsection{Steam Generators}

\subsubsection{Cenaral description}

The AP600 steam generator is a vertical-shell U-tube evaporator with integral moisture separation. The design of the steam generator, except for the configuration of the channel head, is the same as that of an upgraded Model F steari generator with a triangular pitch tube bundle called the Model Delta-75 steam generator, which is currently being used to replace steam generators in existing plants. The channel head is divided into inlet and outlet chambers by a vertical divider plate. The reactor coolant enters the inlet side of the channel head through the hot-leg nozzle. It enters the inverted U-tubes, transferring heat to the secondary (shell) side during the traverse, and returns to the outlet (cold-leg) side of the channel head where it exits through two cold-leg nozzles and returns to the reactor vessel.

The U-tubes are mounted in a tube sheet, which is ferritic steel plate, clad with SS on the primary side. The tubes are tack-rolled, seal-welded, and hydraulically expanded essentially over the full depth of the tubesheet. This differs from the processes used to mount U-tubes in earlier models of Westinghouse steam generators. Westinghouse claims this process was chosen to control secondary water ingress into the tube-to-tubesheet crevice, and to minimize residual stresses in the tubing resulting from the expansion. The tubes are supported by a series of ferritic SS tube support plates. Instead of the simple drilled holes of earlier steam generator models, the holes in the support plate are broached and have a trifoll geometry to minimize crevice formation between the tube and support plate, while still providing substantial support to minimize vibration. Antivibration bars are installed in the $\mathrm{U}$-bend portion of the tube bundle to further minimize the potential for excessive tube vibration.

Steam is generated on the shell side, flows upward, and exits through an outlet nozzle at the top of the vessel. Feedwater enters the steam generator through a feedring located above the top of the U-tubes. The feedwater is dispersed through inverted $J$-nozzles attached to the top of the feedring and mixes with saturated water removed by the moisture separators.

\subsubsection{Materials selection}

The materials used in the AP600 steam generator (Table 14) are the same as those currently used for most steam generator replacements. The shell is fabricated from A533 Grade B plates and A508 forgings. The channel head is also A508 steel. The interior surface of the channel head and the hot- and cold-leg nozzles are clad with weld deposited austenitic SS. The primary side of the tube sheet is clad with a nickel-chromium-iron alloy (ASME SFA-5.14). The steam generator tubes are thermally treated Alloy 690. The divider plate, which separates the hot- and coldleg portions of the channel head, is also Alloy 690. The tube support plates and antivibration bars are Type 405 ferritic SS. 


\subsubsection{Anticipated operating environment}

The primary water chemistry of the AP600 is similar to that currently recommended for other PWRs. The recommended water chemistry limits, given Table 10, are consistent those currently recommended by EPRI guidelines 74 although the guidelines themselves are not referenced. The secondary water chemistry (Table 15) is also consistent with that used in many current operating PWRs and current EPRI guidelines, 77 although the cited guidelines refer to the earlier 1982 version rather than the more recent 1987 and 1992 revisions. The water chemistry of the AP600 is controlled by an all volatile treatment (AVT) control program. However, unlike earlier versions of AVT control programs, morpholine is used instead of ammonia to control $\mathrm{pH}$. This is consistent with the trend in this country and abroad to shift from ammonia additions to other $\mathrm{pH}$ control agents like morpholine. Hydrazine additions are used to ensure that dissolved-oxygen levels are very low. Although the specifications for the AP600 secondary water chemistry will ensure that the bulk water chemistries will have very low impurity levels, large concentration factors can occur in crevice areas where dryout is possible. The AP600 design does seem to incorporate design features like the broached trifoil support plate hole, and fabrication features like hydraulic expansion of the tubes over the full depth of the tubesheet to help minimize crevice chemistry effects. These approaches appear consistent with industry "lessons learned,"78 but it is still impossible to predict crevice operating environments.

\subsubsection{Potential material degradation and failure modes}

Steam generators in current operating plants have been subject to various degradation and failure modes, including material wastage, denting, flow-induced vibrations, fretting, outer-diameter stress corrosion cracking (ODSCC), primary water stress corrosion cracking (PWSCC), flow-accelerated corrosion, and dry-out.59. 78-80 The feedwater piping has been subject to thermal fatigue. These issues are addressed in the AP600 through water chemistry specifications, design and fabrication changes designed to reduce the formation of crevices with aggressive crevice chemistries, and through the choice of materials that are much more resistant to environmental degradation than those used in the steam generators of current operating PWRs. Shell cracking has also been observed in a few PWRs. ${ }^{81,82}$

\subsubsection{Issues}

In laboratory and model boiler testing Alloy 690 with suitable heat treatments has been shown to be much more resistant than Alloy 600 to SCC in caustic (ODSCC) and primary water (PWSCC) environments. 83,84 Except in a few early cases, Alloy 600 inas been used for replacement steam generators in current operating plants. To date, the limited experience in operating plants with Alloy 690 tubing has been favorable, but it is probably premature to assume that $60 \mathrm{yr}$ lives can be achieved.

The use of Type 405 ferritic SS $^{85}$ and the trifoil design in the tube support plates, together with the tighter water chemistry controls used in current operating 
plants and specified for the AP600, would appear to eliminate denting as a likely degradation mode. Operating experience also suggests that the trifoil design makes the tubing much less susceptible to fretting wear (compared for example, with the "egg crate" design used in Combustion Engineering steam generators).

The more open geometry of the trifoll design should also reduce the tendency for the formation of aggressive crevice chemistries between the support plate and the tubing. Together with good control of secondary water chemistry and the greater resistance of Alloy 690 to SCC in caustic environments, the more open geometry should greatly reduce, if not completely eliminate, susceptibility to ODSCC.

The inherent resistance of Alloy 690 to PWSCC, together with improved fabrication procedures that seek to reduce the residual stresses associated with the tube-to-tubesheet joining, should greatly reduce susceptibility to PWSCC.

Some earlier models of Westinghouse steam generators were susceptible to flow-induced vibration problems. However, this appears to have been corrected in later models, and presumably the analyses and experience with the existing Model Delta-75 generators should ensure that no unexpected flow-induced vibration problems will be encountered with the AP600 steam generators.

Stratification and striping and the resulting potential for thermal fatigue are reduced by a design change that raises the feedring relative to the feedwater nozzle allowing the cooler, more dense feedwater to fill the nozzle before rising into the feedring.

Flow-accelerated corrosion problems were experienced on the J-nozzles on the feedwater ring in early Westinghouse steam generator models. These components, as well as the internal blowdown pipe and some primary separator parts, are a nickel-chromium-iron alloy in the AP600 steam generator and should be highly resistant to flow-accelerated corrosion.

In summary, reasonable engineering approaches have been taken to address the modes of degradation that have been observed in current operating steam generators. Virtually all of the design changes and materials proposed for these steam generators have been implemented with apparent success in steam generators being used for replacement in current PWRs. While operating experience is too limited to completely evaluate the success of these changes, taken together with good operating practices, they appear to have the potential to produce steam generators that operate satisfactorily for the life of the plant. 
Table 14. Materials of construction for major AP600 steam generator components

\begin{tabular}{llc}
\hline \multicolumn{1}{c}{ Component } & Material of Construction & $\begin{array}{c}\text { Specification } \\
\text { (ASME or ASTM) }\end{array}$ \\
\hline $\begin{array}{l}\text { Pressure plates (shell) } \\
\text { Pressure forgings (including } \\
\text { nozzles and tube sheet) }\end{array}$ & $\begin{array}{l}\text { Low-alloy ferritic steel plate } \\
\text { forgings }\end{array}$ & A533, Grade B \\
Nozzle safe ends & Austenitic SS weld metal & SA508 \\
Channel heads & Low-alloy ferritic steel & A-8 \\
forgings & Austenitic SS & SA508 \\
Tubes & Alloy 690 & A-8(?) \\
Divider plate & Alloy 690 & SB163 \\
$\begin{array}{l}\text { Tube sheet primary side } \\
\text { cladding }\end{array}$ & Ni-Cr-Fe alloy & Not stated \\
Tube support plates & & SFA-5.14 \\
Anti-vibration bars & Type 405 ferritic SS \\
Other cladding and buttering & SS and Ni-Cr-Fe alloy & Low-alloy steel(?) \\
Closure studs/nuts & Type 405 ferritic SS & Not identified \\
\hline
\end{tabular}


Table 15. Guidelines for normal AP600 secondary water chemistry

\begin{tabular}{|c|c|c|c|c|}
\hline Parameter & Condensate ${ }^{a}$ & Feedwater ${ }^{\mathbf{a}}$ & $\begin{array}{l}\text { Steam } \\
\text { Generator } \\
\text { Blowdowna }\end{array}$ & $\begin{array}{l}\text { Steam } \\
\text { Generator } \\
\text { Water }\end{array}$ \\
\hline $\mathrm{pH}$ at $25^{\circ} \mathrm{C}$ & $>9.0$ & $>9.5$ & $9.0-9.5$ & $9.8-10.5$ \\
\hline $\begin{array}{l}\text { Cation conductivity due } \\
\text { to strong acid anions at } \\
25^{\circ} \mathrm{C}(\mu \mathrm{S} / \mathrm{cm})\end{array}$ & $\leq 0.15$ & $\leq 0.2$ & $\leq 0.5$ & - \\
\hline $\begin{array}{l}\text { Total cation conduc- } \\
\text { tivity at } 25^{\circ} \mathrm{C}(\mu \mathrm{S} / \mathrm{cm})\end{array}$ & $\leq 0.3$ & - & $\leq 0.8$ & - \\
\hline $\begin{array}{l}\text { Specific conductivity at } \\
25^{\circ} \mathrm{C}(\mu \mathrm{S} / \mathrm{cm})\end{array}$ & $2-6$ & $4-12$ & $<3.0$ & - \\
\hline Dissolved oxygen (ppb) & $\leq 10$ & $\leq 2$ & - & - \\
\hline $\begin{array}{l}\text { Total organic carbon } \\
\text { (ppb) }\end{array}$ & $\leq 100$ & - & - & $\leq 100$ \\
\hline Sodium (ppb) & $\leq 1$ & - & $\leq 20$ & $\leq 1000$ \\
\hline Total iron (ppb) & - & $\leq 20$ & - & - \\
\hline Chloride (ppb) & - & - & $\leq 20$ & $\leq 1000$ \\
\hline Sulfate (ppb) & - & - & $\leq 20$ & $\leq 1000$ \\
\hline Silica (ppb) & - & - & $\leq 300$ & - \\
\hline Suspended solids (ppb) & - & - & $<1000$ & - \\
\hline Hydrazine (ppb) & - & $\geq 100$ & - & - \\
\hline Morpholine & d & d & d & e \\
\hline
\end{tabular}

aDuring power operation.

bDuring cold shutdown/wet layup.

cValues apply if hydrazine is used for oxygen scavenging.

$\mathrm{d}_{\mathrm{pH}}$, morpholine, and specific conductivity must correlate.

eAs required to achieve $\mathrm{pH}$ range. 


\subsection{Turbines}

\subsubsection{General description}

The turbine-generator system consists of an 1800-rpm turbine, external moisture-separator reheaters (MSRs), generator, exciter, controls, and associated subsystems. The turbine consists of a double-flow, high-pressure unit, and two double-flow low-pressure units. There is a single direct-driven, gas-cooled generator.

The high-pressure turbine receives steam from each of the two steam generators through two steam lead assemblies. Each steam lead assembly consists of two stop valves and two control valves. Cross ties are provided upstream of the stop valves to permit pressure equalization with one or more stop valves closed. After the steam is expanded through the high-pressure turbine, it flows through two external MSR vessels. The reheaters use a portion of the main steam supply to reheat the steam to superheat conditions.

The turbine generator system is installed on a spring-mounted reinforcedconcrete deck. This spring-mounted support system should be much less site dependent than other turbine pedestal designs, since the soil structure is decoupled from turbine dynamic effects.

\subsubsection{Materials selection}

The materials for the turbine rotors and parts are identified only as nickelchromium-molybdenum-vanadium alloy steels. The most widely used steels of this type are the 3.5Ni-Cr-Mo-V, but presumably the description is left sufficiently general so that other materials in this class could be considered. It is specified that the steels will be vacuum deoxidized and produced by processes that maximize steel cleanliness and provide high fracture toughness. No detailed specifications or references are given. Instead the material characteristics are described only in general terms that are certainly unexceptionable, but vague. From Section 10.2.3.1 of the AP600 SSAR:

Residual elements are controlled to the lowest practical concentrations consistent with melting practices. This material has the lowest fracture appearance transition temperatures (FATTs) and highest Charpy V-notch energies obtainable, on a consistent basis, from water-quenched $\mathrm{Ni}-\mathrm{Cr}-\mathrm{Mo}-\mathrm{V}$ material at the sizes and strength levels used.

The material for other components in the turbine system such as the moisture separator reheaters and the steam piping is carbon steel. 


\subsubsection{Anticipated operating environment}

The operating environment for the high-pressure turbine and the first stages of the low-pressure turbine will be dry steam. As energy is removed from the steam, it will begin to condense. The exact characteristics of this process will depend on the detailed thermodynamics of the turbine, but in a typical nuclear low-pressure turbine the steam begins to condense at the third stage of the low-pressure rotor. ${ }^{86}$ At this point the steam contains $3-5 \%$ water and its temperature is $160-170^{\circ} \mathrm{C}$. At the last stage, the water content in the steam is $<13 \%$, and the temperature is below $90^{\circ} \mathrm{C}$. Based upon the proposed secondary water chemistry for the AP600, the impurity and dissolved-oxygen levels should be very low. The use of morpholine rather than ammonia for $\mathrm{pH}$ control should result in higher $\mathrm{pH}$ levels in the condensate than can be achieved with ammonia. 87

\subsubsection{Potential material degradation and failure modes}

Turbine rotors are subject to catastrophic failure, and it is critical to obtain materlals with high fracture toughness to minimize the likelihood of failure, whether due to fabrication or in-service degradation.

The operating temperatures of the high-pressure rotor is below the stressrupture range for the proposed materials. Therefore, creep-rupture is not considered a significant failure mechanism. However, basic stress and creep-rupture data will be obtained.

Stress corrosion cracking of steam rotors has been a worldwide problem in the nuclear power industry. $50.51,54.55$

Fatigue is another potential method of degradation. Cyclic stresses are unavoidable in rotating machinery, and fatigue life is governed by the inherent fatigue crack growth characteristics of the material and the size of the largest undetectable defects in the rotor.

Flow-accelerated corrosion in wet steam piping associated with turbine systems has occurred in a number of operating reactors. $58-60$

\subsubsection{Issues}

It is well known that in this class of materials cleanliness is critical to achieving high fracture toughness and resistance to temper embrittlement.51 Since actual levels of FATT and Charpy V-notch energy will vary with the size of the part and the location within the forging, these variations must be considered when accepting of a specific forging. Adequate fracture toughness is to be ensured by Charpy V-notch tests on selected samples which are then correlated by the method of Begley and Longsdon. 88 The SSAR makes no explicit reference to the extensive work that has been done on SCC and the optimization of fracture toughness in low-pressure turbine materials for nuclear power systems over the past decade. The differences between 
a low-toughness material that is relatively susceptible to SCC and a high-toughness material that is resistant to SCC are due to changes in impurity levels and fabrication practices that are quite subtle. In vague, general terms, the material specification for the rotors (and the monoblock design) reflect the "good practices" resulting from this work, but the specifications provided for the materials are insufficient to determine whether the materials really conform to these "good practices."

The only explicit reference to a minimum fracture toughness is given in Section 10.2.3.2 of the SSAR. Unfortunately, as written, the specification is incorrect. It requires that the ratio of the fracture toughness $K_{I C}$ to maximum tangential stress at the highest design speed "will be at least 1/2." Inasmuch as the ratio has dimensions of the square root of a length, this statement is meaningless until proper units $(\sqrt{\mathrm{in} .}, \sqrt{\mathrm{mm}}$ ?) are given.

In addition to obtaining high fracture toughness, it is important to avoid defects. The proposed preservice inspections include $100 \%$ volumetric (ultrasonic) inspections and surface visual examinations. All subsurface indications will be either removed or evaluated to ensure that they will not grow to a size that will compromise the integrity of the unit during its service. All finished machined surfaces will be subjected to a magnetic-particle test with no flaw indications permissible. This would seem adequate to detect fabrication defects and provide a baseline for future in-service inspection.

It is in the wet steam environment that SCC of the turbines is most likely to occur.19,24 The problem has been extensively studied and a technology has been developed to deal with cracking.25.26 Several mitigating features have been identifled: good water chemistry, welded or monoblock designs instead of shrink fit disks, and lower yield strength, 50,57 but it is difficult to eliminate the problem completely. The very low dissolved oxygen and low impurity levels in the secondary system of the AP600 help to reduce susceptibility. 50 Because of the monoblock design, there are no keyways to act as stress risers or as crevices and sites for aggressive chemical buildup. The disk profiles are designed to limit the surface stress to $<50 \%$ of the yield strength.

The effect of cyclic stresses and the potential for growth of fatigue flaws can be analyzed by fracture mechanics procedures completely analogous to those used for analyzing the growth of stress corrosion cracks. 56.57 The procedures outlined in the SSAR can deal adequately with this problem.

Flow-accelerated corrosion tends to be more severe in PWR reactors, because of the incentive to reduce dissolved-oxygen levels to minimize steam generator corrosion. 59 Design features or materials selection to reduce susceptibility to flowaccelerated corrosion does not appear to be addressed by the SSAR. The use of morpholine rather than ammonia for $\mathrm{pH}$ control should result in higher $\mathrm{pH}$ levels in the condensate than can be achieved with ammonia, 87 which will have significant benefits in reducing susceptibility to flow-accelerated corrosion. However, a commitment to materials selection or design approach to mitigate now-accelerated corrosion should be included in the SSAR. 


\subsection{Fuel Storage and Handling System}

\subsubsection{General description}

The fuel storage and handling system for the AP600 does not constitute a part of the reactor pressure boundary. Nonetheless, the fallure of critical components in this system could have significant safety implications, and the selection of appropriate materials on construction for these components is an important safety consideration. The principal safety concerns associated with the fuel storage and handling system are (1) maintaining proper cooling of the stored spent fuel to prevent overheating and cladding damage, and (2) maintaining proper spacing of stored fuel elements, both new and spent, to prevent the accidental formation of a critical geometry. The water in the spent fuel storage pit also provides radiological shielding.

\subsubsection{Materials selection}

The fuel storage and handling system for the AP600 is described in Chapter 9, Section 9.1 of the SSAR. However, the proposed materials of construction for critical componerits are given only in general terms. The new fuel storage pit is to be constructed of unlined concrete, whereas the spent fuel storage pit is to be lined with an unspecified SS. An unspecified SS is also to be used in the construction of the spent fuel storage pit pump, heat exchangers, demineralizers, filter, strainer, and valves. For both the new and spent fuel storage facilities, the SSAR states that "materials used in rack construction are compatible with the storage pit environment, and surfaces that come into contact with the fuel assemblies are made of annealed austenitic stainless steel. Structural materials are corrosion resistant and will not contaminate the fuel assemblies or pit environment."

\subsubsection{Anticipated operating environment}

The SSAR indicates that the new fuel elements are to be stored dry, and the spent fuel storage pool is to be filled with borated water ( $2500 \mathrm{ppm}$ boron) at a maximum temperature of $49^{\circ} \mathrm{C}\left(120^{\circ} \mathrm{F}\right)$. No further details on water chemistry are given, except to state that the cooling system of the spent fuel storage pit also serves to remove radioactive corrosion products, fission product ions, and dust to maintain water clarity. This is accomplished by diverting $1 / 3$ of the heat exchanger water flow through a mixed-bed demineralizer and filter. The demineralizer utilizes a hydrogen-type cation resin and a hydroxyl-type anion resin to remove fission and corrosion products.

\subsubsection{Potential material degradation and failure modes}

The greatest threat to the integrity of the spent fuel storage and handling system components under the anticipated conditions is failure by corrosion-related processes. (The new fuel is to be stored dry, and corrosion is not a concern.) Such processes could take the form of either general corrosion or localized effects such as 
crevice corrosion or SCC. Unfortunately, the information provided in the SSAR on the materials of construction and the anticipated operating environment is inadequate for a detailed evaluation. However, it can be stated that the use of SSs for the major components in the spent fuel storage pit cooling system, the pit liner, and surfaces that come into contact with the fuel assemblies should preclude general corrosion. Crevice corrosion can be avoided most effectively be by proper component design. Any use of carbon steel for components in contact with the spent-fuel storage pit water requires that wastage and general corrosion be taken into account in component design.

\subsubsection{Issues}

- The information provided in the SSAR on the materials of construction and the anticipated operating environment for the fuel storage and handling system components is inadequate for a detailed evaluation.

- The use of SSs for the major components in the spent fuel storage pit that come into contact with the water or the fuel assemblies should preclude general corrosion.

- Crevice corrosion can be avoided most effectively by proper component design.

- Any use of carbon steel for components in contact with the spent fuel storage pit water requires that wastage and general corrosion be taken into account in component design. 


\subsection{Use of Cobalt-Based Alloys}

Cobalt-based alloys have historically been used in nuclear reactor applications where high resistance to abrasive and corrosive wear is required. These applications inclucue weld-deposited hard facing on the sealing surfaces of valves and high-wear surfaces on CRD components. Problems arise when small amounts of cobalt from these alloys are carried by the coolant to the core and activated by neutrons to form $60 \mathrm{Co}$, a strong gamma emitter. The ${ }^{60} \mathrm{Co}$ is subsequently transported through the cooling loop and deposited on component surfaces or incorporated into the oxide films forming on these surfaces. The resulting radiation field can create exposure problems for maintenance and repair personnel.

The SSAR for the AP600 reactor addresses the problem of controlling radiation levels produced by the activation of cobalt in Section 12.3 of the SSAR ("Radiation Protection Design Features"). Relatively stringent limits are placed on cobalt impurity levels in alloys used for the major components, and these limits are summarized in Table 16. However, as the table indicates, cobalt-based alloys are still specified for some bearing and hard-facing materials where apparently no satisfactory substitutes have been found.

Unfortunately, the SSAR is again vague on the exact alloys used for specific components, and it is not possible to complle a detailed list of the components that are to be fabricated of cobalt-based alloys. One would expect these alloys to be used primarily in the CRD system for applications where high resistance to wear is required. This is borne out by Table 11 of the present report, which specifies a "Co alloy or qualified substitute" for the control rod assemblies locking button and internal latch assembly link pins. In addition, the latch arm tips are to be "clad with suitable hard facing" equivalent to Stellite-6 or a low- or zero-cobalt substitute. Cobalt-based alloys are probably specified for other applications in the AP600 as well, but these specific components cannot be determined from the SSAR.

The EPRI has sponsored a considerable amount of work in recent years on the development and evaluation of cobalt-free alternatives to the standard hard facing alloys.61-65 Several promising hard-facing alloys have resulted from this research effort, including the NOREM family of Fe-Mo-Cr-Ni-C alloys that can be cast or welddeposited as a hard facing. A number of experimental studies have demonstrated that, in the weld-deposited form, these alloys offer wear and corrosion resistances comparable to that of Stellite 6 . When applied as a weld deposit to gate valve sealing surfaces and tested in a simulated PWR environment, for example, three of the NOREM alloys showed somewhat better wear resistance than the Stellite 6 standard. 62

Despite these encouraging results, no mention is made of the NOREM and other cobalt-free alloys or their possible use in the AP600 SSAR. Because of the increasing emphasis on ALARA in nuclear plant design and operation, it is recommended that the NOREM alloys be considered as replacements for the cobalt-base hard-facing materials presently specified for the AP600 CRD system components listed in Table 11. 
Table 16. Specified limits for cobalt impurity levels in AP600 materials and components

Material, Component, or Application

Max. Cobalt Content (wt.\%)

Inconel and SS components in fuel assembly

0.05

Inconel tubing in steam generators

0.015

Components external to active core but

0.05

in regions of high neutron flux

Steam generator surfaces other than tubing

Other primary components and weld clad surfaces, except hard facing and fasteners indicated below

Auxiliary heat exchangers exposed to

0.10

reactor coolant

Bolting materials in reactor internals

0.05

Other small components in regions of

$$
0.20
$$$$
0.20
$$

high neutron flux

Bearing and hard-facing materials

No limit (average $\approx 60$ )

Auxiliary components (valves, piping, instrumentation, tanks, bolting materials. etc.)

Welding material, except weld cladding

No limit (average $\approx 0.20$ )

No limit (average $\approx 0.20$ ) 


\section{Summary and Conclusions}

Two advanced LWR concepts, namely the General Electric (GE) Simplified Bolling Water Reactor (SBWR) and the Westinghouse Advanced Passive 600 MWe (AP600) were reviewed in detail at Argonne National Laboratory. The objectives of these reviews were to (a) evaluate proposed advanced reactor designs and the materials of construction for the safety systems, (b) Identify all aging and environmentally related degradation mechanisms for materials of construction, and (c) evaluate the suitability of the proposed materials for the design application from the safety viewpoint.

The safety-related systems selected for review for these two LWRs were:

- Reactor pressure vessel.

- Control rod drive system and reactor internals.

- Coolant pressure boundary.

- Engineered safety systems.

- Steam generators (AP600 only).

- Turbines.

- Fuel storage and handling system.

In addition, the use of cobalt-based alloys in these plants was reviewed.

The materials selections for both reactors were generally sound; no major selection errors were found. It was apparent that considerable thought had been given to the materials selection process, making use of lessons learned from previous LWR experience. The review did result in the suggestion of alternative and possibly better materials choices in a number of cases, and several potential problem areas were cited. The review of the AP600 materials of construction was impaired by the fact that the materials designations given in the AP600 Standard Safety Analysis Report (SSAR) were often too vague to identify the specific alloy to be used. With some notable exceptions, the SBWR SSAR generally gave more detailed materials information than did the AP600 SSAR.

Specific issues identified in the reviews of these systems in the two reactor concepts may be summarized as follows:

\subsection{Reactor Pressure Vessel}

- Fabrication procedures and restrictions on copper and phosphorus appear to be adequate to preclude irradiation embrittlement in both the SBWR and the AP600 pressure vessels over the 60-yr design life.

- The limit of 0.01 wt.\% on sulfur content in the SA533, Grade B steel to be used to fabricate the SBWR vessel may not be adequate to ensure no environmental enhancement of fatigue crack growth rates. The AP600 design calls for a $0.005 \mathrm{wt} . \%$ limit on sulfur, and this limit was judged to be sufficiently low to avoid this problem. 
- Both the SBWR and the AP600 designs call for the use of "Ni-Cr-Fe" alloys for a number of applications inside the vessel, but the precise alloys are not identifled. Some of these alloys, including Alloy 600 structural components and Alloy 182 weld butters, have experienced SCC in conventional LWRs, and more information is needed to determine if the optimum alloys have been chosen for the present applications.

- The 17-4 PH precipitation hardening stainless steel (SS) chosen for the control rod drive (CRD) seal housing nuts in the SBWR is subject to severe SCC and hydrogen embrittlement if improperly heat treated, and stringent acceptance criteria are required for this component to avold this potential problem.

- Several ambiguities and apparent errors were noted in some of the materials specifications for the SBWR vessel.

\subsection{Control Rod Drive System and Reactor Internals}

- The SSARs for both the SBWR and the AP600 were somewhat vague with respect to the materials of construction for a number of the important CRD and reactor internal components, and definitive judgments on materials selection were sometimes not possible.

- Potential degradation processes other than thermal sensitizacion and intergranular stress corrosion cracking (IGSCC) applicable to core internal components irradiated to high fluences were not addressed in the AP600 SSAR. These processes include (a) irradiation-assisted stress corrosion cracking (LASCC) of nonsensitized steels, (b) irradiation-inducer degradation in toughness and embrittlement near end of life, and (c) the integrity of weldments at high fluence.

- Accelerated thermal aging under neutron irradiation is possible in the 17-4 PH SS specified for a number of CRD system components in both the SBWR and the AP600. The available data are not sufficient to provide a basis for determining the suitability of this alloy for this application.

- Both Inconel X-750 and Types 304 and 316 SS, which are specified for numerous $\mathrm{CRD}$ and internal components in both reactors, are susceptible to irradiation-assisted stress corrosion cracking (IASCC). Heat-to-heat variations, probably associated with minor variations in chemistry and nicrostructure, appear to play an important role, and materials selection cannot be based upon general ASTM or ASME specifications.

- The water chemistry parameters specified for the SBWR, including the use of hydrogen-water chemistry, should greatly suppress the susceptibility of the core internal components to IASCC. However, it is not clear for the top guide in particular that the local electrochemical potential (ECP) can be maintained 
sufficiently low by hydrogen-water chemistry to prevent IASCC. The proposed approach to water chemistry control, whlle very good, must be combined with careful attention to materials selection and control of stress crevices.

- It is not clear what specific steps, if any, have been taken to maintain the effective stresses on AP600 reactor internal components to levels below the threshold for IASCC. Similarly, the SSAR does not specify what steps have been taken to eliminate crevices in the design of the AP600 internal components.

\subsection{Coolant Pressure Boundary}

- The materials selected for the SBWR coolant pressure boundary components are generally appropriate, and the specified water chemistries are consistent with good practice based on BWR water chemistry guidelines. Accordingly, relatively few materials problems are foreseen for these components.

- The materials information provided for the AP600 for the coolant pressure boundary components is, for the most part, much too vague to permit a detalled review. Assuming that the materials are similar to those used in conventional Westinghouse PWRs (except for the Type 316LN austenitic SS specified for the coolant piping), no corrosion problems are foreseen for these components as long as the specified water chemistries are maintained.

- The SBWR SSAR states that "IGSCC resistance has been achieved through the use of IGSCC-resistant materials such as Type 316 Nuclear Grade SS and stabilized nickel-base Alloy 600M and 182M." However, the materials of construction listed in the SSAR do not specifically indicate the use of Type $316 N G$ SS, unless that is what is meant by the Type 316L SS $10.02 \%$ carbon max.) specified for the isolation condenser condensate piping.

- The stabilized nickel-based alloys are also not specifically called out for the SBWR, except for the use of SB564 for the reactor pressure vessel stub tubes. The SB564 specification refers to Alloy 600 tubes in general, but could be taken to mean the stabilized " $M$ " grade in this case.

- The martensitic SSs specified for selected valve internals in the main steam piping system of the SBWR are very susceptible to SCC when hardened to levels higher than $\approx R_{c} 35$. Care must be taken to ensure proper heat treatment of these components.

- In the SBWR, Alloys 600 and 182, even for the "M" grades, can crack in oxygenated water, particularly under crevice conditions. Proper control of coolant dissolved-oxygen levels and the avoidance of crevice geornetries in component design are essential. 

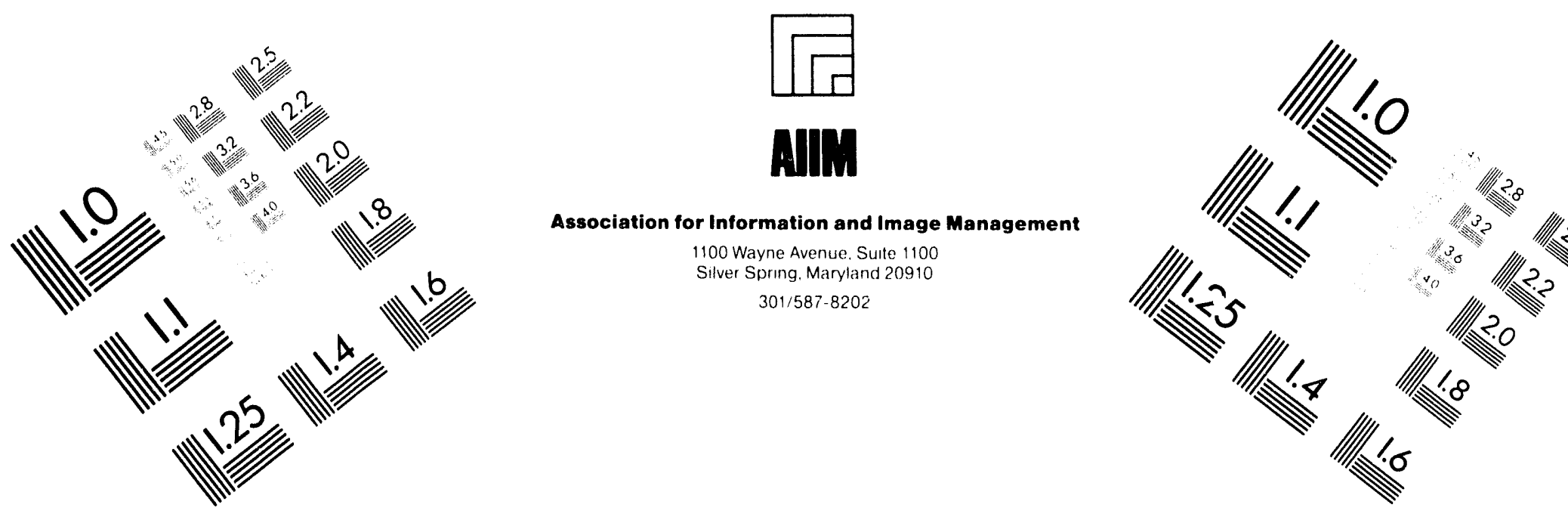

\section{Centimeter}

${ }_{1}$

Inches
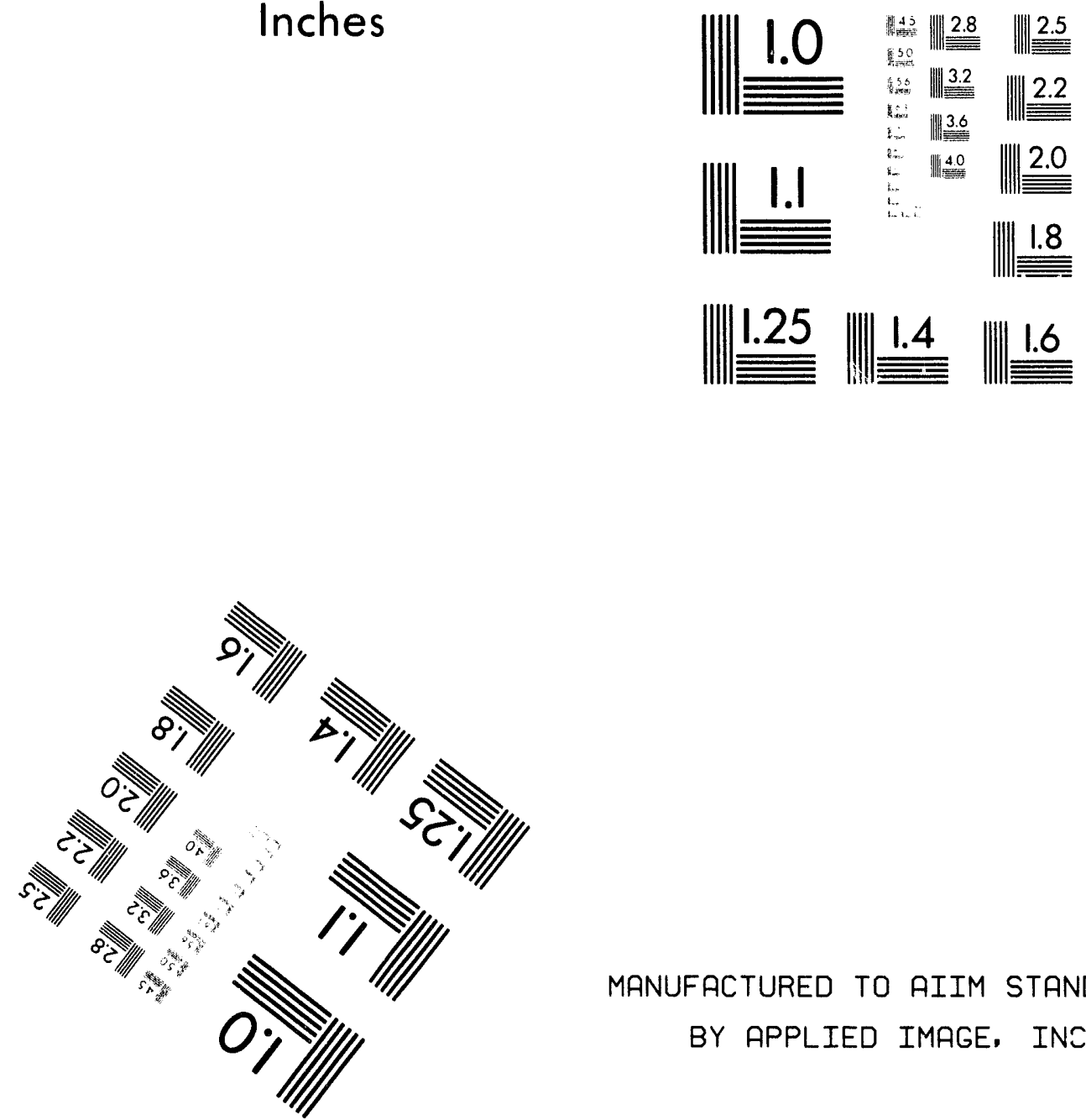

MANUFACTURED TO AIIM STANDARDS

BY APPLIED IMAGE, INC.

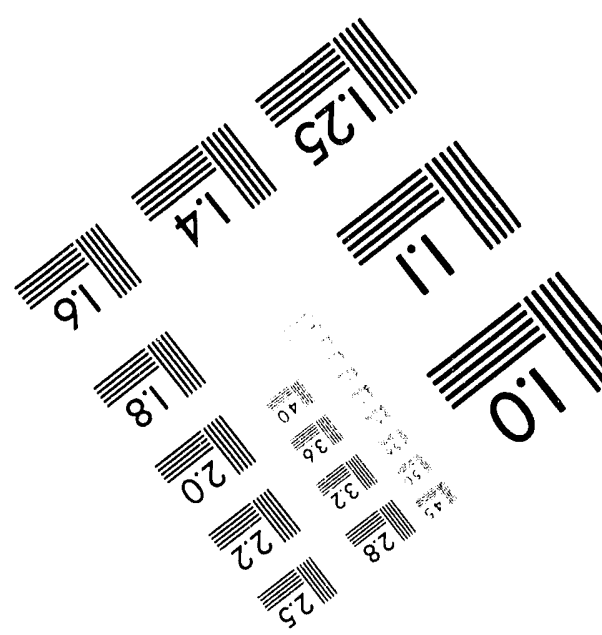



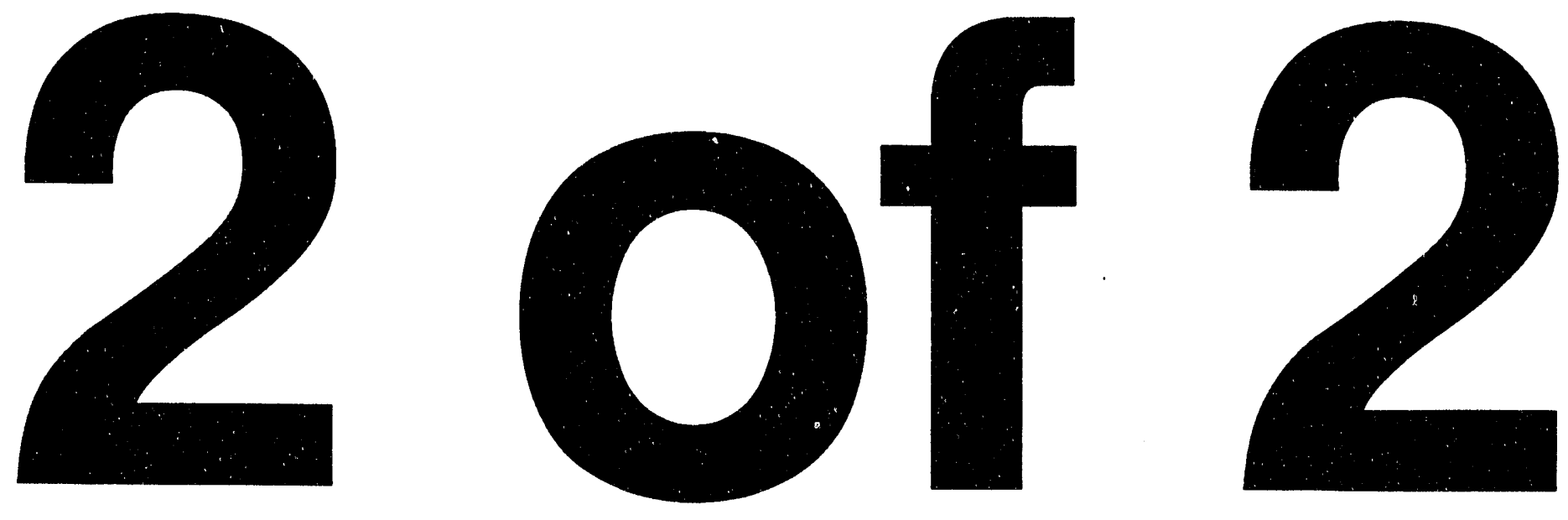
- The SBWR SSAR does not state whether the makeup water and the condensate storage tanks used for final cleaning and flushing of the feedwater system will have an inert nitrogen cover gas to maintain low dissolved-oxygen levels and prevent pickup of carbon dioxide from the air. This feature should be adopted to further minimize impurity ingress into the reactor coolant system.

- The SBWR reactor water cleanup/shutdown system cooling system processing rate of $1 \%$ of the rated feedwater flow is rather low, and it is not clear that this is adequate to maintain the high-quality water chemistry that GE has specified for the SBWR.

- Aging embrittlement of the castings in the AP600 pump bodies is a possible concern. The authors of the AP600 SSAR are referred to NUREG/CR-451340 for detailed information on the aging embrittlement behavior of the cast duplex SSs.

\subsection{Engineered Safety Systems}

- The SBWR depressurization valves will operate in a wet steam reactor coolant environment that creates a significant potential for SCC problems. All valve components should be fabricated of the " $L$ " grades of austenitic SS (Types 304L and 316L) for maximum resistance to SCC.

- Long-term exposure to reactor coolant temperatures creates a potential for both SCC and aging embrittlement in the SBWR cast depressurization valve bodies. Casting alloy CF3 is somewhat more resistant to both degradation modes than CF3M. Lower carbon and lower nitrogen heats of CF3 are more resistant to aging embrittlement than higher carbon and nitrogen heats.

- The carbon steel specified for the SBWR isolation condenser steam piping may suffer excessive general corrosion and wastage if condensation occurs in this line.

- The weld buttering alloy to be used in the fabrication of the AP600 core makeup tanks is believed to be Alloy 82 or 182 . Either of these alloys should give satisfactory service; however Alloy 82 would provide better resistance to SCC.

- Inconel 600, which is believed to be the alloy selected for the AP600 passive residual heat removal heat exchanger tubes, will probably give satisfactory service under the anticipated operating conditions, but Inconel 690 would provide improved resistance to SCC.

- A maximum ductile-to-brittle transition temperature should be specified for the AP600 containment vessel steel, based upon the minimum temperature expected for this component during a shutdown under severe winter conditions. 


\subsection{Steam Generators}

- Reasonable engineering approaches have been taken to address the modes of degradation that have been observed in current operating steam generators. Virtually all of the design changes and materials proposed for these steam generators have been implemented with apparent success in replacement steam generators for current PWRs, and these changes are incorporated into the AP600 design.

- The selection of Alloy 690 over Alloy 600 for the AP600 steam generator tubes should lead to greatly improved resistance to ODSCC and PWSCC, although it is premature to assume that this selection will ensure a 60-yr life.

- The use of Type 405 ferritic SS and the trifoil design in the tube support plates, together with the tight controls of water chemistry specified for the AP600, would appear to eliminate denting as a likely degradation mode. The trifoil design makes the tubing much less susceptible to fretting wear.

- The more open geometry of the trifoil design should also reduce the tendency for the formation of aggressive crevice chemistries between the support plate and the tubing. Together with good control of secondary water chemistry and the greater resistance of Alloy 690 to SCC in caustic environments, this should greatly reduce, if not completely eliminate, susceptibility to ODSCC.

- The inherent resistance of Alloy 690 to PWSCC, together with improved fabrication procedures that seek to reduce the residual stresses associated with tube-to-tubesheet joining, should greatly reduce susceptibility to PWSCC.

- Problems with flow-induced vibration in earlier models of Westinghouse steam generators appear to have been corrected in later models, and no problems are expected with the AP600 steam generators.

- Stratification and striping and the resulting potential for thermal fatigue are reduced by $\approx$. design change in the AP600 steam generator, which raises the feedring relative to the feedwater nozzle, allowing the cooler, more dense feedwater to fill the nozzle before rising into the feedring.

- Flow-accelerated corrosion problems were experienced on the J-nozzles on the feedwater ring in early models of the Westinghouse steam generator. These components, as well as the internal blowdown pipe and some primary separator parts, are to be made of nickel-chromium-iron alloys in the AP600 steam generator and should be highly resistant to flow-accelerated corrosion. 


\subsection{Turbines}

- The SSARs for both the SBWR and the AP600 make no explicit reference to the extensive work that has been done on SCC and the optimization of fracture toughness in low-pressure turbine materials for nuclear power systems over the past decade. The specifications provided for the turbine materials are insufficient to determine whether the materials actually conform to the "good practices" that are alluded to.

- The specification of $100 \%$ volumetric ultrasonic inspections, surface visual examinations, and magnetic-particle inspections of the finished machined surfaces in both SSARs should ensure that fabrication defects will be detected.

- Potential SCC problems have been addressed in both turbine designs, and the SBWR SSAR includes procedures for analyzing fatigue crack growth.

- Flow-accelerated corrosion problems in the AP600 turbine should be mitigated through the use of morpholine rather than ammonia for $\mathrm{pH}$ control.

- The specification of minimum fracture toughness for the AP600 turbine material is incomplete because units were inadvertently omitted.

\subsection{Fuel Storage and Handling System}

- The information provided in the AP600 SSAR on the materials of construction and the anticipated operating environment for the fuel storage and handling system components is inadequate for a detailed evaluation. The information for the SBWR is more complete.

- The low-carbon grades of austenitic SS (e.g., Types 304L and 316L) should be used to fabricate large weldments such as the SBWR spent-fuel pool liner to reduce the likelihood of SCC.

- The general corrosion rates of the carbon steels are sufficiently high in the anticipated environment that corrosion wastage must be taken into account when designing components in both the SBWR and the AP600 that are to be fabricated of carbon steel.

- The design and materials selection for the SBWR fuel storage racks must address issues related crevice and pitting corrosion of aluminum-based alloys for the water chemistry in the low-fl w environment of a storage pool.

- Potential crevice corrosion problems in these systems for both reactors can be most effectively be avoided by proper component design. 


\subsection{Use of Cobalt-Based Alloys}

- The SBWR SSAR specifies a rather lenient limit of $0.15 \mathrm{wt} \%$ cobalt for austenitic SSs that are to be used both inside and outside the core, and a 0.05 wt.\% limit for the XM-19 alloy used in the CRD system. The AP600 SSAR gives detailed limits for a number of alloys used to fabricate the major components, including a tight $0.05 \mathrm{wt}$ \% limit for Inconel and SS in the fuel assembly.

- Cobalt-based alloys are used in hard-facing applications in both reactors, and the possible use of existing cobalt-free alternatives is not mentioned. 
1. SBWR Standard Safety Analysis Report, 25A5113, Rev. A, Volumes 1-15, General Electric Company (August 1992).

2. AP600 Standard Safety Analysis Report, DE-AC03-90SF18495, Rev. 0, Volumes 1-11, Westinghouse Electric Corporation (June 26, 1992).

3. R. J. McCandless and J. R. Redding, Simplicity: the key to improved safety, performance and economics, Nucl. Eng. Int., Vol. 29, pp. 20-24, 1989.

4. D. R. Wilkins, GE Advanced Boiling Water Reactors, Proc. American Power Conference, Vol. 52, pp. 874-881, 1990.

5. D. R. Wilkins, J. F. Quirk, and R. J. McCandless, Status of Advanced Boiling Water Reactors, Proc. Seventh Annual Pacific Basin Conf., Trans. Am. Nucl. Soc., Vol. 61, Suppl. 1, pp. 261-270.

6. R. J. McCandless, A. S. Rao, and C. D. Sawyer, SBWR-Simplifications in Plant Design for the 1990s, Proc. Tech. Committee Meeting on Prog. in Develop. and Design Aspects of Adv. Water Cooled Reactors, Rome, Sept. 9-12, 1991, CONF9109475, pp. 70-74.

7. A. S. Rao, C. D. Sawyer, and R. J. McCandless, SBWR Technology and Development, Proc. Tech. Committee Meeting on Prog. in Develop. and Design Aspects of Adv. Water Cooled Reactors, Rome, Sept. 9-12, 1991, CONF9109475, pp. 95-99.

8. Regulatory Guide i.43, Control of Stainless Steel Weld Cladding of Low-Alloy Steel Components, U.S. Government Printing Office, Washington, DC, May 1973.

9. Regulatory Guide 1.50, Control of Preheat Temperature for Welding of Low-Alloy Steel, U.S. Government Printing Office, Washington, DC, May 1973.

10. Regulatory Guide 1.99, Radiation Embrittlement of Reactor Vessel Materials, Revision 2, U.S. Government Printing Office, Washington, DC, May 1988.

11. D. Worswick, D. R. Tice, P. M. Scott, and J. D. Wilson, Influence of Environmental Variables on Corrosion Fatigue Crack Growth in PWR Pressure Vessel Steels, Proc. 3rd Int. Atomic Energy Agency Specialists' Meeting on Subcritical Crack Growth, NUREG/CP-0112, ANL-90/22 Vol. 1, Argonne National Laboratory (August 1990).

12. F. P. Ford, D. F. Taylor, P. L. Andresen, and R. G. Ballinger, Corrosion-Assisted Cracking of Stainless and Low-Alloy Steels in LWR Environments, EPRI NP5064S, Electric Power Research Institute, Palo Alto, CA (February 1987). 
13. E. D. Eason, EDEAC Status; Analysis Procedures for $d a / d N$ and $S-N$ Data, Technical Information from Workshop Cyclic Life and Environmental Effects in Nuclear Applications, Vol. 2, Pressure Vessel Research Committee and Welding Research Council, Clearwater Beach, FL (1992).

14. Failure Analysis and Prevention, ASM Metals Handbook, Eighth Edition, Vol. 10, pp. 220-221 and 234-235, ASM Int., Materials Park, OH (1975).

15. J. Alexander, C. Briant, W. Clarke, R. Davis, C. Jewett, J. Kass, J. Lemaire, H. Solomon, R. Tunder, and M. Wang, Alternative Alloys for BWR Piping. EPRI ND2671-LD, Electric Power Research Institute, Palo Alto, CA (1982).

16. F. M. Haggag, W. R. Corwin, and R. K. Nanstad, Effects of Irradiation on the Fracture Properties of Stainless Steel Weld Overlay Cladding, Nucl. Eng. Des., Vol. 124, pp. 129-141, 1990.

17. F. M. Haggag and R. K. Nanstad, Effects of Thermal Aging and Neutron Irradiation on the Mechanical Properties of Stainless Steel Weld Overlay Cladding, Proc. 5th Int. Symp. on Environmental Degradation of Materials in Nuclear Power Systems-Water Reactors, August 25-29, 1991, Monterey, CA, American Nuclear Society, La Grange Park, IL, pp. 327-332 (1992).

18. F. M. Haggag, H. M. Chung, P. Shewmon, L. M. Davies, and I. S. Hwang, in Discussion-Session $V$, ibid. pp. 334-335.

19. S. Floreen and L. J. Nelson, The Effects of Heat Treatment and Composition on the Stress Corrosion Cracking Resistance of Inconel Alloy X-750, Met. Trans., Ser. A, Vol. 14, pp. 133-139, 1983.

20. Proceedings: 1986 Workshop on Advance High-Strength Materials, Ed. A. A. Stein, M. S. Gennero, J. L. Nelson, EPRI-NP-6363, Electric Power Research Institute, Palo Alto, CA (1989).

21. Nickel Chromium Iron Alloys for Nuclear Reactor Vessel Components, EPRI NP5429m, Electric Power Research Institute, Palo Alto, CA (1987).

22. Material Specification for Alloy X-750 in LWR Internal Components, EPRI-NP6202, Electric Power Research Institute, Palo Alto, CA (1989).

23. Microstructure and Stress Corrosion Resistance of Alloys X-750, 718, and A-286 in LWR Environments, EPRI NP-6392s-M, Electric Power Research Institute, Palo Alto, CA (1989).

24. F. Garzarolli, D. Alter, P. Dewes, and J. L. Nelson, Deformability of Austenitic Stainless Steels and Ni-Base Alloys in the Core of a Boiling and Pressurized Water Reactor, in Proc. 3rd Int. Symp. on Environmental Degradation of Materials in Nuclear Power Systems-Water Reactors, G. J. Theus and J. R. Weeks, eds., The Metallurgical Society of AIME, Warrendale, PA, pp. 657-664 (1988). 
25. P. O. Andresen, F. P. Ford, State of Knowledge of Radiation Effects on Environmental Cracking in Light Water Reactor Core Materials, Proc. 4th Int. Conf. on Environmental Degradation of Materials in Nuclear Power Systems-Water Reactors, Jekyll Island, GA, National Association of Corrosion Engineers, Houston, TX, August 1989 (1990).

26. H. Hänninen and I. Aho-Mantila, Environment-Sensitive Cracking of Reactor Internals, in Proc. 3rd Int. Symp. Environmental Degradation of Materials in Nuclear Power Systems - Water Reactors, Traverse City, MI, G. J. Theus and J. R. Weeks, eds., The Metallurgical Society of AIME, Warrendale, PA, pp. 77-92 (1988).

27. P. L. Andresen, F. P. Ford, S. M. Murphy, and J. M. Perks, State of Knowledge of Radiation Effects on Environmental Cracking in Light Water Reactor Core Materials, Proc. 4th Int. Symp. Environmental Degradation of Materials in Nuclear Power Systems - Water Reactors, National Association of Corrosion Engineers, Houston, TX, pp. 1-83 to 1-121 (1990).

28. H. M. Chung, W. E. Ruther, J. E. Sanecki, and T. F. Kassner, Irradiation-Induced Sensitization and Stress Corrosion Cracking of Type 304 Stainless Steel CoreInternal Components, in Proc. 5th Int. Symp. Environmental Degradation of Materials in Nuclear Power Systems-Water Reactors, American Nuclear Society, La Grange Park, IL, pp. 795-805 (1992).

29. K. Fukuya, K. Nakata, and A. Horie, An IASCC Study Using High-Energy Ion Irradiation, ibid., pp. 814-820.

30. J. M. Cookson, R. D. Carter, D. L. Damcott, M. Atzmon, G. S. Was, and P. L. Andresen, Stress Corrosion Cracking of High-Energy Proton-Irradiated Stainless Steels, ibid., pp. 806-813.

31. K. Fukuya, S. Shima, H. Kayano, and M. Narui, Stress Corrosion Cracking and Intergranular Corrosion of Neutron-Irradiated Austenitic Steels, J. Nucl. Materials, Vol. 191-194, pp. 1007-1011, 1992.

32. H. M. Chung, W. E. Ruther, J. E. Sanecki, A. G. Hins, and T. F. Kassner, Stress Corrosion Cracking Susceptibility of Irradiated Type 304 Stainless Steels, Effects of Radiation on Materials: 16th Int. Symp., ASTM STP 1175, A. S. Kumar, D. S. Gelles, R. K. Nanstad, and T. A. Little, eds., ASTM, Philadelphia, PA, pp. 851869 (1993).

33. M. Kodama, K. Fukuya, and H. Kayano, Influence of Impurities and Alloying Elements on IASCC in Neutron Irradiated Austenitic Stainless Steels, ibid. pp. 889-901.

34. F. Garzarolli, P. Dewes, R. Hahn, and J. L. Nelson, Deformability of High-Purity Stainless Steels and Ni-Base Alloys in the Core of a PWR, Proc. 6th Int. Symp. on 
Environmental Degradation of Materials in Nuclear Power Systems-Water Reactors, August 1-5, 1993, San Diego, CA, American Nuclear Society, La Grange Park, IL.

35. M. Kodama, J. Morisawa, S. Nishimura, K. Asano, S. Shima, and K. Nakata, Stress Corrosion Cracking and Intergranular Corrosion of Austenitic Stainless Steels Irradiated at 323K, Proc. 5th Intl. Conf. Fusion Reactor Materials, September 27-October 1, 1993, Stresa, Italy.

36. J. S. Armijo, Grain Boundary Studies of Austenitic Stainless Steels, GEAP-5503, General Electric Co. (September 1967).

37. J. S. Armijo, Intergranular Corrosion of Nonsensitized Austenitic Stainless Steels, Corrosion, Vol. 24, pp. 24-30, 1968.

38. R. Duncan, Stainless Steel Failure Investigation Program, GEAP-5530, General Electric Co. (February 1968).

39. A. Jenssen and L. G. Ljunberg, Irradiation Assisted Stress Corrosion Cracking of Stainless Alloys in BWR Normal Water Chemistry and Hydrogen Water Chemistry, Proc. 6th Int. Symp. on Environmental Degradation of Materials in Nuclear Power Systems-Water Reactors, August 1-5, 1993, San Diego, CA, American Nuclear Society, La Grange Park, IL.

40. H. M. Chung, W. E. Ruther, J. E. Sanecki, A. G. Hins, and T. F. Kassner, Irradiation-Assisted Stress Corrosion Cracking of Materials from Commercial BWRs: Role of Grain-Boundary Microchemistry, Proc. 21st Water Reactor Safety Information Meeting, October 25-28, 1993, Bethesda, MD, U.S. Nuclear Regulatory Commission, Washington, DC.

41. S. Kasahara, N. Nakata, K. Fykuya, S. Shima, A. J. Jacobs, G. P. Wozadlo, and S. Suzuki, The Effect of Minor Elements on IASCC Susceptibility in Austenitic Stainless Steels Irradiated with Neutrons, Proc. 6th Int. Symp. on Environmental Degradation of Materials in Nuclear Power Systems-Water Reactors, August 15, 1993, San Diego, CA, American Nuclear Society, La Grange Park, IL.

42. H. M. Chung, W. E. Ruther, J. E. Sanecki, and T. F. Kassner, Grain-Boundary Microchemistry And Intergranular Cracking Of Irradiated Austenitic Stainless Steel, Proc. 6th Int. Symp. on Environmental Degradation of Materials in Nuclear Power Systems-Water Reactors, August 1-5, 1993, San Diego, CA, American Nuclear Society, La Grange Park, IL.

43. M. E. Indig. J. L. Nelson, and G. P. Wozadlo, Investigation of the Protection Potential Against IASCC, Proc. 5th Int. Symp. Environmental Degradation of Materials in Nuclear Power Systems-Water Reactors, American Nuclear Society, La Grange Park, IL, pp. 941-947 (1992). 
44. Kodama, M., Nishimura, S., Morisawa, J., Shima, S., Suzuki, S., and Yamamoto, M., Effects of Fluence and Dissolved Oxygen on LASCC in Austenitic Stainless Steels, in Proc. 5th Int. Symp. Environmental Degradation of Materials in Nuclear Power Systems-Water Reactors, American Nuclear Society, La Grange Park, IL, pp. 948-954 (1992)

45. M. Kodama, R. Katsura, J. Morisawa, S. Nishimura, S. Suzuki, K. Asano, K. Fukuya, and K. Nakata, IASCC Susceptibility of Austenitic Stainless Steels Irradiated to High Neutron Fluence, Proc. 6th Int. Symp. on Environmental Degradation of Materials in Nuclear Power Systems-Water Reactors, August 15, 1993, San Diego, CA, American Nuclear Society, La Grange Park, Il.

46. R. Katsura, J. Morisawa, M. Kodama, S. Nishimura, S. Suzuki, S. Shima, and M. Yamamoto, Effect of Stress on IASCC in Irradiated Stainless Steel, Proc. 6th Int. Symp. on Environmental Degradation of Materials in Nuclear Power SystemsWater Reactors, August 1-5, 1993, San Diego, CA, American Nuclear Society, La Grange Park, IL.

47. W. E. Ruther, O. K. Chopra, and T. F. Kassner, EAC of Cast SSs in Simulated BWR Water, Environmentally Assisted Cracking in Light Water Reactors, Semiannual Report April-September 1992, NUREG/CR-4667, Vol. 15, ANL 93/2, pp. 21-27, Argonne National Laboratory (1992).

48. J. Y. Liu and H. C. Lai, Stress Corrosion Cracking of Rotor Materials in Steam Environment, in Proc. Fourth Int. Symp. on Environmental Degradation of Materials in Nuclear Power Systems-Water Reactors, Ed. D. Cubicciotti, National Association of Corrosion Engineers, Houston, TX (1990).

49. Modeling Hydrogen Water Chemistry of BWR Applications, EPRI NP-6386, Electric Power Research Institute, Palo Alto, CA (1989).

50. M. O. Speidel and R. M. Magdowski. Stress Corrosion Cracking of Steam Turbine Steels-An Overview, in Proc. Second Int. Symp. on Environmental Degradation of Materials in Nuclear Power Systems-Water Reactors, American Nuclear Society, La Grange Park, IL (1986).

51. Superclean Steel Development: Status Report, EPRI GS-6610, Electric Power Research Institute, Palo Alto, CA (1989).

52. W. A. Logsdon and J. A. Begley, Dynamic Fracture Toughness of ASME SA508 Class 2a, ASME SA533, Grade A, Class 2 Base and Heat Affected Zone Material, WCAP-9292, Westinghouse Electric Corp., Pittsburgh, PA (1978).

53. Standard Practice for Conducting Creep, Creep Rupture and Stress Rupture Tests of Metallic Materials. Practice E-139-83, ASTM Section 3, Vol. 03.01, ASTM, Philadelphia, PA, 1989. 
54. F. F. Lyle Jr. and H. C. Burghard Jr., Steam Turbine Disc Cracking Experience, Vols. 1-7, EPRI NP-2429-LD, Electric Power Research Institute, Palo Alto, CA (1982).

55. F. F. Lyle , A. McMinn, and G. R. Leverant, Low-pressure steam turbine disc cracking-an update, Proc. Instn. Mech. Engrs., Vol. 199, pp. 59-67, 1985.

56. Guidelines for Predicting the Life of Steam Turbine Disks Exhibiting Stress Corrosion Cracking, Volumes 1 and 2, EPRI NP-6444, Electric Power Research Institute, Palo Alto, CA (1989).

57. J. Y. Liu, E. E. Lai, C. C. Su, H. C. Lai, and D. H. R. Lin, Life Prediction for Nuclear LP Rotor SCC Cracks, in Proc. Fifth Int. Symp. on Environmental Degradation of Materials in Nuclear Power Systems-Water Reactors, American Nuclear Society, La Grange Park, IL (1992).

58. V. H. Keller, Erosion-corrosion in damp steam turbines, Kraftwerkstechnik, Vol. 54, p. 292, 1974.

59. O. Jonas, Erosion-Corrosion of PWR Feedwater Piping; Survey of Experience, Design, Water Chemistry, and Materials, NUREG/CR-5149, ANL-88-23, Argonne National Laboratory (1988).

60. R. E. Anderson, K. L. Draper, R. A. Kadlec, and R. A. Stoudt, Evaluation of A Moisture Removal Device for Turbine Steam Piping, EPRI NP-3927 Electric Power Research Institute, Palo Alto, CA (1985).

61. Laboratory Evaluations of Iron-Based Hard-Facing Alloys, EPRI NP-5874, Electric Power Research Institute, Palo Alto, CA (June 1988).

62. P. Grobner, E. K. Ohriner, T. Wada, and E. P. Whelan, NOREM Wear-Resistant, Iron-Based Hard-Facing Alloys, EPRI NP-6466-M, Electric Power Research Institute, Palo Alto, CA (July 1989).

63. Cobalt Reduction Guidelines, EPRI NP-6737, Electric Power Research Institute, Palo Alto, CA (March 1990).

64. Qualification Loop Tests of Cobalt-Free Hardfacing Alloys-PWR Phase, 1989-1990 Progress, EPRI NP-7030-D, Electric Power Research Institute, Palo Alto, CA (November 1990).

65. Endurance Tests of Valves with Cobalt-Free Hardfacing Alloys, EPRI TR-101847, Electric Power Research Institute, Palo Alto, CA (January 1993).

66. R. Vijuk and H. Bruschi, AP600 offers a simpler way to greater safety, operability, and maintainability, Nucl. Eng. Int., Vol. 28, pp. 22-28, 1988. 
67. H. J. Bruschi and R. P Vijuk, Development of the AP600 Plant Design, Proc. Amer. Power Conf., Vol. 52, pp. 868-873, 1990.

68. R. J. Slember, From the Bottom up: Nuclear Technology Evolves for the Future, Part 1-The Advanced Passive Reactor, Proc. Seventh Annual Pacific Basin Conf., Trans. Am. Nucl. Soc., Vol. 61, Suppl. 1, pp. 253-260.

69. B. A. McIntyre and R. K. Beck, Westinghouse Advanced Passive 600 Plant, Nucl. Safety, Vol. 33, No. 1, pp. 36-46, 1992.

70. L. E. Conway, The Westinghouse AP600 Passive Safety Systems-Key to A Safe, Simplified PWR. Proc. Am. Nucl. Soc. Int. Topical Meeting on Safety of Next Generation Power Reactors, Seattle, WA, May 1-5, 1988, pp. 552-557.

71. H. Bruschi and T. Anderson, Turning the key, Nucl. Eng. Int., Vol. 31, pp. 15-22, 1991.

72. H. J. Bruschi and R. P. Vijuk, AP600 plant design-meeting Industry needs, Nucl. Eng. Int., Vol. 32, pp. 155-161, 1992.

73. H. J. Bruschi and T. S. Anderson, Status of the AP600 pressurized water reactor, Proc. Amer. Power Conf., Vol. 54, pp. 205-210, 1992.

74. PWR Primary Water Chemistry Guidelines, Revision 2, EPRI NP-7077, Electric Power Research Institute, Palo Alto, CA (November 1990).

75. Regulatory Guide 1.44, Control of the Use of Sensitized Stainless Steel, U.S. Government Printing Office, Washington, DC, May 1973.

76. O. K. Chopra, Estimation of Fracture Toughness of Cast Stainless Steels During Thermal Aging in LWR Systems, NUREG/CR-4513, ANL-90/42, U.S. Nuclear Regulatory Commission, Washington, DC (1990).

77. PWR Secondary Water Chemistry Guidelines: Revision 3, EPRI TR-102134 Rev. 3, Electric Power Research Institute, Palo Alto, CA (May 1993).

78. Nuclear Plant Design and Modification Guidelines for PWR Steam Generator Reliability, EPRI NP-7380, Electric Power Research Institute, Palo Alto, CA (September 1991).

79. V. Shah and P. E. Macdonald, Eds., Residual Life Assessment of Major Light Water Reactor Components-Overview Vol. 1, NUREG/CR-4731 EGG-2469, Idaho National Engineering Laboratory, Idaho Falls, ID (June 1987).

80. P. Wu, Erosion/Corrosion-Induced Pipe Wall Thinning in U. S. Nuclear Pouer Plants, NUREG-1344, U.S. Nuclear Regulatory Commission, Washington, DC (1988). 
81. C. J. Czajkowski. Evaluation of the Transgranular Cracking Phenomenon on the Indian Point No. 3 Steam Generator Vessels, BNL-NUREG-36087, Brookhaven National Laboratory, Upton, NY (1985).

82. NRC Information Notice No. 90-04: Cracking of the Upper Shell-to-Transition Cone Girth Welds in Steam Generators, U.S. Nuclear Regulatory Commission, Washington, DC (1990).

83. Proceedings: Workshop on Thermally Treated Alloy 690 Tubes for Nuclear Steam Generators, EPRI NP-4665M-SR, Electric Power Research Institute, Palo Alto, CA (July 1986).

84. Alloy 690 for Steam Generator Tubing Applications, EPRI NP-6997-M, Electric Power Research Institute, Palo Alto, CA (October 1990).

85. Crevice Corrosion of Support Alloys in the Secondary Envirunment of Nuclear Steam Generators, EPRI NP-5017, Electric Power Research Institute, Palo Alto CA (March 1987).

86. J. Y. Liu and H. C. Lai, Stress Corrosion Cracking of Rotor Materials in Steam Environment, in Proc. Fourth Int. Symp. on Environmental Degradation of Materials in Nuclear Power Systems-Water Reactors, Ed. D. Cubicciotti, National Association of Corrosion Engineers, Houston, TX (1990).

87. Advanced Studies in Chemistry Control With Morpholine, EPRI TR-100758, Electric Power Research Institute, Palo Alto, CA (July 1992).

88. J. A. Begley and W. A. Logsdon, Correlation of Fracture Toughness and Charpy Properties for Rotor Steels, Westinghouse Scientific Paper 71-1E7-MSLRF-P1, Westinghouse Research Labs., Pittsburgh PA (1971). 
Internal:

O. K. Chopra

H. M. Chung

D. R. Diercks (20)

H. Drucker

T. F. Kassner

J. Y. Park

\section{External:}

NRC, for distribution per R5

ANL Libraries

ANL-E (2)

ANL-W

Manager, Chicago Field Office, DOE

Energy Technology Division Review Committee:

H. K. Birnbaum, University of Illinois, Urbana

R. C. Buchanan, University of Cincinnati, Cincinnati

M. S. Dresselhaus, Massachusetis Institute of Technology, Cambridge, MA

B. G. Jones, University of Illinois, Urbana

C. $-Y$. Li, Cornell University, Ithaca, NY

S. N. Liu, Fremont, CA

R. E. Smith, SciTech Inc., Morrisville, NC

Oak Ridge National Laboratory

W. A. Corwin

J. E. Jones, Jr.

R. L. Huddleston

W. J. MacAfee

D. E. McCabe

J. G. Merkle

R. K. Nanstad

D. J. Naus

W. E. Pennell

C. E. Pugh

R. W. Swindeman

E. W. Whitfield

U.S. Nuclear Regulatory Commission, Washington, DC

E. Hackett

A. L. Hiser

M. E. Mayfield

C. Z. Serpan, Jr.

L. C. Shao

J. R. Strosnider

A. Taboada

E. O. Woolridge (20)

J. A. Christensen, Pacific Northwest Laboratories

K. K. Bandyopadhyay, Brookhaven National Laboratory
.J. Shack

R. W. Weeks

TIS Files
R. B. Poeppel 
Review of the Proposed Materials of Construction for the SBWR and AP600 Advanced Reactors

3. DATE REPORT PUBLLSHED

\begin{tabular}{l|l} 
MONTH & YEAR
\end{tabular}

8. PERFORMNG ORGANIZATION - NAME AND ADDRESS (IINRC, provide Division, Office or Region, U.S. Nuclear Regulatory Commission, and mailing address; if contractor, provide name and mailing addross)

Argonne National Laboratory

9700 South Cass Avenue

Argonne, IL 60439

9. SPONSORING ORGANIZATION - NAME AND ADORESS (If NRC, type "Same as above": if contractor, provide NAC Division, Office or Region, U.S. Nuclaar Regulatory Commission, and mailing address.)

Division of Engineering

Office of Nuclear Regulatory Research

U. S. Nuclear Regulatory Commission

Washington, DC 20555

10. SUPPLEMENTARY NOTES

11. ABSTRACT (200 wonds or less)

The General Electric Simplified Boiling Water Reactor (SBWR) and the Westinghouse Advanced. Passive 600 MWe Reactor (AP600) have been reviewed in detail by Argonne National Laboratory. The objectives of these reviews were to (a) evaluate proposed advanced-reactor designs and the materials of construction for the safety systems, (b) identify all aging and environmentally related degradation mechanisms for the materials of construction, and (c) evaluate from the safety viewpoint the suitability of the proposed materials for the design application. The materials selected for both reactors were generally sound. and no major selection errors were found. It was apparent that considerable thought had been given to the materials selection process, making use of lessons learned from previous LWR experience. The review resulted in the suggestion of alternate and possibly better materials choices in a number of cases, and several potential problem areas have been cited. The review of the AP600 materials of construction was impaired by the fact that the materials designations given in the Standard Safety Analysis Report (SSAR) were often too vague to identify the specific alloy to be used. The SSAR for the SBWR generally gave more detailed materials information.

12. KEY WORDS/OESCRIPTORS (List words or phrases that will assist researchers in locating this report)

13. AVAILABLLITY STATEMENT

Unlimited

General Electric Simplified Boiling Water Reactor

Westinghouse AP600 Advanced Reactor

Advanced Light-Water Reactors

Materials

Passive Safety Systems
14. SECURITY CLASSIFICATION

(This Page)

Unclassified

(This Report)

Unclassified

15. NUMBER OF PAGES

16. PRICE 

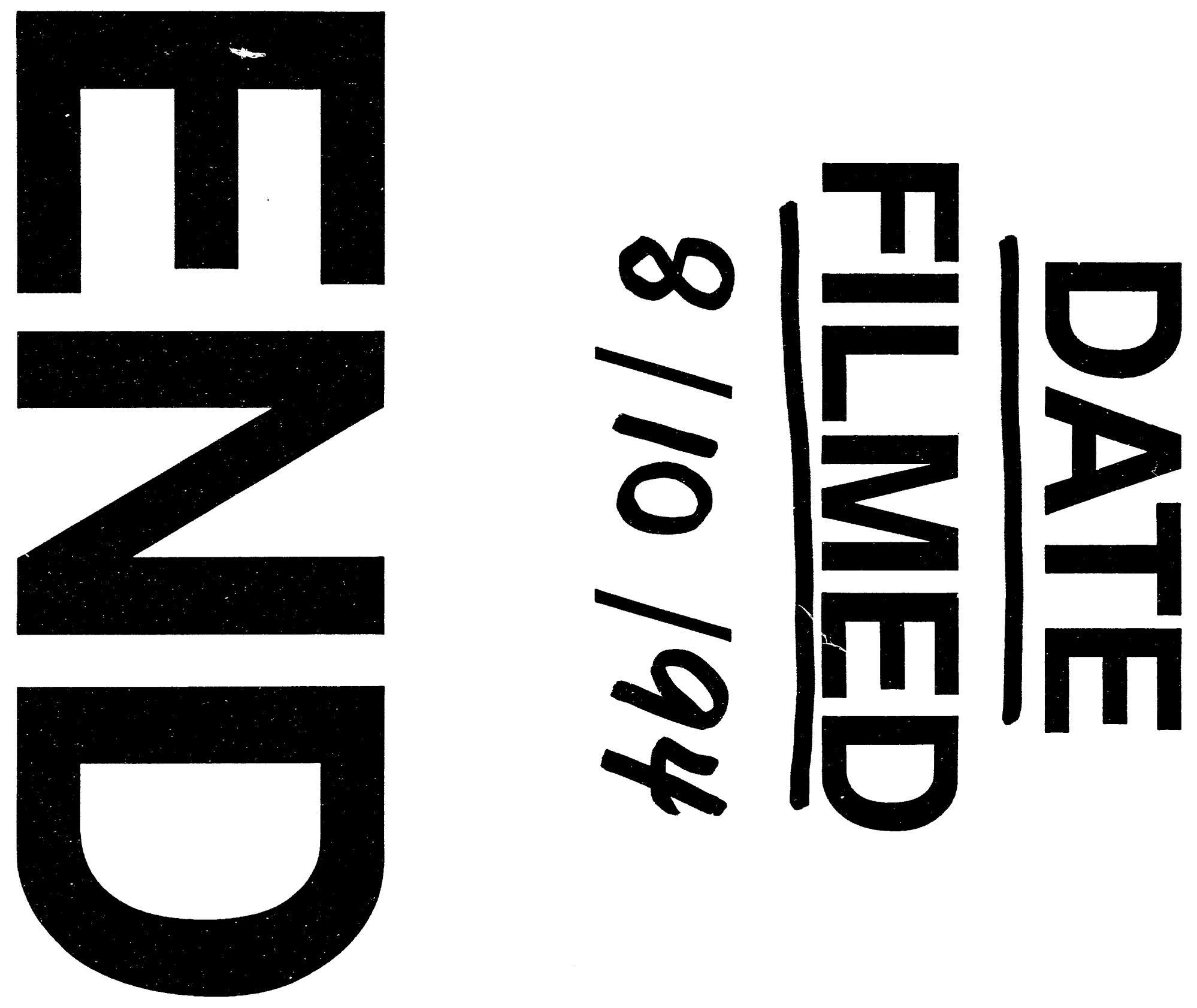


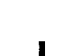

